\title{
Determination of technetium-99 in environmental samples: A review
}

Shi, Keliang; Hou, Xiaolin; Roos, Per; Wu, W.

Published in:

Analytica Chimica Acta

Link to article, DOI:

10.1016/j.aca.2011.10.020

Publication date:

2012

Link back to DTU Orbit

Citation (APA):

Shi, K., Hou, X., Roos, P., \& Wu, W. (2012). Determination of technetium-99 in environmental samples: A review. Analytica Chimica Acta, 709, 1-20. https://doi.org/10.1016/j.aca.2011.10.020

\section{General rights}

Copyright and moral rights for the publications made accessible in the public portal are retained by the authors and/or other copyright owners and it is a condition of accessing publications that users recognise and abide by the legal requirements associated with these rights.

- Users may download and print one copy of any publication from the public portal for the purpose of private study or research.

- You may not further distribute the material or use it for any profit-making activity or commercial gain

- You may freely distribute the URL identifying the publication in the public portal

If you believe that this document breaches copyright please contact us providing details, and we will remove access to the work immediately and investigate your claim 


\title{
Determination of technetium-99 in environmental samples: A review
}

\author{
Keliang Shi ${ }^{1}$, Xiaolin $\mathrm{Hou}^{1,}{ }^{*}$, Per Roos ${ }^{1}$, Wangsuo $\mathrm{Wu}^{2}$ \\ ${ }^{1}$ Risø National Laboratory for Sustainable Energy, Technical University of Denmark, DK-4000 Roskilde, Denmark \\ ${ }^{2}$ Radiochemistry Laboratory, School of Nuclear Science and Technology, Lanzhou University, China
}

\section{Contents}

1. Introduction

1.1. Source term of technetium-99 in the environment

1.2. Environmental level of technetium-99

1.3. Physicochemical properties of technetium and its environmental behaviours

2. Analytical methods for determination of technetium-99 in the environment

2.1 Chemical yield tracers for determination of technetium-99

2.2. Sample pre-treatment

2.2.1. Aqueous samples

2.2.2. Solid samples

2.2.2.1. Initial pre-treatment of samples

2.2.2.2. Separation of technetium from sample matrices

2.3. Chemical separation and purification of technetium

2.3.1. Pre-concentration of technetium by co-precipitation

* Corresponding author, e-mail:xiho@risoe.dtu.dk 


\subsubsection{Solvent extraction}

2.3.3. Anion exchange chromatography

2.3.4. Extraction chromatography

2.3.5. Combination of different chemical separation and purification techniques

2.4. Source preparation for measurement of technetium-99

2.5. Measurement techniques for technetium-99

2.5.1. Radiometric methods

2.5.1.1. $\beta$-Counting

2.5.1.2. Neutron activation analysis

2.5.2. Mass spectrometric methods

2.5.2.1. Inductively coupled plasma-mass spectrometry

2.5.2.2. Accelerator mass spectrometry

2.5.2.3. Other mass spectrometric methods

2.5.3. Comparison of different measurement techniques

3. Automated analytical methods for technetium-99 determination

4. Conclusions and perspectives

\section{List of Abbreviations:}

AMS: $\quad$ Accelerator Mass Spectrometry

DIHEN: Direct Injection High Efficiency Nebulizer

EARP: $\quad$ Enhanced Actinide Removal Plant

EDTA: $\quad$ Ethylenediaminetetraacetic acid 
GBq: $\quad$ Giga Becquerel, $10^{9} \mathrm{~Bq}$

GM: $\quad$ Geiger-Müller

HR: $\quad$ High resolution

ICP-MS: $\quad$ Inductively coupled plasma mass spectrometry

ICP-QMS: Inductively coupled plasma quadrupole mass spectrometry

ICP-SFMS: Inductively coupled plasma sector field mass spectrometry

$\mathrm{K}_{\mathrm{sp}}: \quad$ Solubility product

LSC: $\quad$ Liquid scintillation counting

MCN: $\quad$ Micro concentric nebulizer

MS: $\quad$ Mass spectrometry

NAA: $\quad$ Neutron activation analysis

PBq: $\quad$ Peta Becquerel, $10^{15} \mathrm{~Bq}$

RIMS: $\quad$ Resonance ionization mass spectrometry

TBP: Tri-butylphosphate

TBq: $\quad$ Tera Becquerel, or $10^{12} \mathrm{~Bq}$

ETV: $\quad$ Electrothermal vaporization

TEVA TEVA-Spec ${ }^{\mathrm{TM}}$ resin

TiOA: Tri-isooctylamine

TIMS Thermal ionization mass spectrometry

TOA: $\quad$ Trioctylamine

USN: $\quad$ Ultrasonic nebulizer 


\section{Abstract}

Due to the lack of a stable technetium isotope and the high mobility and long half-life of ${ }^{99} \mathrm{Tc}$, it is considered to be one of the most important radionuclides in safety assessment of environmental radioactivity as well as nuclear waste management. ${ }^{99}$ Tc is also an important tracer for oceanographic research due to the high technetium solubility in seawater as $\mathrm{TcO}_{4}{ }^{-}$. A number of analytical methods, using chemical separation combined with radiometric and mass spectrometric measurement techniques, have been developed over the past decades for determination of ${ }^{99} \mathrm{Tc}$ in different environmental samples. This article summarizes and compares recently reported chemical separation procedures and measurement methods for determination of ${ }^{99} \mathrm{Tc}$. Due to the extremely low concentration of ${ }^{99} \mathrm{Tc}$ in environmental samples, the sample preparation, pre-concentration, chemical separation and purification for removal of the interferences for detection of ${ }^{99} \mathrm{Tc}$ are the most important issues governing the accurate determination of ${ }^{99}$ Tc. These aspects are discussed in detail in this article. Meanwhile, the different measurement techniques for ${ }^{99} \mathrm{Tc}$ are also compared with respect to advantages and drawbacks. Automated analytical methods for rapid determination of ${ }^{99} \mathrm{Tc}$ using solid extraction or ion exchange chromatography for separation of ${ }^{99} \mathrm{Tc}$, employing flow injection or sequential injection approaches are also discussed.

Keywords: Technetium-99, radionuclide, analytical procedure, environmental samples, automated analysis, review. 


\section{Introduction}

Technetium (Tc), atomic number of 43 , has no stable isotope and is generally considered as an "extinct" element on the earth. Tc was first synthesized and isolated by Perrier et al. in 1937 as a product from the bombardment of molybdenum with deuterons or neutrons [1]. So far 45 isotopes of Tc, ranging from ${ }^{85}$ Tc to ${ }^{117} \mathrm{Tc}$, have been synthesized, and most of them are short-lived isotopes with half lives of less than one hour. Table 1 lists the isotopes of Tc with half lives exceeding one hour. Of these, ${ }^{97} \mathrm{Tc}\left(\mathrm{t}_{1 / 2}=2.6 \times 10^{6} \mathrm{y}\right),{ }^{98} \mathrm{Tc}\left(\mathrm{t}_{1 / 2}=4.2 \times 10^{6} \mathrm{y}\right)$ and ${ }^{99} \mathrm{Tc}$ $\left(\mathrm{t}_{1 / 2}=2.1 \times 10^{5} \mathrm{y}\right)$ are the most long-lived. Both ${ }^{97} \mathrm{Tc}$ and ${ }^{98} \mathrm{Tc}$ are mainly formed by activation reactions of neutrons or charged particles, although very small amounts have been produced in anthropogenic nuclear processes, and negligible amounts of ${ }^{97} \mathrm{Tc}$ and ${ }^{98} \mathrm{Tc}$ occur in the environment. ${ }^{99}$ Tc can be produced by thermal neutron induced fission of ${ }^{235} \mathrm{U}$ with a relatively high accumulated fission yield of $6.06 \%$, making ${ }^{99}$ Tc relatively high abundant among fission products $[2,3]$. A large amount of ${ }^{99} \mathrm{Tc}$ has been produced and released to the environment from human nuclear activities, which makes ${ }^{99} \mathrm{Tc}$ the only environmentally significant Tc isotope. Meanwhile ${ }^{99}$ Tc can also be produced through neutron activation of ${ }^{99}$ Mo. Fig.1 shows the formation scheme of ${ }^{99} \mathrm{Tc}$.

The interest in investigating ${ }^{99} \mathrm{Tc}$ in environmental samples results partly from the absence of a stable Tc isotope. ${ }^{99}$ Tc as the completely dominating isotope of Tc is thus the only isotope available for studying the unknown environmental and biological behaviour of this element.

Due to its high mobility, high fission yield, and long half-life, ${ }^{99} \mathrm{Tc}$ is one of the most important radionuclides in safety assessment of environmental radioactivity and repository of nuclear waste, as well as in decommissioning of nuclear facilities and management of nuclear 
waste. The high water solubility of Tc (in the form of $\mathrm{TcO}_{4}{ }^{-}$) and the long half life of ${ }^{99} \mathrm{Tc}$, and thus long residence time in the oceans, make ${ }^{99} \mathrm{Tc}$ an ideal oceanographic tracer for investigation of movement, exchange and circulation of water masses. All these investigations and applications require an accurate determination of ${ }^{99} \mathrm{Tc}$ in various types of samples.

${ }^{99} \mathrm{Tc}$ is a pure $\beta^{-}$emitter with the maximum decay energy of $0.294 \mathrm{MeV}$. It can therefore be measured by radiation counting [4-9]. The $\beta$ counting using gas flow Geiger-Müller (GM) counter and liquid scintillation counter (LSC) are the main techniques for ${ }^{99}$ Tc measurement. Due to the interference of matrix components and the spectrometric interference from other radionculides, especially $\beta$ emitters, a thorough chemical separation of ${ }^{99}$ Tc from the matrices and other radionuclides is required before measurement. Anion exchange chromatography and co-precipitation are widely used to pre-concentrate ${ }^{99}$ Tc from samples $[5,6]$. For further purification, solvent extraction is often utilized to separate ${ }^{99}$ Tc from other interfering radionuclides. In recent years, extraction chromatography using TEVA-Spec ${ }^{\mathrm{TM}}$ (TEVA) resin has been employed to purify ${ }^{99}$ Tc from the interfering radionculides [10-13]. The long halflife, and therefore low specific activity ${ }_{2}$ of ${ }^{99} \mathrm{Tc}\left(0.64 \mathrm{~Bq} \mathrm{ng}^{-1}\right)$ makes mass spectrometry (MS) a potentially sensitive method for measurement of ${ }^{99}$ Tc. Accelerator mass spectrometry (AMS) [14-16], thermal ionization mass spectrometry (TIMS) [17] and inductively coupled plasma mass spectrometry (ICP-MS) [18-21] have been applied for ${ }^{99}$ Tc measurement. Among these MS techniques, ICP-MS is the most widely and frequently used mass spectrometric method for measurement of ${ }^{99} \mathrm{Tc}$ in many types of environmental samples, due to its low cost and easy accessibility. The main challenge in ${ }^{99}$ Tc measurement by ICP-MS is the interferences of 
isobars and molecular ions. At mass 99, isobaric interferences from the stable isotope ${ }^{99} \mathrm{Ru}$ and the molecular ion ${ }^{98} \mathrm{Mo}^{1} \mathrm{H}$ are the main interferences in the measurement of ${ }^{99} \mathrm{Tc}$ using ICP-MS. Highly efficient methods for purification of ${ }^{99} \mathrm{Tc}$ from these interferences before measurement are necessary. The chemical separation techniques used for radiometric methods can also be applied in the mass spectrometric determination of ${ }^{99} \mathrm{Tc}$. The main difference is that the separation methods used for mass spectrometric measurement focuses on the removal of stable isotopic interferences with the mass of 99 AMU [22]. This article aims to discuss and critically compare various analytical methods for the determination of ${ }^{99}$ Tc in the environment. New developments of automated and rapid analytical methods for determination of ${ }^{99} \mathrm{Tc}$ are also discussed.

\subsection{Source term of technetium-99 in the environment}

In nature ${ }^{99}$ Tc can be produced by spontaneous fission of ${ }^{238} \mathrm{U}$ and neutron induced fission of ${ }^{235} \mathrm{U}$ in the earth $[23,24] .{ }^{99} \mathrm{Tc}$ can also be produced by cosmic ray reactions with Mo, Ru and $\mathrm{Nb}$ in the earth crust. It has been estimated that these two types of processes have produced about $60 \mathrm{PBq}\left(6 \times 10^{16} \mathrm{~Bq}\right)$ of ${ }^{99} \mathrm{Tc}$. This ${ }^{99} \mathrm{Tc}$ is mainly distributed in the crust. Due to the relatively long half-life of ${ }^{99} \mathrm{Tc}$, the concentration of the naturally produced ${ }^{99} \mathrm{Tc}$ in the surface environment is too low to be detected. At present, almost all ${ }^{99} \mathrm{Tc}$ in the environment results from anthropogenic nuclear activities, mainly from nuclear weapons testing, reprocessing of spent nuclear fuel, nuclear accidents, nuclear power plants and medical application of ${ }^{99 \mathrm{~m}} \mathrm{Tc}$ $[25,26]$. It has been estimated that the atmospheric nuclear weapons testing in 1940's-1970's has released about $140 \mathrm{TBq}\left(1.4 \times 10^{14} \mathrm{~Bq}\right)$ of ${ }^{99} \mathrm{Tc}$ to the environment [27], which is mainly 
deposited in the Northern hemisphere. Compared with the atmospheric nuclear tests, a large number of nuclear tests were carried out underground, which produced a relatively larger amount of ${ }^{99} \mathrm{Tc}$, but most of this was kept underground. It was estimated that about $21 \mathrm{TBq}$ of ${ }^{99} \mathrm{Tc}$ was released in the underground nuclear tests in Nevada, USA, and $2.5 \mathrm{TBq}$ of ${ }^{99} \mathrm{Tc}$ in French Polynesia [28]. Up to now, a huge amount of ${ }^{99}$ Tc has been produced during the operation of the nuclear power plants. It has been estimated that $16-19 \mathrm{PBq}\left((1.6 \sim 1.9) \times 10^{16}\right.$ $\mathrm{Bq}$ ) of ${ }^{99} \mathrm{Tc}$ had been produced worldwide up to the mid 1980’s [29]. It was calculated that the production rate of ${ }^{99} \mathrm{Tc}$ in nuclear power plants is about $5.8 \mathrm{TBq}(\mathrm{GW}(\mathrm{th}) \mathrm{y})^{-1}$ [30]. About 7.2 TW(e)y electric power has been produced in nuclear power plants from 1971 to 2006 [31], which has resulted in a production of about $140 \mathrm{PBq}$ of ${ }^{99} \mathrm{Tc}$, assuming about $30 \%$ conversion efficiency of thermal energy to electricity. However, most of this ${ }^{99}$ Tc was captured in the elements of the nuclear fuel, and not released to the environment. It was estimated that only 4 GBq $\left(4 \times 10^{9} \mathrm{~Bq}\right){ }^{99} \mathrm{Tc}$ was released from the nuclear power plants until 1990. This was mainly due to the small leakage of the nuclear fuel and relatively small amount of uranium impurities in cooling water and construction materials in the nuclear power reactors. It can therefore be estimated that less than $10 \mathrm{GBq}$ of ${ }^{99} \mathrm{Tc}$ was released from the nuclear power up to 2010 considering the gradually increasing number of nuclear power plants over the past 20 years. However, the release of ${ }^{99}$ Tc from the fuel during the spent fuel reprocessing is the main source of ${ }^{99} \mathrm{Tc}$ in the environment. Many spent nuclear fuel reprocessing plants have been operated or are in operation. Among these the most important ones are those at Sellafield (UK), La Hague (France), Marcoule (France), Mayak (Russia), Kalpakkam (India), Rokkasho (Japan), Hanford (USA) and Savannah (USA). Up to 2009, the Sellafield 
reprocessing plant has discharged $1720 \mathrm{TBq}$ of ${ }^{99} \mathrm{Tc}$ to the Irish Sea, and the La Hague reprocessing plant has discharged about $154 \mathrm{TBq}$ of ${ }^{99} \mathrm{Tc}$ to the English Channel. Fig. 2 shows the annual discharges of ${ }^{99}$ Tc from two European reprocessing plants (Sellafield and La Hague) [32]. No data on ${ }^{99}$ Tc discharge from other reprocessing plants is available. ${ }^{99 \mathrm{~m}} \mathrm{Tc}$ has being widely applied for medical diagnosis and medical research since its first application in the hospital in 1960. It is exclusively supplied by ${ }^{99} \mathrm{Mo}^{99 \mathrm{~m}} \mathrm{Tc}$ generators. It is estimated that about $22 \mathrm{PBq} \mathrm{y}^{-1}$ of ${ }^{99} \mathrm{Mo}$ is required in 2010 for producing the generators to meet the world-wide requirement of medical ${ }^{99 \mathrm{~m}}$ Tc. The ${ }^{99}$ Mo will decay to ${ }^{99 \mathrm{~m}} \mathrm{Tc}$ and finally to ${ }^{99} \mathrm{Tc}$, releasing $0.78 \mathrm{GBq}^{-1}$ of ${ }^{99} \mathrm{Tc}$ to the environment by excretion from the patients at 2010 level. However, a smaller amount of ${ }^{99}$ Tc was released before 1990, which was estimated to be only about $0.20 \mathrm{GBq}^{-1}$ [33]. The total ${ }^{99} \mathrm{Tc}$ released from this type of sources can be estimated to be less than $20 \mathrm{GBq}$, assuming a maximum release of $0.78 \mathrm{GBq} \mathrm{y}^{-1}$ in $1990-2010$ and 0.20 GBq $\mathrm{y}^{-1}$ in $1970-1990 .{ }^{99} \mathrm{Tc}$ has also been released to the environment in nuclear accidents. It was estimated that the Chernobyl accident in 1986 has released about $0.75 \mathrm{TBq}$ of ${ }^{99} \mathrm{Tc}$ to the environment [34]. Although the contribution of this source on a global scale is less important than other sources, the effect on the ${ }^{99} \mathrm{Tc}$ level in local area might be still significant. The Fukushima nuclear accident that took place in March 2011 might also have released some amount of ${ }^{99} \mathrm{Tc}$ to the environment. The estimated atmospheric releases of $30 \mathrm{PBq}$ of ${ }^{137} \mathrm{Cs}$ in the Fukushima accident corresponds to about $1 / 3$ of the estimated ${ }^{137}$ Cs releases from the Chernobyl accident. It might be estimated that the releases of ${ }^{99} \mathrm{Tc}$ to the atmosphere from the Fukushima accident is about $0.25 \mathrm{TBq}$. However, besides the atmospheric releases, a large volume of waste water was discharged to the sea during the accident; but no data on ${ }^{99} \mathrm{Tc}$ 
discharge to the sea by this way is available at present. It can be concluded that the major source of ${ }^{99} \mathrm{Tc}$ in the environment is the nuclear reprocessing plants, which accounts for more than $90 \%$ of the ${ }^{99} \mathrm{Tc}$ in the environment. Table 2 summarizes the major sources of ${ }^{99} \mathrm{Tc}$ in the environment.

\subsection{Environmental level of technetium-99}

Because of the long half-life, ${ }^{99}$ Tc can exist in the environment for a very long time. The concentration of ${ }^{99} \mathrm{Tc}$ in the environment depends not only on the contamination level of the sampling area, but also on the sample type. In areas without direct contamination, the level of ${ }^{99}$ Tc is normally low. The accumulated deposition from weapons fallout is in the order of 500 $\mathrm{mBq} \mathrm{m}^{-2}$ [35] and a ${ }^{99} \mathrm{Tc}$ concentration of $4-88 \mathrm{mBq} \mathrm{kg}^{-1}$ was reported in Japanese soils in 2002 [36]. In precipitation, the concentration of ${ }^{99} \mathrm{Tc}$ ranges from 20 to $60 \mu \mathrm{Bq} \mathrm{L}^{-1}$, while in seawater it is only some few $\mu \mathrm{Bq} \mathrm{L}^{-1}$ [37-39]. However, ${ }^{99} \mathrm{Tc}$ concentrations of $0.4 \mathrm{~Bq} \mathrm{~kg}^{-1}$ (dry mass) in Fucus vesiculosus from northwestern Spain [40], and of $0.1 \mathrm{~Bq} \mathrm{~kg}^{-1}$ (dry mass) from southern Spain have been observed, in areas where no direct ${ }^{99}$ Tc contamination was reported [41]. This is attributed to the very high enrichment of ${ }^{99} \mathrm{Tc}$ in seaweed $\left(10^{5}\right.$ in Fucus).

Because of anthropogenic nuclear activities, the levels of ${ }^{99} \mathrm{Tc}$ in some areas, especially in the contaminated environment near the sources, are relative high. Table 3 summaries the ${ }^{99} \mathrm{Tc}$ level in samples from some specific contaminated areas as well as corresponding background areas. As the major sources of ${ }^{99} \mathrm{Tc}$, Sellafield and La Hague reprocessing plants discharge

${ }^{99}$ Tc directly into Irish Sea and English Channel respectively. This ${ }^{99} \mathrm{Tc}$ is then transported to 
the North Sea and further northwards through the Norwegian Sea to the Arctic and Greenland Sea. Seawater in these areas is contaminated and the concentration of ${ }^{99} \mathrm{Tc}$ is enhanced. About $500 \mathrm{mBq} \mathrm{L}{ }^{-1}$ of ${ }^{99} \mathrm{Tc}$ has been measured in seawater collected in an area close to the discharge point at Sellafield reprocessing plant in the Irish Sea [42], and a concentration of $60 \mathrm{mBq} \mathrm{L}{ }^{-1}$ has been measured in seawater from the open Irish Sea in 1996-1997 [43]. The level of ${ }^{99} \mathrm{Tc}$ then decreases to below $20 \mathrm{mBq} \mathrm{L}{ }^{-1}$ after 1998 [26]. The discharge of radioactive wastes from La Hague reprocessing plant also increases the level of ${ }^{99} \mathrm{Tc}$ in marine waters. A concentration of $5-21 \mathrm{mBq} \mathrm{L}{ }^{-1}$ in coastal seawater from the English Channel has been reported several decades ago [44]. In the North Sea water, concentrations of ${ }^{99}$ Tc range from 15 to $75 \mathrm{mBq} \mathrm{L}{ }^{-1}$ in the early 1980's [45]. A slightly lower value of $9 \mathrm{mBq} \mathrm{L}{ }^{-1}$ has been measured in Norwegian coastal water in1996-1997 [46]. The influence of reprocessing discharges at Sellafield and La Hague has also been observed at the Greenland coasts and in the Arctic environment. A concentration of $0.01-0.3 \mathrm{mBq} \mathrm{L}^{-1}$ of ${ }^{99} \mathrm{Tc}$ in seawater from the Greenland Sea was detected in our laboratory during the years 2000-2008 (unpublished data), and $0.07 \mathrm{mBq} \mathrm{L}^{-1}$ in the Arctic seawater [47]. This is about one order of magnitude higher than that in the background area [37-39].

The concentration of ${ }^{99} \mathrm{Tc}$ in aquatic plants and animals is also higher in contaminated environments than in uncontaminated areas. For example, a concentration of ${ }^{99} \mathrm{Tc}$ up to $10 \mathrm{~Bq}$ $\mathrm{g}^{-1}$ has been observed in Fucus vesiculosus from the Irish Sea during the operation of the Enhanced Actinide Removal Plant (EARP) at Sellafield, because of the increased discharges of ${ }^{99} \mathrm{Tc}$ to the marine system [43]. A long time series of ${ }^{99} \mathrm{Tc}$ measurements in our lab shows that the level of ${ }^{99} \mathrm{Tc}$ ranged from 1 to $40 \mathrm{mBq} \mathrm{g}^{-1}$ in Fucus vesiculosus (dry mass) at the 
coast of Greenland during the years of 1991-2003 (unpublished data). Shellfish like lobster expresses an ability for accumulation of ${ }^{99} \mathrm{Tc}$. The activity concentration of ${ }^{99} \mathrm{Tc}$ in lobsters landed at the Saltee Islands in the southeast coast of Ireland in 1997 was observed to be 1.57 $\mathrm{mBq} \mathrm{g}{ }^{-1}$ (wet weight), where a slight contamination of ${ }^{99} \mathrm{Tc}$ from the Sellafield reprocessing plant was reported. However, much higher values of $48-280 \mathrm{mBq} \mathrm{g}^{-1}$ (wet weight) were observed in the lobster landed at the east coast of Ireland during the years of 1997-1999, reflecting a strong contamination of ${ }^{99} \mathrm{Tc}$ by the discharges from the Sellafield reprocessing plant [43]. In Denmark, our laboratory has measured ${ }^{99}$ Tc concentrations of $20-60 \mathrm{mBq} \mathrm{g}^{-1}$ (dry weight) in lobsters from Danish waters in 1998. A recent investigation showed that concentrations of ${ }^{99} \mathrm{Tc}$ in lobsters are still high in contaminated environments: $250 \mathrm{mBq} \mathrm{g}^{-1}$ (fresh) in the Sellafield coast area and $14-30 \mathrm{mBq} \mathrm{g}^{-1}$ (fresh) in the coastal area of Northern Ireland [32].

The ${ }^{99} \mathrm{Tc}$ level in the atmosphere is relatively low. Concentrations from 0.001 to $0.1 \mathrm{mBq} \mathrm{L}^{-1}$ have been reported in rainwater collected in southern Spain during the years 1984-1987 [48]. A similar value of $0.05 \mathrm{mBq} \mathrm{L}^{-1}$ on average has been reported in rainwater collected from United States in 1967 [49]. Compared with the atmosphere, the level of ${ }^{99} \mathrm{Tc}$ in soil and sediment, especially in samples from contaminated areas, are high. A concentration of 14.9 $\mathrm{mBq} \mathrm{g}^{-1}{ }^{99} \mathrm{Tc}$ has been reported in sediments from the Irish Sea close to Sellafield [50], which is several orders of magnitude higher than the level of ${ }^{99} \mathrm{Tc}$ in normal sediment samples $(<10$ $\mu \mathrm{Bq} \mathrm{g} \mathrm{g}^{-1}$ dry sample). ${ }^{99} \mathrm{Tc}$ concentrations of $1-15 \mathrm{mBq} \mathrm{g}^{-1}$ in soil and $0.2-6 \mathrm{mBq} \mathrm{g}^{-1}$ in vegetation samples collected in the 30-km zone around Chernobyl have been reported [12]. However, in uncontaminated environments, ${ }^{99} \mathrm{Tc}$ concentrations of $0.006-0.1 \mathrm{mBq} \mathrm{g}{ }^{-1}$ have 
been observed in paddy field soil (dry weight) [51].

\subsection{Physicochemical properties of technetium and its environmental behaviours}

Technetium metal is silvery-gray colored and tarnishes slowly in moist air. It dissolves in $\mathrm{HNO}_{3}$, aqua regia and concentrated $\mathrm{H}_{2} \mathrm{SO}_{4}$, but is not soluble in any strength of $\mathrm{HCl}$ solution [52]. Tc can exist in different oxidation states in aqueous solutions including Tc(II), Tc(VI), $\mathrm{Tc}(\mathrm{V}), \mathrm{Tc}(\mathrm{VI})$ and $\mathrm{Tc}(\mathrm{VII})$, and each of them can be prepared under appropriate conditions. In environmental conditions, Tc primarily exists in two oxidation states Tc(IV) and Tc(VII). Under oxidizing conditions, Tc exists as the pertechnetate ion $\left(\mathrm{TcO}_{4}{ }^{-}\right)$in aqueous solution or as volatile $\mathrm{Tc}_{2} \mathrm{O}_{7}$ in the absence of water. $\mathrm{Tc}_{2} \mathrm{O}_{7}$ melts at $119.5{ }^{0} \mathrm{C}$ and boils at $311{ }^{0} \mathrm{C}$, it is very hygroscopic, and dissolves in water to form $\mathrm{HTcO}_{4}$ [53]. In reductive conditions, Tc(IV) is the most stable oxidation state and strongly hydrolyzes in aqueous solutions and is very stable as $\mathrm{TcO}_{2}$ in the absence of water [54]. In addition, various complexes of $\mathrm{Tc}(\mathrm{IV})$ can be formed in the presence of organic or inorganic ligands such as carbonate, EDTA, citrate and natural humic substances [55-58].

$\mathrm{TcO}_{4}{ }^{-}$is stable in water over a wide $\mathrm{pH}$ range in the absence of reducing substances. Because of the week sorption of $\mathrm{TcO}_{4}{ }^{-i n}$ various environmental media, Tc is considered to be one of the most mobile radionuclides in the environment. Strong reductive reagents such as sulphite, meta-bisulphite, hydrazine or ascorbic acid are often applied to reduce $\mathrm{TcO}_{4}{ }^{-}$to lower oxidation states such as Tc(IV) [5,6,38,59]. Conversely, strong oxidants like bromine water, hydrogen peroxide, alkaline peroxide, hypochlorite, or persulphate, are employed to rapidly oxidize the lower oxidation state of $\mathrm{Tc}_{\mathrm{c}}$ to $\mathrm{TcO}_{4}{ }^{-}[60-63]$.

The behavior of ${ }^{99} \mathrm{Tc}$ in environment is complex and controlled by physical, chemical and 
biological processes. ${ }^{99} \mathrm{Tc}$ released from the nuclear reprocessing plants mostly as $\mathrm{TcO}_{4}^{-}$, which has a high mobility and easily enters into ecosystem [64]. After the discharge of ${ }^{99} \mathrm{Tc}$ into the seawater, it can be dispersed by sea currents or concentrated by seaweeds or marine animals. Because of the high mobility of $\mathrm{TcO}_{4}{ }^{-}{ }^{99} \mathrm{Tc}$ is transported by sea currents over long distances from the discharge points (e.g., Sellafield and La Hague). It is therefore widely used as an oceanographic tracer to track seawater movement and coastal pollution [65]. ${ }^{99} \mathrm{Tc}$ was also released and dispersed into air from the atmospheric nuclear weapons testing or nuclear accidents such as the Chernobyl and Fukushima accidents. The uptake in aquatic plants and marine animals is the most important way for ${ }^{99}$ Tc to enter food chains. Seaweed can highly concentrate ${ }^{99}$ Tc. The possible mechanism is that $\mathrm{TcO}_{4}{ }^{-}$in seawater is first taken up through foliar absorption, and then reduced to $\mathrm{Tc}(\mathrm{IV})$ in the chloroplast. The reduced Tc is afterwards absorbed or complexed with organic ligands in seaweed and fixed [66]. ${ }^{99}$ Tc can also be taken up by terrestrial plants from soil and then concentrated by herbivores through ingestion of plants. Aquatic animals like shellfish, especially lobster, expresses a high ability to concentrate ${ }^{99} \mathrm{Tc}$ [43]. After death and decay of plants or animals, ${ }^{99}$ Tc might accumulate in sediments or enter into water, soil and other media. Fig.3 shows the possible transport processes of ${ }^{99}$ Tc in ecosystems.

\section{Analytical methods for determination of technetium-99 in the environment}

So far, a large number of analytical methods have been developed and applied for determination of ${ }^{99} \mathrm{Tc}$ in various environmental samples, such as soil, sediment, seaweed, seawater, groundwater, surface water and nuclear waste [4-9,14-16,18-21]. Table 4 
summarizes the reported methods for ${ }^{99}$ Tc determination along with typical recoveries and detection limits. In general, all of these methods can be implemented in four steps: (1) sample pre-treatment, (2) chemical separation and purification, (3) source preparation and (4) ${ }^{99} \mathrm{Tc}$ measurement. Fig. 4 shows a flow chart of the analytical procedure for ${ }^{99}$ Tc. A detailed discussion on the analytical procedures is presented below.

\subsection{Chemical yield tracers for determination of technetium-99}

As mentioned above, the concentration of ${ }^{99} \mathrm{Tc}$ in environmental samples is normally very low. An extensive chemical separation has to be implemented for concentrating ${ }^{99}$ Tc from samples and removal of matrix components and interferences. The measurement of chemical yield of ${ }^{99}$ Tc during the chemical separation is a key issue for obtaining accurate analytical results. The yield tracer can also be used in mass spectrometric measurement of ${ }^{99} \mathrm{Tc}$ as an internal standard or isotopic addition standard, which can eliminate and/or reduce the analytical error induced by instability of the instrument during the measurement.

Several yield tracers have been used in the determination of ${ }^{99} \mathrm{Tc}$, including isotopic tracers, such as ${ }^{95 \mathrm{~m}} \mathrm{Tc},{ }^{97 \mathrm{~m}} \mathrm{Tc},{ }^{97} \mathrm{Tc},{ }^{98} \mathrm{Tc}$ and ${ }^{99 \mathrm{~m}} \mathrm{Tc}$, and non-isotopic tracers such as enriched stable isotopes of rhenium $\left({ }^{185} \mathrm{Re}\right.$ or $\left.{ }^{187} \mathrm{Re}\right)$ or natural rhenium (Re). Table 5 lists all these yield tracers and their nuclear/physical properties. ${ }^{95 \mathrm{~m}}$ Tc decays mainly by electron capture, and a small fraction by positron emission $(0.44 \%)$, with emission of $\gamma$ rays of energies $204.1 \mathrm{keV}$ (63.3 \%), $582.1 \mathrm{keV}$ (30.0 \%), $835.1 \mathrm{keV}$ (26.6 \%), $786.2 \mathrm{keV}$ (8.7\%), and $820.6 \mathrm{keV}$ (4.7\%). It is therefore easily measured by $\gamma$-spectrometry. The half-life $(61.0 \mathrm{~d})$ makes ${ }^{95 \mathrm{~m}} \mathrm{Tc}$ a useful tracer for days-to-weeks sample pre-treatment especially for field experiments. Meanwhile the large difference in mass compared with ${ }^{99} \mathrm{Tc}$ means that the isobaric 
interference can be avoided in the determination of ${ }^{99}$ Tc by ICP-MS. However, it has been reported that the commercial ${ }^{95 \mathrm{~m}}$ Tc solution often contains detectable amounts of ${ }^{99} \mathrm{Tc}$, which will increase the blank level, and increase the detection limit for low level ${ }^{99}$ Tc measurement [67]. In addition, radioactive ${ }^{95 \mathrm{~m}} \mathrm{Tc}$ interferes in the measurement of ${ }^{99} \mathrm{Tc}$ by beta counting, and due to its $61 \mathrm{~d}$ half life, ${ }^{95 \mathrm{~m}} \mathrm{Tc}$ needs to decay away over several months before measurement of ${ }^{99} \mathrm{Tc}$ by radiometric methods, especially for $\beta$ counting using GM counter. Anyway, ${ }^{95 \mathrm{~m}} \mathrm{Tc}$ has been a popular yield tracer in the determination of ${ }^{99} \mathrm{Tc}$ in the early days. ${ }^{97 \mathrm{~m}} \mathrm{Tc}$, as a metaisomer of ${ }^{97} \mathrm{Tc}$, decays to ${ }^{97} \mathrm{Tc}$ by isomeric transition and a very small fraction $(<0.34 \%)$ by electron capture. Although ${ }^{97 \mathrm{~m}} \mathrm{Tc}$ emits soft $\gamma$ ray $(96.5 \mathrm{keV})$, the intensity of this $\gamma$ ray is very low $(0.31 \%)$, which makes it unsuitable as a yield tracer for determination of ${ }^{99}$ Tc. As a result, its application as a tracer is very limited. ${ }^{95 \mathrm{~m}} \mathrm{Tc}$ and ${ }^{97 \mathrm{~m}} \mathrm{Tc}$ can be produced by cyclotron via ${ }^{95} \mathrm{Mo}(\mathrm{p}, \mathrm{n}){ }^{95 \mathrm{~m}} \mathrm{Tc}$ and ${ }^{97} \mathrm{Tc}\left(\mathrm{n}, \mathrm{n}^{`}\right)^{97 \mathrm{~m}} \mathrm{Tc}$ reactions. Neither ${ }^{95 \mathrm{~m}}$ Tc nor ${ }^{97 \mathrm{~m}}$ Tc can be used as internal standard in ICP-MS because of their relatively short half lives. ${ }^{97} \mathrm{Tc}$ is a long-lived radioisotope of Tc $\left(\mathrm{T}_{1 / 2}=2.6 \times 10^{6} \mathrm{y}\right)$, and decays by electron capture without any $\gamma$ ray emission. Therefore it is difficult to measure by radiometric methods. ${ }^{98} \mathrm{Tc}$ is also a long-lived radioisotope of Tc $\left(\mathrm{T}_{1 / 2}=4.2 \times 10^{6} \mathrm{y}\right)$, which decays by emitting $\beta$ particles of maximum energy of $398.2 \mathrm{keV}$, with $\gamma$ rays of $652.4 \mathrm{keV}(100 \%)$ and $745.4 \mathrm{keV}(100 \%)$. It is difficult to isolate from ${ }^{99} \mathrm{Tc}$ in the radiometric measurement of ${ }^{99} \mathrm{Tc}$. Therefore it seriously interferes in the measurement of ${ }^{99} \mathrm{Tc}$ in $\beta$ counting using GM counter as well as liquid scintillation counter. However, ${ }^{97}$ Tc and ${ }^{98}$ Tc are ideal yield tracers for the determination of ${ }^{99} \mathrm{Tc}$ when mass spectrometric methods are used, because of their long half-lives, and similar amount of mass as ${ }^{99} \mathrm{Tc}$ in the solution. The drawbacks of ${ }^{97} \mathrm{Tc}$ 
and ${ }^{98}$ Tc as yield tracers are their isotopic purity and availability. A pure ${ }^{97}$ Tc or ${ }^{98}$ Tc source is difficult to obtain. Normally the products contain both ${ }^{97} \mathrm{Tc}$ and ${ }^{98} \mathrm{Tc}$, as well as a small amount of ${ }^{99} \mathrm{Tc}$ [68]. In addition, these two isotopes are still not commercial available, which limits their application in routine analysis. ${ }^{99 \mathrm{~m}} \mathrm{Tc}$ is a metastable nuclear isomer of ${ }^{99} \mathrm{Tc}$, with a short half life of only $6.1 \mathrm{~h}$. It de-excites to ${ }^{99} \mathrm{Tc}$ by emitting $\gamma$ ray of $140.5 \mathrm{keV} .{ }^{99 \mathrm{~m}} \mathrm{Tc}$ is normally obtained through decay of ${ }^{99}$ Mo using ${ }^{99} \mathrm{Mo}-{ }^{-99 m}$ Tc generator, where ${ }^{99}$ Mo can be produced by neutron induced fission of ${ }^{235} \mathrm{U}$, and neutron activation of ${ }^{98} \mathrm{Mo}$. Due to its wide application in nuclear medicine, ${ }^{99 \mathrm{~m}} \mathrm{Tc}$ is the most easily available isotope of Tc. Therefore it has often been used as a yield tracer for the determination of ${ }^{99} \mathrm{Tc}[21,61]$. After decay of ${ }^{99 \mathrm{~m}}$ Tc (usually one week), ${ }^{99}$ Tc can be detected by radiometric methods or ICP-MS without obvious interference. Since ${ }^{99 \mathrm{~m}}$ Tc decays to ${ }^{99}$ Tc by isomeric transition, the application of large amounts of ${ }^{99 \mathrm{~m}} \mathrm{Tc}$ or aged ${ }^{99 \mathrm{~m}} \mathrm{Tc}$ from the generator might cause a high blank level for determination of ${ }^{99} \mathrm{Tc}$. Therefore newly in-grown ${ }^{99 \mathrm{~m}} \mathrm{Tc}$ in the generator is used as yield tracer. ${ }^{99 \mathrm{~m}}$ Tc eluted from high radioactive ${ }^{99} \mathrm{Mo}-{ }^{99 \mathrm{~m}}$ Tc generators used in hospitals (about $25 \mathrm{GBq}$ ) might contain a relatively significant amount of ${ }^{99}$ Mo due to the radiolysis effect in the generator. This problem can be solved by purification of the ${ }^{99 \mathrm{~m}}$ Tc eluate using an alumina cartridge, and applying a reduced radioactive ${ }^{99} \mathrm{Mo}^{-99 \mathrm{~m}} \mathrm{Tc}$ generator $(2-4 \mathrm{GBq})$ or a generator in which ${ }^{99}$ Mo is produced by neutron activation of ${ }^{98}$ Mo [63]. The above advantages, especially the easy availability of ${ }^{99} \mathrm{Mo}-{ }^{99 \mathrm{~m}} \mathrm{Tc}$ generators, make ${ }^{99 \mathrm{~m}} \mathrm{Tc}$ the most frequently used chemical yield tracer for the determination of ${ }^{99} \mathrm{Tc}$ in recent years. Re is in the same group (VIIB) as Tc in the periodic table. Therefore the two elements have similar chemical properties. It is possible to use natural Re or enriched stable Re isotopes $\left({ }^{185} \operatorname{Re}\right.$ or $\left.{ }^{187} \mathrm{Re}\right)$ as 
non-isotopic yield tracer in the determination of ${ }^{99} \mathrm{Tc}$ [69-71]. In this case, Re has to be measured by non-radiometric methods. Therefore Re is often used as yield tracer when mass spectrometric methods are used for the measurement of ${ }^{99} \mathrm{Tc}$, so that both ${ }^{99} \mathrm{Tc}$ and isotopes of Re can be simultaneously measured. Re isotopes can be used as an internal standard in the mass spectrometric measurement. Since they are not identical elements, Tc and Re might behave somewhat differently during the chemical separation. The main difference between Re and Tc is their redox potentials. The reduction of Re is more difficult than that of Tc [72], which might cause a significant fractionation between Re and Tc in the separation by coprecipitation of Tc after reducing Tc to Tc(IV) and forming hydroxide in alkali solution. Furthermore, the selectivity and affinity of Re and Tc in the chromatographic resins are also not the same [73], resulting in a different elution curves for the two elements. All these issues have to be considered in the experimental design in order to obtain a reliable chemical yield during the chemical separation.

\subsection{Sample pre-treatment}

\subsubsection{Aqueous samples}

Aqueous samples (e.g., seawater, lake, river rain, and ground water) are first filtered through appropriate filters to remove suspended particulate matter after sampling, and then acidified to $\mathrm{pH} 1-4$ by concentrated acid using $\mathrm{HCl}[21,74,75], \mathrm{H}_{2} \mathrm{SO}_{4}$ [6] or $\mathrm{HNO}_{3}$ [49]. Since the concentration of ${ }^{99} \mathrm{Tc}$ in environmental water samples is normally very low, it requires sample pre-treatment to pre-concentrate ${ }^{99} \mathrm{Tc}$. The enrichment of ${ }^{99} \mathrm{Tc}$ can be achieved by a few approaches, including evaporation [76], activated carbon adsorption [77], co- 
precipitation [21,38,40,59,75], and anion exchange chromatography [2,6] according to the volume and the salt content of the sample.

Evaporation is a simple method and can be adopted for samples with a relatively small volume and low salt content such as rain/snow, river, lake water and some ground water. Because of the volatile property of Tc, it has been suggested that evaporation of water should be carried out in basic medium [4]. Some experiments [76] have shown no loss of ${ }^{99}$ Tc during evaporation of water at $70-80{ }^{0} \mathrm{C}$, and the adjustment of water to basic medium is not necessary when the temperature is kept under $90{ }^{0} \mathrm{C}$ [51]. However, when the solution is evaporated to dryness, some ${ }^{99} \mathrm{Tc}$ might be lost. The reason for this is that ${ }^{99} \mathrm{Tc}$ can be converted to volatile $\mathrm{Tc}_{2} \mathrm{O}_{7}$ when the solution is dried and the temperature rises. Our experiments show that the loss of ${ }^{99} \mathrm{Tc}$ is negligible if the sample solution is not evaporated to dryness (more than $0.5 \mathrm{~mL}$ solution left) even in high concentration of nitric acid. Although the evaporation method is simple, it appears unpractical for large volume samples with high salt content, like seawater. In this case, anion exchange chromatography, co-precipitation or activated carbon adsorption can be utilized to pre-concentrate ${ }^{99}$ Tc from sample matrices.

Based on the very high affinity of $\mathrm{TcO}_{4}{ }^{-}$to anion exchange resin, Chen et al. [6] have reported an ion exchange method to separate and pre-concentrate ${ }^{99}$ Tc from up to $200 \mathrm{~L}$ fresh seawater employing the strong basic anion exchange resin Bio-Rad AG1-×4 in a column with a diameter of $2.5 \mathrm{~cm}$ and a height of $40 \mathrm{~cm}$. After converting all Tc in the water to Tc(VII) by $\mathrm{H}_{2} \mathrm{O}_{2}$ in acidic medium, the seawater sample is loaded to columns at the flow rate of $150-200$ $\mathrm{mL} \min ^{-1}$, and a chemical yield of ${ }^{99} \mathrm{Tc}$ of more than $90 \%$ is obtained. This method has been successfully applied for routine analysis of seawater samples for ${ }^{99} \mathrm{Tc}$ in our laboratory at 
Risø DTU, Denmark. The key issue in this procedure is the conversion of ${ }^{99} \mathrm{Tc}$ to the $\mathrm{TcO}_{4}{ }^{-}$ form, because other forms of Tc could not be sufficiently retained by the anion exchange column. It should be mentioned that the formation of colloids or even larger suspended matters in long term storage of the water sample may cause a problem in the column separation and pre-concentration. The suspended materials in water will be accumulated on the top of the column and cause failure of the separation due to blocking of the column. The colloid formed in the water might coat the surface of the exchange resin, resulting in a low chemical yield of ${ }^{99} \mathrm{Tc}$ in this separation procedure. The long time of operation is the main drawback of this method for pre-concentration of ${ }^{99}$ Tc. For a $200 \mathrm{~L}$ water sample, this step takes about $20 \mathrm{~h}$.

Pre-concentration by co-precipitation is based on insolubility of low oxidation states of Tc, such as $\mathrm{TcO}_{2}$, and their strong sorption to particles or precipitate formed in the solution. In this method, reductants such as $\mathrm{FeSO}_{4}$ or sulphite, and carrier such as $\mathrm{FeCl}_{3} \cdot 6 \mathrm{H}_{2} \mathrm{O}$, are firstly added to the water, and then $\mathrm{NH}_{3} \cdot \mathrm{H}_{2} \mathrm{O}$ or $\mathrm{NaOH}$ is added to adjust $\mathrm{pH}$ to 9 to form $\mathrm{Fe}(\mathrm{OH})_{2}$ precipitation, which carries the formed $\mathrm{TcO}_{2}$ and separates it from the water matrices. This method has been successfully applied to pre-concentrate ${ }^{99}$ Tc from 1-100 L seawater and rain water samples, and chemical yield of 50-80 \% depending on the volume of the sample has been reported [5]. Other carrier/reductant, such as CuS, has also been used for this purpose [78]. Comparing with the anion exchange method, the co-precipitation method is relatively rapid and the problems with column blocking can be avoided when analyzing sample after a long storage time. The most attractive advantage of this method is that it is very suitable for the pre-concentration of ${ }^{99} \mathrm{Tc}$ in the field (or on board a sampling vessel), which significantly 
reduces the problem of transport of large volumes of water samples. However, the chemical yield of ${ }^{99} \mathrm{Tc}$ in the co-precipitation process decreases with the increase in sample volume. Meanwhile a large amount of precipitate formed in the treatment of large volumes of sample will cause other problems in the following separation and purification steps.

Activated carbon adsorption has also been reported for pre-concentration of ${ }^{99}$ Tc from water samples [77]. Because of the large specific surface area $\left(400-1600 \mathrm{~m}^{2} \mathrm{~g}^{-1}\right),{ }^{99} \mathrm{Tc}$ can be effectively adsorbed from water samples using activated carbon. It has been reported that

${ }^{99}$ Tc can be rapidly (5 $\mathrm{L} \mathrm{min}^{-1}$ ) concentrated from very large volume (several hundred liters) of environmental waters on commercial cartridge filters impregnated with activated carbon [77]. The adsorption efficiency of ${ }^{99} \mathrm{Tc}$ can be enhanced when ${ }^{99} \mathrm{Tc}$ is reduced to the low oxidation state of $\mathrm{Tc}(\mathrm{IV})$. However, if organic compounds exist in the sample, the sorption efficiency of ${ }^{99} \mathrm{Tc}$ will obviously be reduced; furthermore, the adsorbed ${ }^{99} \mathrm{Tc}$ needs to be removed from cartridge filters to aqueous solution for further separation. An additional ashing step might be added for this purpose, which will prolong the analysis time. Compared with the co-precipitation and anion exchange chromatography methods, activated carbon sorption is not commonly used as a method for ${ }^{99}$ Tc pre-concentration.

\subsubsection{Solid samples}

\subsubsection{Initial pre-treatment of samples}

For analysis of solid samples (e.g., soil, seaweed, and sediment), the impurity materials such as stones and roots of vegetations are first removed. A sufficient amount of samples is then dried at $60-105{ }^{0} \mathrm{C}$, ground, and sieved to get a homogeneous and representative sample for analysis [79,80]. Afterwards, organic matters in solid samples are decomposed by 
incinerating in muffle furnaces $[8,11,12,21,39,81,82]$. This is a very critical step in the analysis of solid samples for ${ }^{99} \mathrm{Tc}$, because incomplete decomposition of organic matters and volatile loss of ${ }^{99} \mathrm{Tc}$ in this stage will cause an insufficient leaching of ${ }^{99} \mathrm{Tc}$ from the samples and poor yield of ${ }^{99}$ Tc. Some reports suggest that ${ }^{99}$ Tc losses occur at a temperature around $550{ }^{0} \mathrm{C}[8,83]$, whereas others reported an insignificant loss of ${ }^{99} \mathrm{Tc}$ even at as much as $800{ }^{0} \mathrm{C}$ $[84,85]$. It has been reported that the loss of ${ }^{99} \mathrm{Tc}$ can be reduced if the samples are wetted with concentrated $\mathrm{HCl}$ before ashing [5]. This is explained by the reduction of Tc to Tc(IV) in high concentration of $\mathrm{HCl}$, and the stability of the $\mathrm{Tc}(\mathrm{IV})$ oxidation state compared with high oxidation states of Tc. Wigley et al. reported that $\mathrm{NH}_{3} \cdot \mathrm{H}_{2} \mathrm{O}$ is more suitable than $\mathrm{HCl}$ as the wet reagent to prevent the loss of ${ }^{99} \mathrm{Tc}$ in the ashing step [8], because the amount of volatile $\mathrm{HTcO}_{4}$ can be suppressed by the addition of $\mathrm{NH}_{3} \cdot \mathrm{H}_{2} \mathrm{O}$ before ashing. However, some investigations indicate that solid samples such as seaweed treated with $\mathrm{NH}_{3} \cdot \mathrm{H}_{2} \mathrm{O}$ did not show any difference in the chemical yield compared with untreated samples at an ashing temperature below $750{ }^{0} \mathrm{C}$ [11]. To avoid the problem of ${ }^{99} \mathrm{Tc}$ loss during incineration at high temperature, a wet ashing method using concentrated $\mathrm{H}_{2} \mathrm{SO}_{4}$ carbonization and $\mathrm{HNO}_{3}$ digestion has been applied to decompose organic matter for analyzing seaweed [86]. Our recent experiment using ${ }^{99 \mathrm{~m}}$ Tc tracer showed that ashing of soil, sediment and seaweed samples at less than $700{ }^{\circ} \mathrm{C}$ does not cause any loss of ${ }^{99} \mathrm{Tc}$. Yield tracer is normally added after pre-treatment but before ashing of samples in order to estimate the chemical yield of ${ }^{99}$ Tc during the analytical procedure.

\subsubsection{Separation of technetium from sample matrices}


Before further chemical separation, ${ }^{99} \mathrm{Tc}$ should be released from the sample matrices into solution. Two common techniques for releasing ${ }^{99}$ Tc from solid samples after ashing are acid leaching $[8,11,12,82]$ and alkali fusion [17,87-89]. Concentrated $\mathrm{HNO}_{3}$ [6,90], 8 mol L${ }^{-1}$ $\mathrm{HNO}_{3}[8,82], 4 \mathrm{~mol} \mathrm{~L}^{-1} \mathrm{HNO}_{3}[12,80,91], 6 \mathrm{~mol} \mathrm{~L}^{-1} \mathrm{HCl}+\mathrm{H}_{2} \mathrm{O}_{2}[83]$ and $3 \mathrm{~mol} \mathrm{~L}^{-1} \mathrm{HCl}+$ $\mathrm{H}_{2} \mathrm{O}_{2}$ [92] have been utilized to leach ${ }^{99}$ Tc from ashed samples under heating and reflux on a hot plate at 70-125 ${ }^{0} \mathrm{C}$. Wigley et al. [8] compared different leaching reagents (8 mol L ${ }^{-1}$ $\mathrm{HNO}_{3}$, diluted aqua regia, $8 \mathrm{~mol} \mathrm{~L}-1 \mathrm{HCl}+\mathrm{H}_{2} \mathrm{O}_{2}, 4 \mathrm{~mol} \mathrm{~L}^{-1} \mathrm{HCl}$ ) for analysis of seaweed and sediment samples, and reported that $8 \mathrm{~mol} \mathrm{~L}^{-1} \mathrm{HNO}_{3}$ showed the highest yield of ${ }^{99} \mathrm{Tc}$ and $2 \mathrm{~h}$ are necessary to release ${ }^{99} \mathrm{Tc}$ from sample matrices. Diluted aqua regia and $\mathrm{HCl}$ are less efficient for leaching ${ }^{99} \mathrm{Tc}$ compared with $\mathrm{HNO}_{3}$ but the reason is still unclear [8,93]. In fact, $8 \mathrm{~mol} \mathrm{~L}^{-1} \mathrm{HNO}_{3}$ is also the most often used reagent for leaching ${ }^{99} \mathrm{Tc}$ in the determination of ${ }^{99}$ Tc in environmental samples. Acid leaching is not only the most commonly used method but is also suitable in connection with the pre-treatment of large samples. However, acid leaching might give rise to poor yield of ${ }^{99}$ Tc when the organic matters are not decomposed completely before leaching. Addition of $\mathrm{H}_{2} \mathrm{O}_{2}$ in the acid digestion is therefore used to remove organic maters which were not completely decomposed before acid leaching. It should be mentioned that acid digestion/leaching can only release/remove ${ }^{99} \mathrm{Tc}$ absorbed on the surface of grains of solid samples. It is difficult to release ${ }^{99} \mathrm{Tc}$, which remains inside the crystal of sample grains. Alkali fusion is a method for complete decomposition of solid samples, especially soil, sediment and rocks. A mixture of $\mathrm{Na}_{2} \mathrm{O}_{2}$ and carbonate-free $\mathrm{NaOH}$ was often used as fusion reagents for the decomposition of solid samples at $400{ }^{0} \mathrm{C}-700{ }^{0} \mathrm{C}$ $[17,88,89]$. The fusion cake is dissolved with water or diluted acid solution prior to isolation 
of ${ }^{99}$ Tc. This method can completely decompose the sample in short time (usually less than 1h) and all of the ${ }^{99}$ Tc would be released into solution. However, this method is not suitable for large samples, for example more than $10 \mathrm{~g}$ of soil or sediment, because 3-5 times the amount of fusion reagents is normally used in this method, which will make the further treatment difficult when a large sample (for example $100 \mathrm{~g}$ soil or sediment) is analyzed. Oxidizing combustion methods can also be used for releasing ${ }^{99}$ Tc from solid samples [85, 94]. This method is based on the volatility of Tc in oxidative medium and at high temperature. The solid sample is placed in a quartz boat which is inserted in a quartz tube in a furance. The sample in the tube furnace is combusted under an oxygen stream at more than $1000{ }^{0} \mathrm{C}$ for $3 \mathrm{~h}$. The ${ }^{99} \mathrm{Tc}$ in sample is converted to volatile $\mathrm{Tc}_{2} \mathrm{O}_{7}$ and released from the sample, which is transported by the gas flow and trapped in alkaline solution or just water [85, 94]. Compared with alkali fusion, the combustion method can be used to treat large samples using a big tube oven, and most of the matrix components as well as many interfering radionculides and stable elements can be directly removed from the ${ }^{99} \mathrm{Tc}$ because of their lesser volatility in the combustion conditions. The chemical yield of ${ }^{99}$ Tc with this method can easily exceed $95 \%$. It has been reported that this method is difficult to use for analysis of large numbers of samples, because only one sample can be treated per day. In recent years, a multi-tube combustion furnace has become commercially available. This furnace was initially designed for determination of ${ }^{14} \mathrm{C}$ and ${ }^{3} \mathrm{H}$ in solid waste, but with small modification, it can be used for ${ }^{99}$ Tc (as well as for ${ }^{129} \mathrm{I}$ ) determination in solid samples [95]. In this case, a large sample throughput is possible using the combustion method.

In summary, when organic maters in the solid samples are well incinerated and ${ }^{99} \mathrm{Tc}$ mainly 
exists on the surface of the sample grain, acid leaching is the most suitable and convenient method for release of ${ }^{99} \mathrm{Tc}$ from sample matrices. The alkali fusion method is more suitable for the samples in which ${ }^{99}$ Tc might exist inside the crystal of sample grains, but difficult to use for large samples. Oxidizing combustion is a simple and efficient method for releasing ${ }^{99}$ Tc from large samples, but suffers from low sample throughput.

\subsection{Chemical separation and purification of technetium}

The accuracy and precision of an analytical method for determination of ${ }^{99}$ Tc rely on the level of removal of interferences and matrix components. Due to the low concentration of ${ }^{99} \mathrm{Tc}$ in the environment, a large sample is normally required for the analysis in order to obtain sufficient signal. The method adopted for the chemical separation of ${ }^{99} \mathrm{Tc}$ should be able not only to give a good decontamination from interferences but also to provide a high chemical yield of ${ }^{99}$ Tc. For measurement of ${ }^{99}$ Tc using radiometric methods, a thorough chemical separation of almost all other radionuclides from ${ }^{99} \mathrm{Tc}$ is required because of bad spectrometric resolution of the beta counting method [61, 96]. For measurement of ${ }^{99}$ Tc using mass spectrometric methods, for example ICP-MS, besides the interference of matrix elements, the interferences from isobaric and molecular ions in the mass of 99 is the main challenge [21, 97]. Of these, the most important isobaric interferences are from ${ }^{98} \mathrm{Mo}^{1} \mathrm{H}$ and ${ }^{99} \mathrm{Ru}$. Table 6 shows the main potential interferences for the measurement of ${ }^{99} \mathrm{Tc}$ by radiometric and spectrometric methods. For separation and purification of ${ }^{99} \mathrm{Tc}$, a variety of techniques have been used The most common are co-precipitation, solvent extraction, ion exchange chromatography, extraction chromatography or a combination of two or more 
methods $[5,8,62,82,89,98]$, these techniques are summarized and compared below.

\subsubsection{Preconcentration of technetium by co-precipitation}

Co-precipitation is a traditional method for radiochemical separation. For the precipitation of an element as its compound, the concentration of the precipitation reagent has to be high enough to excess its solubility product $\left(K_{s p}\right)$. Since the concentrations of ${ }^{99} \mathrm{Tc}$ in environmental samples are generally very low, and there is no stable isotope of Tc, its solubility products are seldom exceeded even with a saturated concentration of precipitation reagent in the sample solution. The co-precipitation technique is therefore often used to separate ${ }^{99}$ Tc from sample matrices.

Under reductive conditions, ${ }^{99} \mathrm{Tc}$ mainly exists in the oxidation state of $\mathrm{Tc}(\mathrm{IV})$, which easily forms insoluble species of $\mathrm{TcO}_{2} \cdot \mathrm{nH}_{2} \mathrm{O}$ in aqueous solution (usually in the form of $\mathrm{TcO}_{2} \cdot \mathrm{H}_{2} \mathrm{O}$ ) and can be co-precipitated by carrier such as $\mathrm{Fe}(\mathrm{OH})_{2}$ or $\mathrm{FeS}(\mathrm{CuS})$ from sample matrices. Two issues need to be considered during the co-precipitation: a suitable medium for coprecipitation and the reductive reagent. As discussed above, Tc is difficult to reduce to Tc(IV) in the $\mathrm{HNO}_{3}$ medium but it can be realized easily in $\mathrm{HCl}$ solution. The sample solution is therefore converted to diluted $\mathrm{HCl}$ medium (e.g. $0.1 \mathrm{~mol} \mathrm{~L}^{-1} \mathrm{HCl}$ ) before the reduction and co-precipitation of Tc takes place. Many reductive reagents have been used for converting Tc to $\mathrm{Tc}(\mathrm{IV})$. In earlier studies, Holm et al. [5] compared the reductive abilities of $\mathrm{SnCl}_{2}$ $\left(\mathrm{Fe}(\mathrm{OH})_{2}\right.$ as co-precipitation reagent) and $\mathrm{FeSO}_{4} \cdot 7 \mathrm{H}_{2} \mathrm{O}$ for ${ }^{99} \mathrm{Tc}$ in $5 \mathrm{~L}$ seawater samples. It was reported that both $\mathrm{SnCl}_{2}\left(0.5 \mathrm{~g} \mathrm{~L}^{-1}\right)$ and $\mathrm{FeSO}_{4} \cdot 7 \mathrm{H}_{2} \mathrm{O}\left(0.7 \mathrm{~g} \mathrm{~L}^{-1}\right)$ can convert Tc to Tc(IV) and ${ }^{99} \mathrm{Tc}$ is efficiently co-precipitated with $\mathrm{Fe}(\mathrm{OH})_{2}$. However, the dissolution of the co- 
precipitated Tc by re-oxidation of $\mathrm{Tc}(\mathrm{IV})$ to $\mathrm{Tc}(\mathrm{VII})$ is difficult if the $\mathrm{SnCl}_{2}$ is used as reductive reagent and the mechanism is still not clear. Comparing with $\mathrm{SnCl}_{2}, \mathrm{FeSO}_{4} \cdot 7 \mathrm{H}_{2} \mathrm{O}$ shows better characteristics for Tc separation by co-precipitation, and it is not necessary to add additional iron compounds such as $\mathrm{FeCl}_{3} \cdot 6 \mathrm{H}_{2} \mathrm{O}$ to form $\mathrm{Fe}(\mathrm{OH})_{2}$ precipitation. In fact, $\mathrm{FeSO}_{4} \cdot 7 \mathrm{H}_{2} \mathrm{O}$ has often been utilized to reduce Tc during co-precipitation separation of ${ }^{99} \mathrm{Tc}$ in liquid samples as well as from the leachate of seaweed [40]. However, for soil and sediment, it is not very sensible to choose $\mathrm{FeSO}_{4} \cdot 7 \mathrm{H}_{2} \mathrm{O}$ as the reductive reagent because of a large amount of iron existing in these types of samples. In addition, a large amount of precipitate will be produced if $\mathrm{FeSO}_{4} \cdot 7 \mathrm{H}_{2} \mathrm{O}$ is used, which might decrease the chemical yield of ${ }^{99} \mathrm{Tc}$ during the separation of Tc from iron by converting $\mathrm{Tc}(\mathrm{IV})$ to soluble $\mathrm{TcO}_{4}{ }^{-}$and removal of iron by precipitation of $\mathrm{Fe}(\mathrm{OH})_{3}$. This might be attributed to the fact that some $\mathrm{TcO}_{4}{ }^{-}$can be enwrapped in $\mathrm{Fe}(\mathrm{OH})_{3}$ precipitate although Tc has been converted to $\mathrm{Tc}(\mathrm{VII}) . \mathrm{K}_{2} \mathrm{~S}_{2} \mathrm{O}_{5}$ ( $\mathrm{KHSO}_{3}$ form in solution) is another reductive reagent which can be used in the reduction of $\mathrm{TcO}_{4}{ }^{-}$to $\mathrm{Tc}(\mathrm{IV})$. It has been reported that $\mathrm{TcO}_{4}{ }^{-}$can be easily reduced to $\mathrm{Tc}(\mathrm{IV})$ by $\mathrm{K}_{2} \mathrm{~S}_{2} \mathrm{O}_{5}$, and the formed Tc(IV) in the co-precipitate can be transferred to solution by oxidizing it to $\mathrm{TcO}_{4}{ }^{-}$again [74]. In fact, $\mathrm{K}_{2} \mathrm{~S}_{2} \mathrm{O}_{5}$ has been widely applied in many analytical procedures of ${ }^{99}$ Tc for the reduction of Tc to low oxidation state [13,61].

After the pre-concentration of ${ }^{99} \mathrm{Tc}$ by co-precipitation, it is necessary to transfer ${ }^{99} \mathrm{Tc}$ into aqueous solution for further separation, and this can be accomplished by oxidizing Tc(IV) to $\mathrm{TcO}_{4}{ }^{-}$based on the high solubility of $\mathrm{TcO}_{4}{ }^{-}$in aqueous solution. Different oxidative reagents like $\mathrm{H}_{2} \mathrm{O}_{2}$ or $\mathrm{K}_{2} \mathrm{~S}_{2} \mathrm{O}_{8}$ have been added after dissolving the co-precipitate of Tc with $\mathrm{Fe}(\mathrm{OH}) 2$ in acid to oxidize $\mathrm{Tc}(\mathrm{IV})$ to $\mathrm{Tc}(\mathrm{VII})$; Fe as well as other transition metals, actinides and 
lanthanides are then removed effectively through $\mathrm{Fe}(\mathrm{OH})_{3}$ co-precipitation, while leaving $\mathrm{TcO}_{4}{ }^{-}$in solution [62].

Co-precipitation is a very simple method and can be used to separate ${ }^{99} \mathrm{Tc}$ from sample matrices effectively. A batch of samples (8-12) is treated in a short time and no other chemical waste is produced during the process. However, a low recovery of ${ }^{99} \mathrm{Tc}$ might be the result when analyzing a large volume of water (for example $200 \mathrm{~L}$ seawater). In addition, the decontamination factor of this method alone is normally not very high for most interferences. In practice, the co-precipitation technique is often used to pre-concentrate and separate Tc from the major matrix components of large samples; it is common to combine with other techniques like solvent extraction, anion exchange or extraction chromatography for ${ }^{99} \mathrm{Tc}$ separation and purification.

\subsubsection{Solvent extraction}

Several extractants like tri-iso-octylamine (TiOA), tri-butylphosphate (TBP) and cyclohexanone have been applied for separation of ${ }^{99}$ Tc from other radionuclides and matrix components.

TiOA is the most common extractant applied for the separation of ${ }^{99} \mathrm{Tc}[4,8,9,74,99]$. This is based on the formation of a neutral complex of $\mathrm{TcO}_{4}{ }^{-}$with TiOA in low concentration of acid. It has been reported that ${ }^{99} \mathrm{Tc}$ can be easily extracted by $5 \%$ TiOA /xylene (ratio of volume) from $0.5 \mathrm{~mol} \mathrm{~L}^{-1} \mathrm{H}_{2} \mathrm{SO}_{4}$ solution, and ${ }^{99} \mathrm{Tc}$ in the organic phase can be back-extracted by low concentration $\mathrm{NaOH}$ solution [4]. As the main interference in ${ }^{99} \mathrm{Tc}$ measurement, $\mathrm{Ru}$ can be removed effectively in this step. Reported distribution coefficients for Ru and ${ }^{99}$ Tc between $5 \%$ 
TiOA/xylene and $0.5 \mathrm{~mol} \mathrm{~L}^{-1} \mathrm{H}_{2} \mathrm{SO}_{4}$ solution are $3.8 \times 10^{-3}$ and $2.5 \times 10^{3}$, respectively [6]. This feature can be explained as that in low concentration $\mathrm{H}_{2} \mathrm{SO}_{4}$, Tc is oxidized to $\mathrm{TcO}_{4}{ }^{-}$, but $\mathrm{Ru}$ is kept in a low oxidiation state, which cannot be extracted by $5 \% \mathrm{TiOA} / x y l e n e$ if a mild oxidizing reagent such as $\mathrm{H}_{2} \mathrm{O}_{2}$ is used. It has been observed that ${ }^{99}$ Tc cannot be separated from $\mathrm{Ru}$ by extraction with $5 \% \mathrm{TiOA}$ /xylene in $\mathrm{H}_{2} \mathrm{SO}_{4}$ solution if a strong oxidizing reagent such as $\mathrm{NaClO}$ is used [6]. In this case, Tc and $\mathrm{Ru}$ are oxidized to $\mathrm{TcO}_{4}{ }^{-}$and $\mathrm{RuO}_{4}{ }^{-}$ respectively, and both of them are extracted by TiOA. As another trioctyl amine, Trioctylamine (TOA) has also been applied to extract ${ }^{99} \mathrm{Tc}$ for separation of it from other interfering cations. $\mathrm{H}_{2} \mathrm{SO}_{4}$ medium is often used in the extraction of Tc using TiOA/xylene although this is not effective for Mo decontamination.

TBP is a conventional extractant extensively used in plutonium-uranium extraction in PUREX process in the spent fuel reprocessing. It can also be used to separate ${ }^{99}$ Tc from other interferences $[2,21,93,99]$. This is based on the fact that in acid medium, $\mathrm{TcO}_{4}{ }^{-}$combines with $\mathrm{H}^{+}$or $\mathrm{H}_{3} \mathrm{O}^{+}$to form neutral molecular $\mathrm{HTcO}_{4}$ or $\mathrm{HTcO}_{4}\left(\mathrm{H}_{2} \mathrm{O}\right)$, which can form a complex with TBP to be extracted [100]. The choice of a suitable medium for TBP extraction is very critical. Relatively low concentration of $\mathrm{HNO}_{3}$ or $\mathrm{H}_{2} \mathrm{SO}_{4}$ is often utilized during ${ }^{99} \mathrm{Tc}$ extraction. ${ }^{99} \mathrm{Tc}$ is easy extracted by TBP in $0.1-2 \mathrm{~mol} \mathrm{~L}^{-1} \mathrm{HNO}_{3}$ solution, and chemical yield of ${ }^{99} \mathrm{Tc}$ is not high in other concentrations of $\mathrm{HNO}_{3}$ [101]. This can be explained as that in low concentration of $\mathrm{HNO}_{3}, \mathrm{HTcO}_{4}$ is not easily formed, while in higher concentration of $\mathrm{HNO}_{3}$, the competitive complexation of $\mathrm{HNO}_{3}$ to TBP with $\mathrm{HTcO}_{4}$ reduces the distribution coefficient of ${ }^{99}$ Tc. In most cases, ${ }^{99} \mathrm{Tc}$ is separated from interferences by TBP extraction in $\mathrm{H}_{2} \mathrm{SO}_{4}$ solution. It has been reported that the distribution coefficient of ${ }^{99} \mathrm{Tc}$ in $\mathrm{H}_{2} \mathrm{SO}_{4}$-TBP 
medium is a couple of times higher than that in $\mathrm{HNO}_{3}$-TBP medium, and about $98 \%{ }^{99}$ Tc can be extracted by TBP in xylene from $2 \mathrm{~mol} \mathrm{~L}^{-1} \mathrm{H}_{2} \mathrm{SO}_{4}$ [2]. Because of the relatively inert complex behaviour of $\mathrm{SO}_{4}{ }^{2-},{ }^{99} \mathrm{Tc}$ can be extracted from 1-6 mol L ${ }^{-1} \mathrm{H}_{2} \mathrm{SO}_{4}$ solution by TBP, and the influence of $\mathrm{H}_{2} \mathrm{SO}_{4}$ concentration is not obvious [5,21]. After the extraction of ${ }^{99} \mathrm{Tc}$ into organic phase, $\mathrm{NaOH}$ or $\mathrm{NH}_{3} \cdot \mathrm{H}_{2} \mathrm{O}$ solution is normally used to back-extract ${ }^{99} \mathrm{Tc}$ to aqueous phase for further separation. Although ${ }^{99} \mathrm{Tc}$ can be extracted from $\mathrm{H}_{2} \mathrm{SO}_{4}$ solution by TBP with a high chemical recovery (usually above $90 \%$ ), decontamination of $\mathrm{Ru}$ in this process is not satisfactory.

Because of the effective separation of $\mathrm{Ru}$ and other radionuclides from ${ }^{99} \mathrm{Tc}$, cyclohexanone has also been used for purification of ${ }^{99} \mathrm{Tc}$, especially before its measurement by ICP-MS. It has been reported that $\mathrm{Ru}$ can be more efficiently removed from ${ }^{99} \mathrm{Tc}$ by extraction using cyclohexanone in $\mathrm{K}_{2} \mathrm{CO}_{3}$ solution than in $\mathrm{HNO}_{3}$ medium, although the chemical yield (about $80 \%$ ) of ${ }^{99} \mathrm{Tc}$ is slightly lower than that in the $\mathrm{HNO}_{3}$ medium [81]. The adjustment of oxidation states of $\mathrm{Ru}$ and Tc in sample solution before extraction is a critical factor which influences the decontamination of Ru. A decontamination factor of $7.0 \times 10^{4}$ for $\mathrm{Ru}$ has been reported when sample solution is pre-treated by $30 \% \mathrm{H}_{2} \mathrm{O}_{2}$ in $1 \mathrm{~mol} \mathrm{~L}^{-1} \mathrm{~K}_{2} \mathrm{CO}_{3}$ medium before extraction. In this condition, $\mathrm{H}_{2} \mathrm{O}_{2}$ acts as a reductant in alkali medium to reduce $\mathrm{Ru}$ to low oxidation state, while Tc remains in the form of $\mathrm{TcO}_{4}{ }^{-}$. The reduced $\mathrm{Ru}$ could not be extracted by cyclohexanone, and remains in the aqueous phase, thus separated from ${ }^{99} \mathrm{Tc}$ which is extracted to the organic phase. It should be mentioned that the decontamination of Mo using cyclohexanone extraction is not satisfactory [51,102,103], while ${ }^{99}$ Mo as ${ }^{98} \mathrm{Mo}^{1} \mathrm{H}$, is one of the major isobaric interferences for ${ }^{99} \mathrm{Tc}$ measurement by mass spectrometry. 
Therefore, other methods are still needed before measurement of ${ }^{99} \mathrm{Tc}$.

Solvent extraction offers a great advantage of selection among numerous extractants, whereby the selectivity can be readily modulated. However, there are some disadvantages when the solvent extraction method is used. Firstly, solvent extraction is relative laborconsuming for routine analysis because several extractions should be consecutively performed to separate the analyte from the bulk solution completely. Secondly, a large volume of hazardous organic solvent has to be used, which is harmful not only to the operators, but also to the environment. In recent years, with the development of new chromatography techniques, especially extraction chromatography, solvent extraction is no longer a frequently used technique in routine analysis of environmental samples for ${ }^{99} \mathrm{Tc}$, and is gradually replaced by anion exchange chromatography and extraction chromatography in many laboratories, although it is still applied in some cases, for example in analysis of a few high level nuclear waste samples.

\subsubsection{Anion exchange chromatography}

Anion exchange chromatography is one of the most frequently used separation techniques for determination of ${ }^{99} \mathrm{Tc}$ in environmental samples [17,81,102,104]. Strong basic anion exchange resin, for example Dowex 1 (or Bio-Rad AG1) resin, has a very high selectivity for $\mathrm{TcO}_{4}{ }^{-}$anion in a wide range of $\mathrm{pH}[83,98]$, because the affinity of $\mathrm{TcO}_{4}{ }^{-}$to the resin is much higher compared with other common anions in environmental samples, such as $\mathrm{Cl}^{-}, \mathrm{NO}_{3}{ }^{-} \mathrm{Br}^{-}$, and $\mathrm{CO}_{3}{ }^{2-}$. Before separation, Tc needs to be converted to $\mathrm{TcO}_{4}{ }^{-}$. Addition of $\mathrm{H}_{2} \mathrm{O}_{2}$ and/or $\mathrm{K}_{2} \mathrm{~S}_{2} \mathrm{O}_{8}$ to the sample solution in acidic medium, normally $\mathrm{HNO}_{3}$, is a common method for 
this purpose. The solution in diluted acid or neutral medium is loaded to an anion exchange chromatographic column, and $\mathrm{TcO}_{4}{ }^{-}$, as well as some other anions, are absorbed on the column. Almost all cations and matrix components can be removed in this step. The column is then washed with water, diluted acid including $\mathrm{HNO}_{3}$, and $\mathrm{HCl}$ to remove the remained cations and most of anions. In earlier works, ${ }^{99} \mathrm{Tc}$ on the column was eluted by $\mathrm{NaClO}_{4}$ and $\mathrm{Na}_{2} \mathrm{SO}_{3}$ solution. This exploits the relative higher affinity of $\mathrm{ClO}_{4}{ }^{-}$comparing with that of $\mathrm{TcO}_{4}{ }^{-}$, and reduction of $\mathrm{TcO}_{4}{ }^{-}$to low oxidation state of Tc to enable removal from the anion exchange column [104]. In recent years, high concentration of $\mathrm{HNO}_{3}\left(10-12 \mathrm{~mol} \mathrm{~L}^{-1}\right)$ is often used to elute $\mathrm{TcO}_{4}{ }^{-}$from the column. This simplifies the operation of further separation of Tc. However, a low degree of decontamination of Mo and Ru is observed in the eluate, which interferes with the mass spectrometric measurement of ${ }^{99}$ Tc. Meanwhile radioisotopes of Ru, such as ${ }^{106} \mathrm{Ru}$ and ${ }^{103} \mathrm{Ru}$, which occurred in the fresh fallout of the nuclear accident and nuclear waste from nuclear power plants, also interfere with the radiometric measurement of ${ }^{99} \mathrm{Tc}$ [81]. It has been reported that Mo absorbed on the column as $\mathrm{MoO}_{4}{ }^{2-}$ can be removed by washing with $0.5 \mathrm{~mol} \mathrm{~L}^{-1} \mathrm{HCl}$, cold and hot water [102], but the decontamination of Ru is still not satisfactory. In order to remove ${ }^{106} \mathrm{Ru}$ in environmental samples contaminated by Chernobyl accident fallout, Chen et al. [61] employed a washing procedure using $\mathrm{NaClO}$ solution followed by $\mathrm{H}_{2} \mathrm{O}_{2}$ and $\mathrm{NaOH}$ solution, and reported a better decontamination of ${ }^{106} \mathrm{Ru}$ in the final solution.

Other types of anion exchange resins have also been employed for ${ }^{99}$ Tc separation $[17,42]$, including macro-pore anion exchange resin (Bio-Rad AG MP-1) and IRA-400. It has been reported that AG MP-1 resin is a useful resin to remove transition elements [17] and 
Amberlite IRA-400 anion exchange resin is effective to remove Mo [42]. A major advantage of the anion exchange method for separation of Tc is that treatment of large samples is possible, for example up to $200 \mathrm{~L}$ of seawater, due to the high affinity of $\mathrm{TcO}_{4}{ }^{-}$on the resin. Also, the removal of the matrix components and most interferences is effective. Although anion exchange chromatography has been widely used in most analytical procedures for ${ }^{99} \mathrm{Tc}$, the decontamination factors of some important interfering anions such as $\mathrm{RuO}_{4}{ }^{-}$and $\mathrm{MoO}_{4}{ }^{2-}$ are normally not sufficient. The method is therefore not satisfactory for the measurement of

low level ${ }^{99}$ Tc. To obtain a lower detection limit and more accurate analytical results, further separation of Mo, Ru and ${ }^{99} \mathrm{Tc}$ in the eluate of anion exchange chromatography is therefore followed [20].

\subsubsection{Extraction chromatography}

Extraction chromatography has advantages of both solvent extraction and chromatography, i.e. combining the selectivity of solvent extraction with the high separation efficiency of the chromatographic method. In this method, the extractant is immobilized on the surface of inert resin beads, corresponding to the organic, stationary phase in solvent extraction and chromatography, respectively. Since commercialization of extraction chromatographic resins by Eichrom Technologies Inc. in 1990's, extraction chromatography has been widely used in radiochemical analysis of ${ }^{99}$ Tc [7,10,11,21,25,62,73,105-107].

The most commonly used extraction chromatographic resin for ${ }^{99}$ Tc separation is TEVA $^{\circledR}$ (TEVA), which is produced and commercialized by Eichrom Technologies Inc. The function group on TEVA resin is trialkyl methyl ammonium salt, also called Aliquat® 336 . This is 
mainly used to separate tetravalent actinides and Tc. The separation of Tc using TEVA resin is based on the high affinity of $\mathrm{TcO}_{4}{ }^{-}$to TEVA resin in low concentration of acid ( $\mathrm{K}^{\prime}$ values are $6 \times 10^{3}$ for $0.1 \mathrm{~mol} \mathrm{~L}^{-1} \mathrm{HNO}_{3}$ and $6 \times 10^{4}$ in $0.1 \mathrm{~mol} \mathrm{~L}^{-1} \mathrm{HCl}$ medium), and the affinity ( $\mathrm{K}^{\prime}$ value) decreases with the increase of acid concentration to less than 2 at $8 \mathrm{~mol} \mathrm{~L}^{-1} \mathrm{HNO}_{3}$. Therefore it is very useful for the separation of ${ }^{99} \mathrm{Tc}$ from matrix components, and interferences including actinides. Another advantage of TEVA resin is its applicability in the separation of Tc from $\mathrm{Ru}$ and Mo, this is based on the great difference in the affinity of $\mathrm{TcO}_{4}{ }^{-}$ to TEVA compared with those of $\mathrm{MoO}_{4}{ }^{2-}$ and $\mathrm{RuO}_{4}{ }^{-}$. Uchida et al. [10] have reported a decontamination factor of 100 for $\mathrm{Ru}$ when loading the sample solution in an alkaline solution, compared with a decontamination factor of 250 when loading in $0.1 \mathrm{~mol} \mathrm{~L}^{-1} \mathrm{HNO}_{3}$ solution. Washing the column with relatively high concentration of $\mathrm{HNO}_{3}$ increases the removal of Ru from ${ }^{99} \mathrm{Tc}$. However, it has been observed that a washing solution of $\mathrm{HNO}_{3}$ with a concentration higher than $4 \mathrm{~mol} \mathrm{~L}^{-1}$ can also remove Tc from the column, resulting in a low chemical yield [108]. The affinity of Tc on TEVA resin decreases with increasing $\mathrm{HNO}_{3}$ concentration and therefore a high concentration of $\mathrm{HNO}_{3}$ is used to elute Tc from the resin [25]. Considering the measurement by ICP-MS (normally injecting sample in 0.3-0.6 mol L-1 $\mathrm{HNO}_{3}$ solution), high concentration of $\mathrm{HNO}_{3}$ (such as concentrated $\mathrm{HNO}_{3}$ ) as eluent requires a high dilution before ICP-MS measurement, resulting in a higher detection limit. Therefore, the eluate of 8-12 mol L-1 of $\mathrm{HNO}_{3}$ is first evaporated to a small volume and then diluted with deionized water to a $\mathrm{HNO}_{3}$ concentration of $0.5 \mathrm{~mol} \mathrm{~L}^{-1}$ to improve the detection limit [108]. A common procedure for separation of ${ }^{99} \mathrm{Tc}$ using extraction chromatography employing TEVA resin $[21,92,103,108,109]$ is shown in Fig.5. ${ }^{99}$ Tc in the sample solution is first 
converted to $\mathrm{TcO}_{4}{ }^{-}$, and the prepared solution in low concentration of $\mathrm{HNO}_{3}$ (usually $0.1 \mathrm{~mol}$ $\mathrm{L}^{-1} \mathrm{HNO}_{3}$ or $\mathrm{HCl}$ ) is then loaded to a chromatographic column filled with TEVA (about $2 \mathrm{~mL}$ ) resin. $\mathrm{TcO}_{4}{ }^{-}$is absorbed very strongly on the column, while matrix components and most $\mathrm{Ru}$ and Mo pass through the column and are separated from ${ }^{99}$ Tc. The column is washed with 1-2 mol $\mathrm{L}^{-1}$ nitric acid solution to remove the remaining $\mathrm{Ru}$ and $\mathrm{Mo}$, as well as other interferences. The $\mathrm{TcO}_{4}{ }^{-}$on the column is finally eluted using high concentration nitric acid (usually $8 \mathrm{~mol} \mathrm{~L}^{-1} \mathrm{HNO}_{3}$ ).

Besides TEVA, some other types of extraction chromatographic resins such as AnaLig ${ }^{\circledR}$ Tc02 gel, and $\mathrm{C}_{18}$ Silica have also been investigated and applied for separation of ${ }^{99} \mathrm{Tc}$ from sample matrices $[109,110]$. Warwick et al. [110] used $\mathrm{C}_{18}$ Silica to purify ${ }^{99}$ Tc from sample solution. ${ }^{99}$ Tc was firstly converted to Tc-tripentylamine complex form and prepared in 2 mol $\mathrm{L}^{-1} \mathrm{H}_{2} \mathrm{SO}_{4}$ medium, and then loaded to a $\mathrm{C}_{18}$ Silica column. The column was washed with sulfuric acid/tripentylamine mixture to remove contaminating radionuclides such as $\mathrm{Ru}$, and ${ }^{99}$ Tc was finally eluted from the column using a dilute alkali solution. Remence [109] has investigated AnaLig ${ }^{\circledR}$ Tc-02 gel resin for separation of ${ }^{99}$ Tc from other radionuclides. The pretreated sample solution was loaded onto the column, and the column was washed with $0.01 \mathrm{~mol} \mathrm{~L}^{-1} \mathrm{HCl}+0.1 \mathrm{~g} \mathrm{~mL}^{-1} \mathrm{NaCl} .{ }^{99} \mathrm{Tc}$ on the column was then eluted with $10 \mathrm{~mL}$ of hot deionized water at $80-90{ }^{0} \mathrm{C}$. The main advantage of this method is that deionized water is used to elute ${ }^{99}$ Tc from the column, whereby additional evaporation or dilution steps are avoided before measurement, compared with the TEVA resin, for which high concentration of $\mathrm{HNO}_{3}$ was used in the elution step. The decontamination of other $\beta$ emitters is also effective. The decontamination factor for ${ }^{137} \mathrm{Cs}$ is more than $10^{5}$, and for ${ }^{60} \mathrm{Co}$ about $10^{4}$. However, 
comparing with TEVA, these two types of extraction chromatographic resins are less commonly investigated and used, and no decontamination factors for Mo and Ru have been reported using these two types of resins.

The advantages of extraction chromatography, especially employing TEAV resin, are apparent, such as small size column, high decontamination for Mo and Ru interferences, high chemical yield, and less toxic waste production. However, extraction chromatography using TEVA resin is more expensive compared with anion exchange and solvent extraction, which to some extent limits its application for routine analysis.

\subsubsection{Combination of different chemical separation and purification techniques}

Since the above discussed separation methods have their specific disadvantages in the separation of ${ }^{99} \mathrm{Tc}$ with respect to removal of matrix components and interferences, a single separation method usually cannot obtain satisfactory removal of interferences for the determination of low level ${ }^{99} \mathrm{Tc}$ in environmental samples. In addition, the separation efficiency of a specific method also depends on the composition of the sample solution. Poor removal of interferences and low chemical yield might result from the separation if the salt content is very high in the sample solution. In most cases, two or more techniques are combined to improve the decontamination with respect to potential interferences for ${ }^{99} \mathrm{Tc}$ determination. In general, the major matrix components including alkali and alkaline earth metals, and major anion such $\mathrm{Cl}^{-}, \mathrm{Br}^{-}, \mathrm{NO}_{3}{ }^{-}$and $\mathrm{SO}_{4}{ }^{2-}$, are first removed from the sample by co-precipitation of Tc as Tc(IV) with $\mathrm{Fe}(\mathrm{OH})_{2}$, and ${ }^{99} \mathrm{Tc}$ is then further purified by extraction chromatography, anion exchange chromatography and/or solvent extraction to remove the 
interferences, especially $\mathrm{Ru}$ and Mo. Chen et al. [6] described an analytical method to determine ${ }^{99} \mathrm{Tc}$ in large volumes of seawater by $\beta$ counting. ${ }^{99} \mathrm{Tc}$ in the seawater is first preconcentrated by anion exchange chromatography using Bio-Rad AG 1-×4 resin. ${ }^{99}$ Tc is strongly absorbed on the resin, while most matrix components are removed during the sample loading and washing with diluted $\mathrm{HNO}_{3}$. After eluting ${ }^{99} \mathrm{Tc}$ from the column, an AgCl precipitation step is added to remove ${ }^{110 \mathrm{~m}} \mathrm{Ag}$ which might occur in fresh fallout of nuclear accidents and nuclear power plant releases, and $\mathrm{Fe}(\mathrm{OH})_{3}$ precipitation follows to remove transition metals. To remove ${ }^{103} \mathrm{Ru}$ and ${ }^{106} \mathrm{Ru}$, a solvent extraction using $5 \%$ TIOA-xylene is followed, combined with evaporation at $\mathrm{H}_{2} \mathrm{SO}_{4}$ medium. ${ }^{99} \mathrm{Tc}$ in the separated solution is finally purified again by anion exchange chromatography, and a total recovery of about $70 \%$ was recorded for $200 \mathrm{~L}$ seawater. This method has been successfully applied for routine analysis of seawater samples collected from different locations, and accurate and reliable results were obtained in many intercomparison exercises. However, as mentioned before, the colloids and suspending materials formed during the sample storage may cause a problem during the pre-concentration step using anion exchange chromatography. It should be noted that the procedure is relatively long and time consuming. Keith-Roach et al. [20] have modified this procedure for determination of ${ }^{99} \mathrm{Tc}$ in seawater samples, employing ICP-MS for ${ }^{99}$ Tc measurement. Fig. 6 shows the schematic diagram of this procedure. The water sample is first acidified to $\mathrm{pH}$ less 1.5 with concentrated $\mathrm{HNO}_{3}$ and then heated at a temperature exceeding $90{ }^{0} \mathrm{C}$ for $2 \mathrm{~h}$ to break down any organic complexes and precipitate phases. A hydroxide precipitation step is then added to remove transition metals and actinides, which easily form precipitate in alkali medium. The supernatant is neutralized and loaded to 
an anion exchange column (AG1-×4). Most of the cations are removed to the effluent, after washing the column with water and diluted $\mathrm{HNO}_{3}$, and ${ }^{99} \mathrm{Tc}$ is then eluted with $10 \mathrm{~mol} \mathrm{\textrm {L } ^ { - 1 }}$ $\mathrm{HNO}_{3}$ in a small volume. For further separation of Mo and $\mathrm{Ru}$, extraction chromatography using TEVA resin is employed. This procedure overcomes the drawback of pre-concentration of stored water samples using anion exchange AG1-X4 column and also shortens the measurement time by using ICP-MS. However, the complicated pre-treatment and separation procedures prolong the analytical time and decrease the chemical yield of ${ }^{99} \mathrm{Tc}$ in some cases. For determination of ${ }^{99} \mathrm{Tc}$ in solid samples, such as soil, sediment and seaweed samples, ${ }^{99} \mathrm{Tc}$ is normally first separated from the leachate/fusion extracts by co-precipitation or anion exchange chromatography to remove most matrix components. Then a further purification to remove $\mathrm{Ru}$ and Mo is carried out before measurement, using solvent extraction or extraction chromatography like TEVA resin. Butterworth et al. [62] have described a method to determine ${ }^{99} \mathrm{Tc}$ in soil and sediment samples using ICP-MS. After destroying organic matter with $30 \% \mathrm{H}_{2} \mathrm{O}_{2}$, concentrated $\mathrm{HCl}$ was used to leach ${ }^{99} \mathrm{Tc}$ from the sample matrix. The transition metals, actinides and lanthanides were first removed by precipitation using $\mathrm{Fe}(\mathrm{OH})_{3}$, and alkali as well as alkaline earth metals remaining in the solution with ${ }^{99} \mathrm{Tc}$ were then removed using anion exchange chromatography (Dowex 1-×8). An evaporation step was followed to reduce the size of the eluate. The obtained solution was then diluted to $0.5 \mathrm{~mol}$ $\mathrm{L}^{-1} \mathrm{HNO}_{3}$ for further decontamination of $\mathrm{Ru}$ and Mo by extraction chromatography with TEVA resin. Most matrix components and interferences can be removed in this procedure and a relatively clean solution was obtained prior to the measurement by ICP-MS. The main drawbacks of the method appear to be the time consuming during the evaporation step and 
the relatively inefficient decontamination of Mo and Ru because washing with $0.5 \mathrm{~mol} \mathrm{~L}{ }^{-1}$ $\mathrm{HNO}_{3}$ in the TEVA purification step is not enough to remove all of Mo and Ru. McCartney et al. [11] have proposed a simple method to remove the matrix components in the leachate by re-crystallisation. The leachate from a solid sample was evaporated to incipient dryness. The residue was then leached with a small volume of water (30 $\mathrm{mL}$ for 10 samples), and the leachate was used for further separation of ${ }^{99}$ Tc. It has been reported that chemical yield of

${ }^{99}$ Tc in this step is higher than $98 \%$, while most matrix elements including the salts of alkali and alkaline earth metals, transition metals, and actinides are removed. It was also observed that about $20 \%$ of Ru can be removed in this step. Although this method can remove most matrix elements and is simple to operate, the efficiency of matrix removal is normally mild, which may reduce the separation efficiency in the further purification steps. However, if large samples are analyzed, loss of ${ }^{99} \mathrm{Tc}$ in the re-crystallisation step might become significant, which will result in a low chemical yield of ${ }^{99} \mathrm{Tc}$ in the whole procedure. In general, most reported analytical procedures for ${ }^{99}$ Tc determination in environmental samples are tedious and time consuming. The development of a high efficiency method with a short analytical time, while providing high decontamination of interferences and low detection limits, as well as reducing the cost of the analysis is still a challenge in the determination of ${ }^{99} \mathrm{Tc}$ in environmental samples.

\subsection{Source preparation for measurement of technetium-99}

As a pure $\beta^{-}$emitter, ${ }^{99} \mathrm{Tc}$ is conventionally measured by radiometric methods including LSC $[7,8,69]$ and GM-gas flow counter $[61,78,111]$. In recent years, more and more measurements 
of ${ }^{99} \mathrm{Tc}$ are carried out by mass spectrometry, especially ICP-MS. Depending on the measurement techniques, the separated ${ }^{99} \mathrm{Tc}$ has to be prepared in a suitable medium before measurement. For the detection of ${ }^{99}$ Tc by LSC, the ${ }^{99}$ Tc solution separated from matrix and interfering radionuclides and in a small volume $(<5 \mathrm{~mL})$ has to be mixed with scintillation cocktail for activity measurement. If the ${ }^{99} \mathrm{Tc}$ is separated and collected in an organic solution, which is fully soluble and high compatible with scintillation cocktail, a high counting efficiency will be obtained. Most frequently, ${ }^{99} \mathrm{Tc}$ is in an aqueous solution which is not completely compatible in the organic cocktail. Especially for a solution with high salt content, high acid or alkali concentration, a high quench (low counting efficiency) will occur, and it is normally necessary to prepare the solution in diluted acid/alkali solution with less salt content to be able to obtain a high counting efficiency, and therefore a low detection limit. For measurement with GM-gas flow counter, the sample is normally prepared in solid form and the amount of the final sample should be as small as possible to minimize self-absorption. Co-precipitation and electro-deposition are frequently used methods for preparing counting sources for measurement using GM counter. Co-precipitation methods, e.g., reducing $\mathrm{TcO}_{4}{ }^{-}$ to low oxidation state and co-precipitating with $\mathrm{Fe}(\mathrm{OH})_{2}$ or $\mathrm{CuS}$, has been used. However, because of the low recovery and reproducibility, as well as the relatively large mass of precipitation which increases self adsorption, this technique is not a commonly used method for solid source preparation. Electro-deposition is the most commonly used source preparation method for measurement of ${ }^{99}$ Tc by GM counter [61,78,111]. Electro-deposition of ${ }^{99}$ Tc onto a metal disk (normally a stainless steel disk) can be carried out in various media, including oxalic acid, sulfuric acid, and $\mathrm{NaOH}$ solution $[45,61]$. It has been reported that a 
yield of $98 \%$ for ${ }^{99}$ Tc could be obtained when the electro-deposition was carried out in oxalic acid and sulfuric acid medium on a bronze disc under the current of $200 \mathrm{~mA}$ for $8 \mathrm{~h}$. A shorter electro-deposition time of only 4 h has also been used for ${ }^{99}$ Tc on stainless steel disks in 1-2 mol L $\mathrm{L}^{-1} \mathrm{NaOH}$ solution, which produced a yield of 95-100 \% under a direct current of 300 $\mathrm{mA}$. The disk with electrodeposited ${ }^{99}$ Tc needs to be quickly rinsed with water at $\mathrm{pH} 9$ to remove any salt on the disk surface, and then dried at 80-90 ${ }^{\circ} \mathrm{C}$ before measurement [61].

In the case of mass spectrometric measurement, the final source of ${ }^{99} \mathrm{Tc}$ has to be prepared in a form that depends on the mass spectrometric technique to be employed. For instance for measurement using RIMS, the separated ${ }^{99}$ Tc is electroplated or evaporated onto Re filaments [112]. The source for AMS is normally prepared as oxides, and is pressed in a target holder. In general, a high pure aluminum power with a known concentration of Re solution or niobium is added to the eluate of ${ }^{99} \mathrm{Tc}$ in $\mathrm{HNO}_{3}$ solution. The mixture is then evaporated to dryness, and the residue is baked at $400-450{ }^{0} \mathrm{C}$ under nitrogen gas flow for $1 \mathrm{~h}$ to form Tc and carrier metal oxides $[15,16]$. If samples are measured by ICP-MS, especially when a sample introduction system of solution is applied, the final solution is normally prepared in diluted $\mathrm{HNO}_{3}$ medium, e.g. 0.3-0.6 mol L-1 $\mathrm{HNO}_{3}$, and low salt content is normally needed to obtain a high measurement efficiency [98]. When an electrothermal vaporization (ETV) system is applied for introducing sample to the system for ICP-MS measurement, the final sample in a very small volume of solution, normally a few tens of microlitres, is transferred to an electrically conductive cell for analysis. It has been reported that the addition of $\mathrm{NaClO}_{3}$ and $\mathrm{NH}_{3} \cdot \mathrm{H}_{2} \mathrm{O}$ to the solution as chemical modifier can improve the signal intensity of ${ }^{99} \mathrm{Tc}$ in the ICP-MS measurement $[19,113]$. In this case, the ${ }^{99} \mathrm{Tc}$ in $8-10 \mathrm{~mol} \mathrm{~L}^{-1} \mathrm{HNO}_{3}$ eluate from 
extraction chromatography or anion exchange chromatography is evaporated to near dryness. After re-dissolving in 0.1 mol L-1 $\mathrm{HNO}_{3}$, a small amount of $\mathrm{NaClO}_{3}$ or $\mathrm{NH}_{3} \cdot \mathrm{H}_{2} \mathrm{O}$ is added to prepare a final solution for ETV-ICP-MS measurement.

\subsection{Measurement techniques for technetium-99}

Both radiometric and mass spectrometric techniques have been used for measurement of ${ }^{99} \mathrm{Tc}$, these techniques include $\beta$ counting using GM gas flow counter and LSC, neutron activation analysis, ICP-MS, TIMS, RIMS and AMS. Of these, the GM gas flow counter and ICP-MS are the most commonly used techniques.

\subsubsection{Radiometric methods}

As a pure $\beta^{-}$emitter, ${ }^{99} \mathrm{Tc}$ can be detected by $\beta$ counting using gas ionization detector or LSC. Compared to the MS techniques, these methods have lower cost, relatively higher reliability and easier operation. However, counting time is much longer than with MS techniques, and the detection limit of LSC is normally higher compared with mass spectrometric methods, due to high background level. In addition, the neutron activation analysis (NAA) has also been used for the detection of ${ }^{99}$ Tc. These techniques are discussed and compared below.

\subsubsection{1. $\beta$-Counting}

LSC has been accepted as the generally preferred method for counting soft $\beta$ emitters such as

${ }^{99} \mathrm{Tc}$ (a pure $\beta^{-}$emitter with a maximum energy of $0.294 \mathrm{MeV}$ ) $[8,96]$. This technique is based on radiation-induced light formation and transformation of the light into electric pulses. It has 
the following characteristics: negligible self-absorption, no absorption of radiation by air or in detector window, no radiation scattering prior to incidence upon the detector and $4 \pi$ counting [22]. The counting efficiency of this method for ${ }^{99}$ Tc measurement, depending on quench level and the width of the energy windows selected, ranges from $75 \%$ to $98 \%$. Compared with other radiometric methods, simple source preparation and short counting time are main advantages of LSC. However, the higher detection limit of the technique constitutes a restriction for its application, especially for low level ${ }^{99}$ Tc determination. This is attributed to the relatively high background/blank counts of this technique, even for low level background instruments, such as Quantalus. A detection limit of $17 \mathrm{mBq}$ (equal to $2.7 \times 10^{-11} \mathrm{~g}$ ${ }^{99} \mathrm{Tc}$ ) has been reported with a counting time of $2 \mathrm{~h}$ and counting efficiency of $90 \%$ [8]. In addition to the high detection limit, quench is another drawback during LSC determination. Color or chemical quench from the undesired chemicals in the final sample solution should be taken into account [68]. Ideally all potential quenching reagents need to be removed from the samples before measurement. Among various quenches, acid and alkali solutions, as well as various salts in the final sample solution are the common quench reagents. However, the sample volume should also be reduced as much as possible to be able to reduce quench and thus improve counting efficiency.

Gas ionization detector, especially gas flow GM counter, is a traditional instrument, which has been widely applied for $\beta$ emitter (such as ${ }^{99} \mathrm{Tc}$ ) detection [5,61]. Gas proportional counters have also been used for measurement of ${ }^{99} \mathrm{Tc}$ in earily days (1980's), but seldom used in present days because of their poor detection limit. The counting efficiency of a GM counter varies from $10 \%$ to $70 \%$ depending on the energy of the emitted $\beta$ particles, 
thickness of the source, and counter properties [22]. For low level ${ }^{99} \mathrm{Tc}$ analysis in environmental samples, a low background GM counter is required. This is mainly achieved by using lead shielding and guard detectors above the sample detectors, and operating in anticoincidence mode with the sample detectors. The detection limit of this technique depends on the count rate of blanks and the counting time. A typical detection limit by gas flow GM detector is of the order of several $\mathrm{mBq}$, which corresponds to about $10^{-12} \mathrm{~g}$ of ${ }^{99} \mathrm{Tc}$ [61]. Although there are several advantages of gas flow GM detectors, like the relatively low detection limit, the long counting time is usually the main drawback for its application compared with MS methods.

Because of the advantage of low cost and easy access in most of radiochemical laboratories, the $\beta$ counting technique has been the most widely used method for measurement of ${ }^{99} \mathrm{Tc}$ in both environmental and waste samples. It normally provides a reliable analytical result because a high separation efficiency of interferences from other radionculides is easily achieved especially when LSC is used for measurement. However, the detection limits of these methods, especially LSC, are high, and consequently, large samples would be required to reach a suitable detection limit for analysis of low level environmental samples. Also, these techniques are time consuming. Normally several hours to days are needed according to the concentration of ${ }^{99} \mathrm{Tc}$. Consequently, $\beta$ counting methods are not suitable for measurement of samples in emergency situations, where analytical results should be obtained within a shorter time frame (less than one day).

\subsubsection{Neutron Activation Analysis (NAA)}


NAA, based on the two reactions ${ }^{99} \mathrm{Tc}(\mathrm{n}, \gamma){ }^{100} \mathrm{Tc}$ and ${ }^{99} \mathrm{Tc}\left(\mathrm{n}, \mathrm{n}^{\prime}\right){ }^{99 \mathrm{~m}} \mathrm{Tc}$, can also be used for measurement of ${ }^{99} \mathrm{Tc}$ [22]. It is theoretically a more sensitive method for ${ }^{99} \mathrm{Tc}$, and detection limits ranging from $10^{-12} \mathrm{~g}$ to $10^{-9} \mathrm{~g}$ have been obtained, depending on the Tc isotope counted [114]. When counting ${ }^{100} \mathrm{Tc}$, separation of ${ }^{99} \mathrm{Tc}$ from the sample matrices and purification of ${ }^{99} \mathrm{Tc}$ is necessary because of the very short half-life of ${ }^{100} \mathrm{Tc}$ ( $\beta$ emitter, half-life of $\left.15.8 \mathrm{~s}\right)$. A fast sample transfer system has to be used. Foti et al. [84] developed a fast radiochemical separation procedure based on the precipitation of $\mathrm{Fe}(\mathrm{OH})_{3}$ to remove metals, coprecipitation of Tc with tetraphenylarsonium perrhenate, and evaporation of tetraphenylarsonium perrhenate by heating. The whole separation procedure can be completed in 40-45 s. Due to the low $\gamma$ ray emission probability of ${ }^{100} \mathrm{Tc}$ (7 \% for $539.5 \mathrm{keV}$, $5.7 \%$ for $590.8 \mathrm{keV} \gamma$ ray), low background $\beta$ counters have been used to detect ${ }^{100} \mathrm{Tc}$ (a $\beta$ emitter with maximum energy of $3.02 \mathrm{MeV}$ ), to improve the counting efficiency. In this case, post-irradiation separation has to be completed to get a high purity ${ }^{100}$ Tc source and a lower detection limit of $5 \times 10^{-11} \mathrm{~g}$ has been obtained by this method.

Compared with ${ }^{100} \mathrm{Tc},{ }^{99 \mathrm{~m}} \mathrm{Tc}$ has a relatively long half-life, which makes the post-irradiation separation easier. However, the low neutron activation cross section $\left(0.24\right.$ b) of the ${ }^{99} \mathrm{Tc}\left(\mathrm{n}, \mathrm{n}{ }^{`}\right)$ ${ }^{99 \mathrm{~m}}$ Tc reaction limits its analytical sensitivity [115]. The reported detection limit of this method is more than $10^{-9} \mathrm{~g}$, which is even higher than that of LSC and is insufficient for the measurement of ${ }^{99} \mathrm{Tc}$ in environmental samples [116]. So far, NAA has mainly been used for analysis of samples with high ${ }^{99}$ Tc concentration, such as radioactive waste. The application of this method for determination of ${ }^{99} \mathrm{Tc}$ in environmental samples is still limited because of the relatively short half-life of ${ }^{100} \mathrm{Tc}$, and requirement of a nuclear reactor. 


\subsubsection{Mass spectrometric methods}

With the advantages of high sensitivity and short analysis time, MS has been applied in many areas and studied extensively, in recent years for measurement of ${ }^{99} \mathrm{Tc}$, especially in low level environmental samples [14-21,112,117-119]. The first trace-level analysis of ${ }^{99}$ Tc using MS was reported by Anderson et al. [87]. Since then, extensive measurement of ${ }^{99} \mathrm{Tc}$ has been carried out using this technique. So far, several MS techniques, including AMS [14-16], RIMS [112,117], TIMS [17,118,119], and the popular ICP-MS [18-21], have been introduced to determine the concentration of ${ }^{99} \mathrm{Tc}$.

\subsubsection{Inductively Coupled Plasma-Mass Spectrometry (ICP-MS)}

ICP-MS is a relatively powerful technique which has been extensively utilized to determine ${ }^{99}$ Tc in environmental samples [18-21,75,88,120-122]. Compared with $\beta$-counting, ICP-MS possesses evident advantages including short analytical time (usually several minutes per sample) and relatively high sensitivity. The first measurement of ${ }^{99}$ Tc using ICP-MS in environmental samples was reported in 1989 by Kim et al. [18]. In their work, sample solution was introduced to ICP-MS by a common concentric nebulizer. A detection limit of $10^{-12} \mathrm{~g}$ (about $1 \mathrm{mBq}$ ) was reported, which is lower than that achievable with LSC and comparable to that of GM counters. Since then, application of ICP-MS for measurement of

${ }^{99}$ Tc has rapidly increased, while this analytical technique has been optimized and improved. By applying a Meinhard Type C nebulizer for sample introduction into a Scotts water-cooled spray chamber, Beal et al. [25] improved the detection limit to the $\mathrm{pg} \mathrm{mL}^{-1}$ level. Due to the 
very low introduction efficiency of the conventional concentric/cross flow nebulizer $(<1 \%)$, many efforts have been made to improve the analytical sensitivity of ICP-MS, employing high efficiency nebulizers, such as ultrasonic nebulizers (USN), microconcentric nebulizers (MCN), direct injection high efficiency nebulizers (DIHEN), and electrothermal vaporation devices (ETV). It has been reported that the detection limit of quadrupole ICP-MS for ${ }^{99} \mathrm{Tc}$ has been improved more than 10 times to $3 \times 10^{-14} \mathrm{~g} \mathrm{~mL}^{-1}$,using an ultrasonic nebulizer instead of the conventional concentric nebulizer [42].

Using an ETV system for sample introduction, Hepiegne et al. [123] reported a detection limit of $2 \times 10^{-13} \mathrm{~g} \mathrm{~mL}^{-1}$ for ${ }^{99}$ Tc measured by quadrupole ICP-MS. This is attributed to the high introduction efficiency of ETV (70-100 \%) comparing with concentric nebulizers. To improve the removal of $\mathrm{Ru}$, Song et al. [19] described a method where $\mathrm{NaClO}_{3}(0.7 \%)$ and $\mathrm{HNO}_{3}(1 \%)$ was added as modifiers to the samples. Selecting a suitable evaporation temperature, the $\mathrm{Ru}$ signal can then be significantly suppressed, thus providing an extra decontamination of Ru in the ICP-MS measurement. At the same time, the detection limit and analytical reliability of the ${ }^{99}$ Tc measurements are also significantly improved. Recently, Skipperud et al. [113] reported a similar method: by employing $\mathrm{NH}_{3} \cdot \mathrm{H}_{2} \mathrm{O}$ as the modifier, they observed a similar suppression of the $\mathrm{Ru}$ signal as that obtained using $\mathrm{NaClO}_{3}$ and $\mathrm{HNO}_{3}$, but a more stable ${ }^{99} \mathrm{Tc}$ signal during measurement. A detection limit of $5 \times 10^{-13} \mathrm{~g} \mathrm{~mL}^{-1}$ of ${ }^{99}$ Tc has been recorded using this method with quadrupole ICP-MS. However, it should be mentioned that as ETV-ICP-MS requires small sample volume (a few microliter), the final ${ }^{99}$ Tc solution eluted from the chromatographic column has to be concentrated to a few microlitres by evaporation, which increases the time required for sample preparation. 
Compared with quradrupole type ICP-MS, high resolution ICP-MS (HR-ICP-MS) is more sensitive and enables removal of some polymolecular ion interference [124]. A detection limit of $10^{-13} \mathrm{~g}{ }^{99} \mathrm{Tc}$ has been obtained using HR-ICP-MS, which is about 10 times lower than that obtained by $\beta$ counting and quadruple type ICP-MS with the same concentric sample introduction system, and comparable with that of quadruple ICP-MS with ETV sample introduction [20,102]. Although HR-ICP-MS has high sensitivity for ${ }^{99} \mathrm{Tc}$, a limiting factor is the high cost of the instrument.

To normalize any drift and instability of the instrument response, an internal standard needs to be added to the sample before measurement. In general, the internal standard should have a similar ionization potential and a mass in the same region as the analyte [97]. ${ }^{103} \mathrm{Rh}$ fulfils most of these demands but it is difficult to stabilize in weak $\mathrm{HNO}_{3}$ solutions for prolonged periods. McCartney et al. [11] tested different nuclides as internal standard and reported that the behaviour of ${ }^{115} \mathrm{In}$ is most similar to that of ${ }^{99} \mathrm{Tc}$, and the potential risk of disturbing the mass 115 by ${ }^{99} \mathrm{Tc}^{16} \mathrm{O}$ is insignificant. The memory effects of In are easily eliminated compared with Rh. In practice, ${ }^{115}$ In is most frequently used as an internal standard not only for ${ }^{99}$ Tc measurement, but also for many other isotopes. It should be mentioned that when using long-lived Tc isotopes ( ${ }^{97} \mathrm{Tc}$ and ${ }^{98} \mathrm{Tc}$, as well as stable ${ }^{185} \mathrm{Re}$ and $\left.{ }^{187} \mathrm{Re}\right)$, as yield tracer, no extra internal standard is needed, because these yield tracers can also act as internal standard for the normalization of the instrument for ${ }^{99}$ Tc measurement.

ICP-MS is a rapid, sensitive and suitable method for determination of low level ${ }^{99}$ Tc. The major challenge of this analytical technique is the isobaric and spectrometric interferences, which will not only raise the detection limit of the method, but also reduce the reliability of 
the analytical results. Also, high concentrations of matrices elements may lead to signal suppression [75], and consequently, reduced sensitivity. The concentration of total dissolved solid in the sample solution generally needs to be kept below $0.1 \%$. Effective separation and purification, especially for Ru and Mo, is particularly critical for accurate determination of

${ }^{99}$ Tc in low level samples. Several separation procedures are often combined, especially for samples with high concentration of $\mathrm{Mo}$ and $\mathrm{Ru}$, which in some case increase the analytical time. Clean laboratory conditions, including glassware, as well as high quality chemicals are also required to avoid contamination of $\mathrm{Ru}$, $\mathrm{Mo}$ and other interferences during the sample preparation.

\subsubsection{Accelerator Mass Spectrometry (AMS)}

AMS is the most sensitive method for determination of low level radionuclides in environmental samples, and has been applied for measurement of ${ }^{99} \mathrm{Tc}$. The major advantage of this method is its high sensitivity. Consequently, small amounts of sample are required [125]. The challenge in connection with AMS measurement of ${ }^{99} \mathrm{Tc}$ is related to the isobaric interference of ${ }^{99} \mathrm{Ru}[126]$.

In AMS measurement, negative ions of Tc or its compound are generated in a Cs sputter source, and pass through a magnetic sector where they are accelerated through a potential of several MV to a positive terminal. At the terminal, a passage through a thin foil or low pressure gas generates positive ions of high charge, which then accelerate back to ground potential where they pass through further electrostatic and magnetic selection, and are finally measured by ion detector (normally ionization chamber). AMS is a relative analytical 
method, i.e. it gives a ratio of two isotopes, normally the target isotope and another isotope of the same element (e.g., ${ }^{129} \mathrm{I} /{ }^{127} \mathrm{I}$ for ${ }^{129} \mathrm{I}$ measurement and ${ }^{239} \mathrm{Pu} /{ }^{242} \mathrm{Pu}$ for ${ }^{239} \mathrm{Pu}$ measurement;. Here ${ }^{127} \mathrm{I}$ is the stable isotope of iodine and ${ }^{242} \mathrm{Pu}$ is another radioactive isotope of plutonium). Because there is no stable isotope of Tc in nature, long-lived isotopes of Tc, e.g. ${ }^{97} \mathrm{Tc}$ and ${ }^{98} \mathrm{Tc}$, are used for this purpose. However, Mo typically exists as impurity and/or contamination in the Cs ion source in the AMS. ${ }^{97} \mathrm{Mo}$ and ${ }^{98} \mathrm{Mo}$ are stable isotopes with similar mass as ${ }^{97} \mathrm{Tc}$ and ${ }^{98} \mathrm{Tc}$ and can give a very high background, which prohibits the application of ${ }^{97} \mathrm{Tc}$ and ${ }^{98}$ Tc in AMS measurement of ${ }^{99} \mathrm{Tc}$. Therefore an isotope of an other element has to be used for the AMS measurement. ${ }^{185} \mathrm{Re},{ }^{187} \mathrm{Re}$ and ${ }^{93} \mathrm{Nb}$ are the most widely used isotopes for normalization of ${ }^{99} \mathrm{Tc}$ signal in AMS measurement. In this case, ${ }^{185} \mathrm{Re},{ }^{187} \mathrm{Re}$ or ${ }^{93} \mathrm{Nb}$ is measured by Faraday cup, while ${ }^{99}$ Tc is measured by ionization chamber, and a ratio of ${ }^{99} \mathrm{Tc} /{ }^{185} \mathrm{Re},{ }^{99} \mathrm{Tc} /{ }^{187} \mathrm{Re}$ or ${ }^{99} \mathrm{Tc} /{ }^{93} \mathrm{Nb}$ is presented. Based on the amount of carrier (Re or Nb) added to the separated Tc solution during source preparation, the ${ }^{99}$ Tc content in the final separated sample can be calculated, and taking into account the chemical yield measured by tracer, the ${ }^{99}$ Tc concentration in the sample can be calculated.

The very small difference in the atomic mass of ${ }^{99} \mathrm{Ru}$ and ${ }^{99} \mathrm{Tc}(\Delta \mathrm{m}=0.0003154 \mathrm{u})$ makes the isolation of ${ }^{99} \mathrm{Ru}$ from ${ }^{99} \mathrm{Tc}$ in AMS difficult, and therefore ${ }^{99} \mathrm{Ru}$ is the major interference in the AMS measurement of ${ }^{99} \mathrm{Tc}$. Removal of ${ }^{99} \mathrm{Ru}$ from ${ }^{99} \mathrm{Tc}$ by chemical separation is needed before the AMS measurement of ${ }^{99}$ Tc. Extraction chromatography using TEVA resin for measurement of ${ }^{99}$ Tc by ICP-MS can also be used for determination of ${ }^{99}$ Tc using AMS. Discrimination between ${ }^{99} \mathrm{Tc}$ and ${ }^{99} \mathrm{Ru}$ using physical methods in AMS has been investigated intensively. A small difference in the energy loss of ${ }^{99} \mathrm{Tc}$ and ${ }^{99} \mathrm{Ru}$ ions in the gas ionization 
chamber has been used to discriminate ${ }^{99} \mathrm{Ru}$ from ${ }^{99} \mathrm{Tc}$, using multiple anodes for measurement of the energy loss of the ions as they slow down in the gas ionization chamber. This is only effective when the ion energy is at least $120 \mathrm{MeV}$ [16]. Hence a large accelerator operating at more than $10 \mathrm{MV}$ is required for this purpose. It has been reported that up to $90 \%$ of the ${ }^{99} \mathrm{Ru}$ can be discriminated from ${ }^{99} \mathrm{Tc}$ when an 8 segmented anode is used for measurement of energy loss in the ionization chamber, and Tc ions are accelerated to 220 $\mathrm{MeV} \mathrm{Tc}{ }^{14+}$ using a $14.5 \mathrm{MV}$ accelerator [14]. Fifield et al. [15] reported another method to eliminate the interference of ${ }^{99} \mathrm{Ru}$ by quantifying and subtracting the contribution of ${ }^{99} \mathrm{Ru}$ from ${ }^{99} \mathrm{Tc}$ by accounting for ${ }^{101} \mathrm{Ru}$ and using the natural ratio of ${ }^{99} \mathrm{Ru} /{ }^{101} \mathrm{Ru}$. The detection limit of AMS for analysis of ${ }^{99} \mathrm{Tc}$ could reach up to $10^{-15} \mathrm{~g}$ using this method. However, a large uncertainty results if the energy loss information from the detector is used to reject the bulk of the ${ }^{99} \mathrm{Ru}$.

Negative ions of both ${ }^{99} \mathrm{Tc}^{-}$and ${ }^{99} \mathrm{TcO}^{-}$can be formed in the ion source with similar prolificacy [14,15], but the yield of $\mathrm{Ru}^{-}$is much higher than that of the $\mathrm{RuO}^{-}$ion (the $\mathrm{Ru}^{-}$ $/ \mathrm{RuO}^{-}$yield relationship is about 6). The ${ }^{99} \mathrm{Ru}$ signal can be suppressed to some extent using oxide ions [15], and therefore the negative oxide ion ${ }^{99} \mathrm{TcO}^{-}$is often applied as the analyte for ${ }^{99}$ Tc measurement by AMS. It has been reported that the yield of $\mathrm{TcC}^{-}$is much higher than that of $\mathrm{TcO}^{-}$(with a ratio of $\mathrm{TcC}^{-} / \mathrm{TcO}^{-}$of 25 ), whereas similar yields of $\mathrm{RuC}^{-}$and $\mathrm{RuO}^{-}$have been measured (with a ratio of $\mathrm{RuC}^{-} / \mathrm{RuO}^{-}$of only 1.3 ). This provides a potential for better suppression of Ru in AMS measurement of ${ }^{99} \mathrm{Tc}$ [127]. In this case, the source of Tc should be prepared by mixing Tc oxide with graphite. A new investigation has shown a preferable formation of $\mathrm{TcF}_{4}{ }^{-}$compared with $\mathrm{RuF}_{4}{ }^{-}$. Therefore orders of magnitude suppression of the 
Ru signal is expected when using this method without employing a high energy accelerator [128].

Although AMS can provide a better detection limit for ${ }^{99}$ Tc measurement, the high cost and lesser availability of AMS limits the use of this technique as a routine measurement method for ${ }^{99}$ Tc. With the increased numbers of AMS facilities installed in the recent years, the application of this technique for ${ }^{99} \mathrm{Tc}$ measurement will become more popular and much lower level of ${ }^{99}$ Tc can be detected with small sample size.

\subsubsection{Other mass spectrometric methods}

In addition to ICP-MS and AMS, some other MS methods have also been used to measure ${ }^{99}$ Tc in environmental samples. Thermal ionization mass spectrometry (TIMS) and resonance ionization mass spectrometry (RIMS) are two of the more important of these $[17,112,117$ 119]. TIMS with multiple ion collectors is generally the method of choice for isotope ratio measurements with high precision (down to $0.002 \%$ ). ${ }^{99}$ Tc levels from $10^{-9} \mathrm{~g}$ down to less than $10^{-15} \mathrm{~g}\left(6 \times 10^{6}\right.$ atoms) have been successfully measured with ionization efficiencies of more than $2 \%$ using negative thermal ionization [118]. However, the interferences from iodine $\left(\mathrm{I}^{-}\right)$and the complex molecule molybdenum fluoride trioxide $\left(\mathrm{MoFO}_{3}{ }^{-}\right)$are the main problems in analysis of environmental samples using TIMS. The $\mathrm{I}^{-}$ion might form an ion cloud which greatly reduces $\mathrm{TcO}_{4}{ }^{-}$ion production and transmission, causing a count rate drop to nearly zero. The $\mathrm{MoFO}_{3}{ }^{-}$ions, mainly formed on the hot thermal surface, can cause two analytical problems: (i) isobaric interference that requires large corrections to the data, and (ii) reduction of ionization efficiency of $\mathrm{TcO}_{4}{ }^{-}$. It has been reported that a longer filament heating 
time at $930{ }^{0} \mathrm{C}$ can efficiently remove $\mathrm{I}^{-}$, while $\mathrm{TcO}_{4}^{-}$still remains on the filament. To eliminate $\mathrm{MoFO}_{3}{ }^{-}$interference, Dixon et al. [17] described a method in which small amounts of $\mathrm{Ca}\left(\mathrm{NO}_{3}\right)_{2}$ (usually $1 \mu \mathrm{L}$ of $0.0165 \mathrm{~mol} \mathrm{~L}^{-1}$ ) were added to the sample, which was dried at $80{ }^{0} \mathrm{C}$ prior to loading onto the filament. It was explained that $\mathrm{Ca}^{2+}$ may interact with $\mathrm{MoFO}_{3}{ }^{-}$ and suppress its volatility. A detection limit of $10^{-14} \mathrm{~g}$ has been obtained using this technique for environmental samples. Although the sensitivity of TIMS for ${ }^{99} \mathrm{Tc}$ is better than that of ICP-MS, the size of the sample loaded to the filament for measurement is normally very small (a few microlitres), and the sample preparation is very time consuming and labour intensive. Also, the high cost and poor accessibility of the instrument are reasons why TIMS is not often used for measurement of ${ }^{99} \mathrm{Tc}$ in environmental samples.

RIMS has also been applied for ${ }^{99}$ Tc measurement in environmental samples. In connection with resonance ionization analyses, two critical aspects need to be considered: selectivity and sensitivity. In terms of selectivity, Mo and Ru are the main interferences which might cause poor analytical results. It has been reported that three-photon ionization of ${ }^{99}$ Tc shows a good RIMS scheme for analysis of samples containing Mo [117]. The mass spectral interference of Ru can be reduced using the multiplicative selectivity of multiple resonance as well as proper selection of ionization schemes [129]. The major impediment to realize the ultimate sensitivity of RIMS lies in the amount of the Tc in the samples which is evaporated as atoms. Initial RIMS studies of ${ }^{99}$ Tc were carried out using a tuneable ultraviolet pulse laser via a resonant two-photon ionization scheme [130], but the sensitivity for ${ }^{99}$ Tc is relatively low. Downey et al. [117] reported on a technique using a three-photon, two-color resonance ionization scheme for mass spectrometric analysis of ${ }^{99} \mathrm{Tc}$. Samples containing more than $10^{8}$ 
atoms of ${ }^{99} \mathrm{Tc}$ ( $>10^{-14} \mathrm{~g}$ Tc) could be detected by RIMS if $100 \%$ of the sample evaporates as atoms. However, because of the loss of ${ }^{99}$ Tc during the sample preparation, like failure to evaporate ${ }^{99}$ Tc or evaporation in a non-analyzable (molecular) form, the ionization efficiency of ${ }^{99} \mathrm{Tc}$ is always low and high detection limit is seen. In order to improve the ionization efficiency as well as the sensitivity of RIMS, Trautmann [112] proposed a method using three-colour, three-step resonant excitation via an auto-ionizing state with a high-repetitive pulsed laser system for ${ }^{99}$ Tc detection. Instead of the filament technique, a laser ion source has been used in the RIMS schemes. The laser ion source consists of many cavities with a small hole to inject the laser beams and to extract the photoions; the atoms of Tc are confined inside the cavity and can interact several times with the laser light. An overall efficiency of $4 \times 10^{-4}$ and a detection limit of $10^{6}$ atoms of ${ }^{99} \mathrm{Tc}\left(10^{-16} \mathrm{~g}{ }^{99} \mathrm{Tc}\right)$ have been obtained, which is about two orders of magnitude better than that obtained with the filament technique. Compared with other methods, RIMS has some advantages, such as good overall efficiency, strong suppression of atomic or molecular isobaric interference, high isotopic selectivity and low background. However, there are still no commercial RIMS instruments available, which makes the technique rather rare in application compared with the other MS techniques such as ICP-MS.

\subsubsection{Comparison of different measurement techniques}

Table 7 summarizes the major detection techniques for ${ }^{99}$ Tc by comparing their detection limits and analytical cost. $\beta$ counting is the traditional detection technique, which has been extensively applied for measurement of ${ }^{99} \mathrm{Tc}$ in environmental samples as well as in various 
waste samples. It is still a powerful and often used technique for routine analysis of environmental samples for ${ }^{99} \mathrm{Tc}$ because of the simplicity of measurement, reliability and reasonable sensitivity. However, long counting time and interference from other radionuclides are the major disadvantages. A relatively quick measurement can be achieved by LSC after a thorough separation of ${ }^{99} \mathrm{Tc}$ from other radionuclides, while the relatively high detection limit is its major demerit. NAA as a radiometric technique can also be used for measurement of ${ }^{99} \mathrm{Tc}$ with a reasonable detection limit if the ${ }^{99} \mathrm{Tc}(\mathrm{n}, \gamma){ }^{100} \mathrm{Tc}$ reaction is employed and ${ }^{100} \mathrm{Tc}$ is counted. However, a fast separation of the short-lived ${ }^{100}$ Tc formed by neutron activation of ${ }^{99}$ Tc is needed; in addition a nuclear reactor is also required for this work. This technique is therefore seldom used for determination of ${ }^{99} \mathrm{Tc}$ in environmental samples. ICP-MS has become a commonly used technique for measurement of ${ }^{99} \mathrm{Tc}$ in environmental samples. This is attributed to its rapid analytical capacity, relatively high sensitivity, low cost and high accessibility. The major challenge in ICP-MS measurement for ${ }^{99} \mathrm{Tc}$ is the isobaric interferences at mass 99 contributed from stable isotopes (mainly ${ }^{99} \mathrm{Ru}$ and ${ }^{98} \mathrm{Mo}^{1} \mathrm{H}$ ). To obtain a reliable analytical result and sufficiently low detection limit, it is necessary to carry out a thorough decontamination of $\mathrm{Ru}$ and $\mathrm{Mo}$, as well as other matrices elements before measurement. Also high quality laboratory conditions, including glassware, air and chemicals are key parameters to ensure sufficiently low reagent blank at mass 99. TIMS and AMS can provide higher sensitivity and even better detection limit, but the analysis is costly and the instruments are not easy to assess. Therefore these methods are not often used for determination of ${ }^{99} \mathrm{Tc}$ in environmental samples. For TIMS, a special separation procedure is needed to obtain a small sample solution and good precision of isotopic measurements. It is 
always time consuming and labour intensive. AMS operation is more complex and a well experienced team is required, although a very low detection limit can be obtained. Yet, this detection technique is becoming increasingly popular because of instrumental developments. The application of RIMS is still limited because there are no commercial RIMS instruments available at present.

In summary, although a lot of techniques can be used for measurement of ${ }^{99} \mathrm{Tc}$, the most frequently used are $\beta$ counting using GM counter and ICP-MS. The detection limits of these two techniques are similar if quadruple ICP-MS and low background GM counters are used.

\section{Automated analytical methods for technetium-99 determination}

Due to the low concentration of ${ }^{99} \mathrm{Tc}$ in environmental samples, a thorough chemical separation of matrix components and interferences is required before measurement of ${ }^{99} \mathrm{Tc}$. As described above, this chemical separation is often time consuming and labour intensive, which increases the analytical cost and limits the analytical capacity. The development of automated analytical methods is an approach to overcome these drawbacks. Automation of the analytical procedure can also reduce the risk of exposure of operators to the hazardous chemicals and thus enhance the safety. With the increased requirement for rapid radiochemical analysis for emergency situations, such as nuclear accidents and radiological attacks, automated and rapid analytical methods become more and more important.

Although some automated analysis procedures have been reported for determination of radionuclides like $\mathrm{Pu}$ in environmental samples [131], the application of these approaches for

${ }^{99}$ Tc determination is still limited and only applied in few laboratories [91,132]. In early 
studies, the automation of the analysis of ${ }^{99} \mathrm{Tc}$ is mainly focused on the separation step using anion exchange or extraction chromatography techniques. Hollenbach et al. [133] reported a method using a flow injection system for on-line separation of ${ }^{99} \mathrm{Tc}$ in small soil samples. After pretreatment, the sample solution was pumped through a mini-column packed with TEVA (50 $\mu \mathrm{L}$ resin), $\mathrm{TcO}_{4}{ }^{-}$was absorbed on the column and separated from the matrix components and interferences. ${ }^{99} \mathrm{Tc}$ on the column was then eluated and measured by ICP-MS through injection of eluate directly into the instrument. For a $0.25 \mathrm{~g}$ soil sample, a detection limit of $11 \mathrm{mBq} \mathrm{g}{ }^{-1}\left(1.72 \times 10^{-11} \mathrm{~g} \mathrm{~g}^{-1}\right)$ has been reported. Compared with the conventional manual procedure, separation using flow injection system is faster and less labour intensive; however, because a small column is applied for ${ }^{99}$ Tc purification, the decontamination of Mo and Ru is poor, especially for large samples, if no other separation method is included, which causes a deteriorated detection limit for ${ }^{99}$ Tc. Egorov et al. [132] introduced an approach using a FIALab 3000 sequential injection system with stopped flow radiometric detection for automated determination of ${ }^{99}$ Tc in nuclear waste. Fig. 7 shows the schematic diagram of this system. The on-line separation is carried out using a TEVA column $(20-50 \mu \mathrm{m}, 0.83 \mathrm{~mL})$. The eluate of ${ }^{99}$ Tc from the column is directly measured using a flow radiometric detector. All operation in a closed system is carried out in a fully automated model by computer control, and one analysis can be completed in 20-40 minutes, excluding the sample pre-treatment. Nuclear waste samples (e.g. $1 \mathrm{~mL}$ ) from storage tanks of a reprocessing plant have been successfully analysed using this method. Compared with the continuous flow injection with peristaltic pump, the sequential injection system is more flexible and attractive. For example, the syringe pump can eliminate the frequent pump tubing replacement and tedious flow rate 
calibrations. However, as mentioned above, the method can only be applied for analysis of small samples, and is not suitable for analysis of environmental samples with low level of ${ }^{99}$ Tc.

Kim et al. [91] have described a different automated separation system for determination of low level ${ }^{99}$ Tc in soil samples using an on-line flow injection system. Two TEVA columns with different sizes $(0.75 \mathrm{~mL}$ and $0.17 \mathrm{~mL})$ were employed to remove the interferences. The whole separation could be finished in 53 minutes for one analysis. Because of the application of two chromatographic columns, the removal of interferences is effective, and decontamination factors of $1.6 \times 10^{4}$ for Mo and $9.9 \times 10^{5}$ for $\mathrm{Ru}$ have been reported, and therefore a relatively low detection limit of $0.05 \mathrm{mBq} \mathrm{mL}^{-1}\left(7.8 \times 10^{-14} \mathrm{~g} \mathrm{~mL}^{-1}\right)$ for ${ }^{99} \mathrm{Tc}$ was obtained by HI-ICP-MS measurement. However, as with most other on-line analytical methods, the samples are processed one after another during the separation process, which might increase the analytical time. In addition, the sample size is still restricted to a few grams in this system, and not suitable for analysis of environmental samples with very low level of ${ }^{99} \mathrm{Tc}$.

For low level environmental samples, the pre-treatment process is usually carried out manually. However, for nuclear waste, especially high level nuclear waste, fully automated analysis is necessary to reduce the risk of the exposure of the operator to the radioactive materials. Egorov et al. [134] have described an analytical approach for determination of ${ }^{99}$ Tc in aged nuclear waste streams. A fluid handling step, including acidification of caustic sample and microwave-assisted sample digestion using peroxidisulfate oxidant were applied for sample pre-treatment. The prepared sample was then directed to an anion exchange 
chromatography using AG MP-1 resin $(0.83 \mathrm{~mL})$ for separation of ${ }^{99}$ Tc. The eluate was directly delivered to a flow-through scintillation detector for measurement. This procedure has been applied successfully for determination of ${ }^{99} \mathrm{Tc}$ in aged nuclear waste samples, but the feasibility for separation and analysis of ${ }^{99}$ Tc from fresh nuclear waste samples with more interfering radionuclides, as well as from other large environmental samples might be not satisfactory. Automated sample pre-treatment is a difficult step in the automation of analytical procedures for ${ }^{99} \mathrm{Tc}$ in different types of samples, and the method is still limited. Therefore an on-line multi-sample analytical system as well as a fully automated analysis procedure will be the two major future challenges for automated analysis of ${ }^{99} \mathrm{Tc}$ in environmental samples.

\section{Conclusions and perspectives}

Important aspects governing the reliability of measurements of ${ }^{99} \mathrm{Tc}$ in environmental samples comprise chemical separation including pre-concentration of ${ }^{99} \mathrm{Tc}$ and removal of matrix components and interferences, and measurement of ${ }^{99}$ Tc. The sample pre-treatment is a critical step. The release and transfer of ${ }^{99} \mathrm{Tc}$ from solid sample to solution is normally carried out by ashing or alkali fusion followed by acid leaching. Converting all Tc to $\mathrm{TcO}_{4}{ }^{-}$is a key step to ensure a successful transfer Tc to solution because of the high solubility of $\mathrm{TcO}_{4}{ }^{-}$ compared with other species of Tc. Adjustment of the oxidation state of Tc is also a key step for pre-concentration of Tc from water samples, which is based on the water insolubility of $\mathrm{Tc}(\mathrm{IV})$ and high affinity of $\mathrm{TcO}_{4}{ }^{-}$on anion exchange resin. Another very important issue is the loss of Tc during the ashing and evaporation steps due to the high volatility of $\operatorname{Tc}_{2} \mathrm{O}_{7}$. Ashing of solid samples to remove organic matters should be carried out at a temperature 
lower than $700{ }^{\circ} \mathrm{C}$, and ${ }^{99} \mathrm{Tc}$ solution, especially in $\mathrm{HCl}$ medium, should not be evaporated to complete dryness, to avoid significant loss of Tc in these steps. Co-precipitation and anion exchange chromatography are two efficient techniques for pre-concentrating ${ }^{99}$ Tc from large volumes of water, and from leachates from solid samples, as well as to remove most matrix components from the samples. The formed precipitate, especially carried by $\mathrm{CuS}$ or FeS, should be dissolved over short time after separation to avoid the difficulties in redissolving the reduced Tc in the precipitate. Formation of colloids and organisms during water storage may cause a significantly reduced chemical yield of Tc during anion exchange chromatographic separation; this effect can be partly reduced by shortening the storage time and acidifying and poisoning water after collection. Solvent extraction, anion exchange chromatography and extraction chromatography are effective methods for purification of ${ }^{99} \mathrm{Tc}$ from interferences. Of these, solvent extraction and extraction chromatography using TEVA resin are suitable for decontamination of $\mathrm{Ru}$ and Mo, the two major interferences in mass spectrometric measurement of ${ }^{99}$ Tc. To obtain sufficient chemical separation of ${ }^{99}$ Tc for its determination in low level, a combination of two or more separation techniques are often applied: for example anion exchange or co-precipitation followed by extraction chromatography.

ICP-MS and $\beta$ counting are two commonly used detection methods for ${ }^{99} \mathrm{Tc}$. The radiometric method using low level GM counters is easily accessible and cost-effective, but requires relatively long measurement time. ICP-MS is fast and sensitive, but the isobaric and spectrometric interferences to mass 99 are major challenges for obtaining a reliable result. With the development and increased installation of instruments, ICP-MS is becoming a more 
popular and frequently used technique for ${ }^{99} \mathrm{Tc}$ measurement in low level environmental samples. However, an improvement of chemical separation procedures and experimental conditions is still needed to obtain a better and more stable decontamination of Ru and Mo. The applicability of both $\beta$ counting with GM counter and ICP-MS can be proven by comparison exercises where the same sample is measured using the two techniques. Due to short analytical time, less labour, and on-line analytical characterisation, automated analytical methods by hyphenating chromatographic separation employing flow/sequential injection with rapid measurement using ICP-MS are becoming more attractive, especially with the

requirement of rapid determination of ${ }^{99} \mathrm{Tc}$ in emergency situations and the increased application of ICP-MS and extraction chromatography. Its application is currently limited to a few laboratories. However, with the development of this technique and commercialization of automated separation instruments, it might in a near future become a popular and routine analytical method for determination of ${ }^{99} \mathrm{Tc}$.

\section{Acknowledgements}

K.L. Shi acknowledges the China Scholarship Council for the partial financing of his $\mathrm{PhD}$ study at DTU. The authors thank Dr. Kasper Andersson in Risø DTU for his kindly improvement of the English presentation of this article.

\section{Reference}

[1] C. Perrier, E. Segre, J. Chem. Phys. 5 (1937) 712-716.

[2] Ihsanullah, J. Radioanal. Nucl. Chem. 176 (1993) 303-313. 
[3] T. Sekine, M. Hiraga, T. Fujita, A. Mutalib, K. Yoshihara, J. Nucl. Sci. Technol. 30 (1993) 1131-1135.

[4] N.W. Golchert, J. Sedlet, Anal. Chem. 41 (1969) 669-671.

[5] E. Holm, J. Rioseco, M. Garcia-Leon, Nucl. Instrum. Meth. Phys. Res. 223 (1984) 204-207.

[6] Q.J. Chen, H. Dahlgaard, H.J.M. Hansen, A.Aarkrog, Anal. Chim. Acta 228 (1990) 163-167.

[7] A.D. Banavali, J.M. Raimondi, E.M. Moreno, D.E. McCurdy, Radioact. Radiochem. 6 (1995) 26-35.

[8] F. Wigley, P.E. Warwick, I.W. Croudace, J. Caborn, A.L. Sanchez, Anal. Chim. Acta 380 (1999) 73-82.

[9] M.B. Gomez, A.M. Gutierrez, C. Camara, V. Gomez, Radioact. Radiochem. 12 (2001) 21-34.

[10] S. Uchida, K. Tagami, J. Radioanal. Nucl. Chem. 221 (1997) 35-39.

[11] M. McCartney, K. Rajendran, V. Olive, R.G. Busby, P. McDonald, J. Anal. At. Spectrom. 14 (1999) 1849-1852.

[12] S. Uchida, K. Tagami, W. Ruhm, M. Steiner, E.Wirth, Appl. Radiat. Isot. 53 (2000) 69-73.

[13] T.K. Ikaheimonen, V.P. Vartti, E. Ilus, J. Mattila, J. Radioanal. Nucl. Chem. 252 (2002) 309-313.

[14] L. Wacker, L.K. Fifield, S.G. Tims, Nucl. Instr. Meth. B 223-224 (2004) 185-189.

[15] L.K. Fifield, R.S. Carling, R.G. Cresswell, P.A. Hausladen, M.L. di Tada, J.P. Day, Nucl. Instr. Meth. B 168 (2000) 427-436.

[16] B.A. Bergquist, A.A. Marchetti, R.E. Martinelli, J.E. McAninch, G.J. Nimz, I.D. Proctor, J.R. Southon, J.S. Vogel, Nucl. Instr. Meth. B 172 (2000) 328-332.

[17] P.Dixon, D.B. Curtis, J. Musgrave, F. Roensch, J, Roach, D. Rokop, Anal. Chem. 69 (1997) 1692-1699.

[18] C.K. Kim, M. Otsuji, Y. Takaku, H. Kawamura, K. Shiraishi, Y. Igarashi, S. Igarashi, N. Ikeda, Radioisotopes 38 (1989) 151-152.

[19] M. Song, T.U. Probst, Anal. Chim. Acta 413 (2000) 207-215.

[20] M.J. Keith-Roach, S. Turup, D.H. Oughton, H.H. Dahlgaard, Analyst 127 (2002) 70-75. 
[21] J.L. Mas, M. Garcia-Leon, J.P. Bolivar, Radiochim. Acta 92 (2004) 39-46.

[22] X.L. Hou, P. Roos, Anal. Chim. Acta 608 (2008) 105-139.

[23] R.E. Wildung, K.M. McFadden, T.R. Garland, J. Environ. Qual. 8 (1979) 156-161.

[24] D. Curtis, J. Fabryka-Martin, P. Dixon, J. Cramer, Geochim. Cosmochim. Acta 63 (1999) 275-285.

[25] D.M. Beals, J. Radioanal. Nucl. Chem. 204 (1996) 253-263.

[26] M. Garcia-Leon, J. Nucl. Radiochem. Sci. 6 (2005) 253-259.

[27] A. Aarkrog, H. Dahlgaard, L. Hallstadius, E. Holm, S. Mattsson, J. Rioseco, Timer trend of ${ }^{99}$ Tc in seaweed from Greenland waters, in: G. Desmet, C. Myttenaere (Eds.), Technetium in the Environment, Elsevier, London, 1986, pp. 69-78.

[28] Q.H. Hu, J.Q. Weng, J.S. Wang, J. Environ. Radioact. 101 (2010) 426-437.

[29] M. Dowdall, S. Gerland, M. Karcher, J.P. Gwynn, A.L. Rudjord, A.K. Kolstad, J. Environ. Radioact. 84 (2005) 111-130.

[30] F. Luykx, Technetium discharges into the Environment, in: G. Desmet, C. Myttenaere (Eds.), Technetium in the Environment, Elsevier, London, 1986, pp. 21-27.

[31] IAEA, Increase in nuclear power capacity and generation 1971-

2006, http://www.iaea.org/Publications/Magazines/Bulletin/Bull492/art10-fig2.pdf

[32] CEFAS, Radioactivity in food and the environment, 2009, RIFE-15, 2010, http://www.cefas.co.uk/publications/rife/rife15.pdf

[33] E. Holm, Radiochim. Acta 63 (1993) 57-62.

[34] A. Aarkrog, L. Carlson, Q.L. Chen, H. Dahlgaard, E. Holm, L. Huynh-Ngoc, L.H. Jensen, S.P. Nielesn, H. Nies, Nature 335 (1988) 338-340.

[35] E. Holm, J. Rioseco, J. Environm. Radioact. 5 (1987) 343-357. 
[36] K. Tagami, S. Uchida, J. Nucl. Radioanal. Sci. 3 (2002) 1-5.

[37] H. Dahlgaard, Q. Chen, J. Herrmann, H. Nies, R.D. Ibbett, P.J. Kershaw, J. Mar. Syst. 6 (1995) 571-578.

[38] N. Momoshima, M. Sayad, Y. Takashima, Radiochim. Acta 63 (1993) 73-78.

[39] K. Tagami, S. Uchida, Appl. Radiat. Isot. 47 (1996) 1057-1060.

[40] M. Garcia-Leon, J. Radioanal. Nucl. Chem. 138 (1990) 171-179.

[41] G. Manjon, M. Garcia-Leon, S. Ballestra, J. J. Lopez, J. Environ. Radioact. 28 (1995) 171-189.

[42] A.E. Eroglu, C.W. McLeod, K.S. Leonard, D. McCubbin, J. Anal. At. Spectrom. 13 (1998) 875-878.

[43] V. Smith, M. Fegan, D. Pollard, S. Long, E. Hayden, T.P. Ryan, J. Environ. Radioact. 56 (2001) 269-284.

[44] F. Patti, M. Masson, G. Vergnaud, L. Jeanmaire, Activities of technetium measured in the wastewater, seawater and two bioindicates, in: G. Desmet, C. Myttenaere (Eds.), Technetium in the Environment, Elsevier, London, 1986, pp. 37-51.

[45] J.P. Riley, S.A. Siddiqui, Anal. Chim. Acta 139 (1982) 167-176.

[46] J.E. Brown, A.K. Kolstad, A.L. Brungot, B. Lind, A.L. Rudjord, P. Strand, L. Foyn, Mar. Pollut. Bull. 38 (1999) 560-571.

[47] H. Dahlgaard, J. Environ. Radioact. 25 (1994) 37-55.

[48] M. Garcia-Leon, G. Manjon, C.I. Sanchez-Angulo, J. Environ. Radioact. 20 (1993) 49-61.

[49] M. Attrep, J.A. Enochs, L.D. Broz, Environ. Sci. Technol. 5 (1971) 344-345.

[50] J. Kuwabara, M. Yamamoto, S. Oikawa, K. Komura, D.J. Assinder, J. Radioanal. Nucl. Chem. 240 (1999) 593-601.

[51] K. Tagami, S. Uchida, Environmental Pollution 95 (1997) 151-154.

[52] J.E. Till, Source term for technetium from muclear fuel cycle facilities, in: G. Desmet, C. Myttenaere (Eds.), Technetium in the Environment, Elsevier, London, 1986, pp. 1-20. 
[53] K. Schwochau, Technetium: Chemistry and radiopharmaceutical application, WILEY-VCH Verlag Gmbh, D-69469 Weinheim (Federal Republic of Germany), 2000.

[54] K.H. Lieser, KNuclear and Radiochemistry: Fundaments and Applications, 2nd edition, Wiley-VCH, New York, 2001.

[55] T. Sekine, N. Asai, T. Mine, K. Yoshihara, Radiochemistry 39 (1997) 309-311.

[56] R.E. Wildung, Y.A. Gorby, K.M. Krupka, N.J. Hess, S.W. Li, A.E. Plymale, J.P. McKinley, J.K. Fredrickson, Appl. Environ. Microbiol. 66 (2000) 2451-2460.

[57] A. Abdelouas, B. Grambow, M. Fattahi, Y. Andres, E. Leclerc-Cessac, Sci. Total Environ. 336 (2005) 255268.

[58] B.H. Gu, C.M. Ruan, Anal. Chem. 79 (2007) 2341-2345.

[59] J.H. Chiu, T.C. Chu, P.S. Weng, J. Radioanal. Nucl. Chem. 150 (1991) 493-507.

[60] S. Ballestra, G. Barci, E. Holm, J. Lopez, J. Gastaud, J. Radioanal. Nucl. Chem. 115 (1987) 51-58.

[61] Q.J. Chen, H. Dahlgaard, S.P. Nielsen, Anal. Chim. Acta 285 (1994) 177-180.

[62] J.C. Butterworth, F.R. Livens, P.R. Makinson, Sci. Total. Environ. 173-174 (1995) 293-300.

[63] X.L. Hou, M. Jensen, S.P. Nielsen, Appl. Radiat. Isot. 65 (2007) 610-618.

[64] K.S. Leonard, D. McCubbin, M.B. Lovett, Sci. Total Environ. 175 (1995) 9-24.

[65] P. Lindahl, Studies of long-lived radionuclides in the environment, PhD. thesis, The University of Lond, 2003.

[66] J. Hattink, Accumulation of technetium in duckweed, PhD. thesis, The Delft University of Technology, 2000.

[67] K. Tagami, Behaviour of Technetium in Paddy Fields, Ph.D. thesis, Tsukuba University, 1997.

[68] F. Wigley, Mechanisms for accumulation and migration of ${ }^{99}$ Tc in saltmarsh sediments, PhD. thesis, The 
University of Southampton, 2000.

[69] B.R. Harvey, J.K. Williams, M.B. Lovett, R.D. Ibbett, J. Radioanal. Nucl. Chem. 158 (1992) 417-436.

[70] M.J. Wharton, B. Atkins, J.M. Charnock, F.R. Livens, R.A.D. Pattrick, D. Collison, Appl. Geochem. 15 (2000) 347-354.

[71] J.L. Mas, K. Tagami, S. Uchida, Anal. Chim. Acta 509 (2004) 83-88.

[72] R.C. Richter, S.R. Koirtyohann, S.S. Jurisson, J. Anal. At. Spectrom. 12 (1997) 557-562.

[73] K. Tagami, S. Uchida, Anal. Chim. Acta 405 (2000) 227-229.

[74] Q.J. Chen, A. Aarkrog, H. Dahlgaard, S.P. Nielsen, E. Holm, H. Dick, K. Mandrup, J. Radioanal. Nucl. Chem. 131 (1989) 171-187.

[75] S. Nicholson, T.W. Sanders, L.M. Blaine, Sci. Total Environ. 130-131 (1993) 275-284.

[76] K. Tagami, S. Uchida, J. Radioanal. Nucl. Chem. 190 (1995) 31-36.

[77] E. Holm, T. Gafvert, P. Lindahl, P. Roos, Appl. Rad. Isot. 52 (2000) 153-157.

[78] N. Matsuoka, T. Umata, M. Okamura, N. Shiraishi, N. Momoshima, Y. Takashima, J. Radioanal. Nucl. Chem. 140 (1990) 57-73.

[79] N. Momoshima, N. Inoue, Y. Takashima, J. Radioanal. Nucl. Chem. 155 (1991) 335-342.

[80] K. Tagami, S. Uchida, T. Hamilton, W. Robison, Appl. Radiat. Isot. 53 (2000) 75-79.

[81] S. Mortia, C.K. Kim, Y. Takaku, R. Seki, N. Ikeda, Appl. Radiat. Isot. 42 (1991) 531-534.

[82] J.L. Mas, M. Garcia-Leon, J.P. Bolivar, Appl. Radiat. Isot. 64 (2006) 502-507.

[83] B.R. Harvey, K.D. Ibbett, J.K. Williams, M.B. Lovett, Aquat. Environ. Protect. : Anal. Methods 8 (1991) 1-22.

[84] S. Foti, E. Delucchi, V. Akamian, Anal. Chim. Acta 60 (1972) 269-276.

[85] K. Tagami, S. Uchida, Radiochim. Acta 63 (1993) 69-72. 
[86] Q.J. Chen, A. Aarkrog, S.P. Nielsen, H. Dajlgaard, B. Lind, A.K. Kolstad, Y.X., Yu, Procedures for determination of $\mathrm{Pu}, \mathrm{Am}, \mathrm{Np}, \mathrm{U}$, Th, Tc, Pb, Po in environmental materials, Risø-R-1263 2001, Risø Natioonal Laboratory, Denmark.

[87] T.J. Anderson, R.L. Walker, Anal. Chem. 52 (1980) 709-713.

[88] P. Zhao, Q.H. Hu, T.P. Rose, G.J. Nimz, M. Zavarin, J. Radioanal. Nucl. Chem. 276 (2008) 755-761.

[89] J. H. Chao, C. L. Tseng, C. J. Lee, J. Radioanal. Nucl. Chem. 251 (2002) 105-112.

[90] S. Hirano, M. Matsuba, H. Kamada, Radioisotopes 38 (1989) 186-189.

[91] C. K. Kim, C. S. Kim, B. H. Rho, J. I. Lee, J. Radioanal. Nucl. Chem. 252 (2002) 421-427.

[92] R. Seki, M. Kondo, J. Radioanal. Nucl. Chem. 263 (2005) 393-398.

[93] S. Watanabe, K. Hashimoto, J. Radioanal. Nucl. Chem. 201 (1995) 361-370.

[94] K. Tagami, S. Uchida, Radioact. Radiochem. 10 (1999) 30-34.

[95] X.L. Hou, V. Hansen, A. Aldahan, G. Possnert, O.C. Lind, G. Lujaniene, Anal. Chim. Acta 632 (2009) 181196.

[96] A.E. Nevissi, M. Siverson, R.S. Strebin, J.H. Kaye, J. Radioanal. Nucl. Chem. 177 (1994) 91-99.

[97] P. Roos, Analysis of radionuclides using ICP-MS, in: P.P. Povinec (Ed.), Analysis of Environmnetal Radionuclide, Elsevier, 2007, pp. 295-330.

[98] Ihsanullah, B.W. East, Radioact. Radiochem. 5 (1994) 20-26.

[99] Ihsanullah, Sep. Sci. Technol. 29 (1994) 781-797.

[100] R. Schurhammer, G. Wipff, J. Phys. Chem. B 115 (2011) 2338-2348.

[101] G.H. Zhu, H. Jiang, H.L. Gao, W.C. Xie, Q. Hu, J. Nucl. Radiochem. (Chinese) 19 (1997) 28-34.

[102] M. Yamamoto, Syarbaini, K. Kofuji, A. Tsumura, K. Komura, K. Ueno, D.J. Assinder, J. Radioanal. Nucl. Chem. 197 (1995) 185-194. 
[103] K. Tagami, S. Uchida, J. Radioanal. Nucl. Chem. 239 (1999) 643-648.

[104] R.J. Silve, R. Evans, J.H. Rego, R.W. Buddemeier, J. Radioanal. Nucl. Chem. 124 (1988) 397-405.

[105] E.P. Horwitz, M.L. Dietz, R. Chiarizia, H. Diamond, S.L. Maxwell, M.R. Nelson, Anal. Chim. Acta 310 (1995) 63-78.

[106] K. Tagami, S. Uchida, M. Garcia-Leon, J. Radioanal. Nucl. Chem. 234 (1998) 147-151.

[107] S.K. Fiskum, R.G. Riley, C.J. Thompson, J. Radioanal. Nucl. Chem. 245 (2000) 261-272.

[108] S. Uchida, K. Tagami, Anal. Chim. Acta 357 (1997) 1-3.

[109] B. Remenec, Czech. J. Phys. 56 (2006) D645-D651.

[110] P.E. Warwick, I.W. Croudace, A.G. Howard, Anal. Chem. 72 (2000) 3960-3963.

[111] E. Holm, J. Rioseco, S. Ballestra, A. Walton, J. Radioanal. Nucl. Chem. 123 (1988) 167-179.

[112] N. Trautmann, Radiochim. Acta 63 (1993) 37-43.

[113] L. Skipperud, D. H. Oughton, L.S. Rosten, M. J. Wharton, J. P. Day, J. Environ. Radioact. 98 (2007) 251263.

[114] X.L. Hou, Activation analysis for the determination of long-lived radionuclide, in: P.P. Povinec (Ed.), Analysis of Environmnetal Radionuclide, Elsevier, 2007, pp. 371-406.

[115] N. Ikeda, R. Seki, M. Kamemoto, M. Otsuji, J. Radioanal. Nucl. Chem. 131 (1989) 65-71.

[116] W. Goerner, B. Noll, H. Spies, K. Thieme, J. Radioanal. Nucl. Chem. 122 (1988) 291-298.

[117] S.W. Downey, N.S. Nogar, Int. J. Mass Spectrom. Ion Processes 61 (1984) 337-345.

[118] D.J. Rokop, N.C. Schroeder, K. Wolfsberg, Anal. Chem. 62 (1990) 1271-1274.

[119] N.C. Schroeder, D. Morgan, D.J. Rokop, J. Fabrykamartin, Radiochim. Acta 60 (1993) 203-209.

[120] S. Mortia, K. Tobita, M. Kurabayshi, Radiochim. Acta 63 (1993) 63-67.

[121] J.S. Becker, Spectrochim. Acta, Part B-At. Spectrosc. 58 (2003) 1757-1784. 
[122] D.K. Smith, D.L. Finnegan, S.M. Bowen, J. Environ. Radioact. 67 (2003) 35-51.

[123] P. Hepiegne, D. Dall’ava, R. Clement, J.P. Degros, Talanta 42 (1995) 803-809.

[124] C.K. Kim, R. Seki, S. Morita, Y. Yamasaki, A. Tsumura, Y. Takaku, Y. Igarashi, M. Yamamoto, J. Anal. At. Spectrom. 6 (1991) 205-209.

[125] L.K. Fifield, Accelerator mass spectrometry of long-lived heavy redionuclides, in: P.P. Povinec (Ed.), Analysis of Environmnetal Radionuclide, Elsevier, 2007, pp. 263-293.

[126] J.E. McAninch, A.A. Marchetti, B.A. Bergquist, N.J. Stoyer, G.J. Nimz, M.W. Caffee, R.C. Finkel, K.J. Moody, E. SiderasHaddad, B.A. Buchholz, B.K. Esser, I.D. Proctor, J. Radioanal. Nucl. Chem. 234 (1998) 125-129.

[127] M. He, S. Jiang, B. Peng, X.D. Ruan, K.J. Dong, Y.J Guan, S. H. Li, S.Y. Wu, J. Z. Qiu, X.Y. Yin, Y. Q. Ding, Nucl. Instr. Methods, B 259 (2007) 708-713.

[128] X.L. Zhao, A.E. Litherland, Nucl. Instr. Methods, B 268 (2010) 812-815.

[129] V.S. Letokhov, V.I. Mishin, Opt. Commum. 29 (1979) 168-171.

[130] N.S. Nogar, R.K. Sander, S.W. Downey, C.M. Miller, Proc. Sco. Photo-Opt. Instrum. Eng. 380 (1983) 291.

[131] J.X. Qiao, X.L. Hou, M. Miro, P. Roos, Anal. Chim. Acta 652 (2009) 66-84.

[132] O. Egorov, M.J. O’Hara, J. Ruzicka, J. W. Grate, Anal. Chem. 70 (1998) 977-984.

[133] M. Hollenbach, J. Grohs, S. Mamich, M. Kroft, J. Anal. At. Spectrom. 9 (1994) 927-933.

[134] O.B. Egorov, M.J. O’Hara, J. W. Grate, J. Radioanal. Nucl. Chem. 263 (2005) 629-633. 
Figure captions:

Fig.1. Decay scheme of ${ }^{99} \mathrm{Mo}$

Fig.2. Liquid discharges of ${ }^{99}$ Tc from two European reprocessing plants at Sellafield (UK) and Cap de La Hague (France) to the marine system [32].

Fig.3. Possible transport processes of ${ }^{99}$ Tc in ecosystems (Modified from Wigley, 2000 [68])

Fig.4. Flow chart of an analytical procedure for determination of ${ }^{99} \mathrm{Tc}$ in environmental samples.

Fig.5. General procedure for separation of ${ }^{99}$ Tc by extraction chromatography using TEVA resin.

Fig.6. An analytical procedure for the determination of ${ }^{99} \mathrm{Tc}$ in large volume water sample[20].

Fig.7. A schematic diagram of the sequential injection ${ }^{99}$ Tc analyzer (Adapted from Ref. [132] with permission from American Chemical Society). C: carrier (water); SP: Syring pump; HC: holding coil; S: sample line; E: eluent line; W: waste; MPV: multiposition valve; SC: TEVA resin column; PL: purge line; DV: two-way diverter valve; LSC: liquid scintillation cocktail; CP: cocktail pump; DC: detector flow cell; MC: mixing coil. 
Table 1 Nuclear properties of technetium isotopes with a half-life more than one hour

\begin{tabular}{|c|c|c|c|c|}
\hline Isotopes & Half-life & Decay mode & $\beta E_{\max }(\mathbf{k e V})$ & Main $\gamma$-X-ray energy (keV) (intensity) \\
\hline${ }^{93} \mathrm{Tc}$ & $2.8 \mathrm{~h}$ & $\mathrm{EC}+\beta^{+}$ & - & $\gamma(1363.0,66 \% ; 1520.4,24.4 \%)$ \\
\hline${ }^{94} \mathrm{Tc}$ & $4.9 \mathrm{~h}$ & $\mathrm{EC}+\beta^{+}$ & - & $\gamma(702.6,99.6 \% ; 849.7,95.7 \% ; 871.1,100 \%)$ \\
\hline${ }^{95} \mathrm{Tc}$ & $20.0 \mathrm{~h}$ & $\mathrm{EC}+\beta^{+}$ & - & $\gamma(765.8,93.8 \%) ;$ X-ray $(17.5,56.5 \%)$ \\
\hline${ }^{95 \mathrm{~m}} \mathrm{Tc}$ & $61.0 \mathrm{~d}$ & $\mathrm{EC}+\beta^{+}, \mathrm{IT}$ & - & $\gamma(204.1,63.3 \% ; 582.1,30 \% ; 835.1,26.6 \%)$ \\
\hline${ }^{96} \mathrm{Tc}$ & $4.3 \mathrm{~d}$ & $\mathrm{EC}+\beta^{+}$ & - & $\gamma(778.2,100 \% ; 812.6,82 \% ; 849.9,98 \%)$ \\
\hline${ }^{97} \mathrm{Tc}$ & $2.6 \times 10^{6} \mathrm{y}$ & EC & - & - \\
\hline${ }^{97 \mathrm{~m}} \mathrm{Tc}$ & $90.1 \mathrm{~d}$ & EC, IT & - & X-ray $(18.4,27 \%)$ \\
\hline${ }^{98} \mathrm{Tc}$ & $4.2 \times 10^{6} \mathrm{y}$ & $\beta^{-}$ & $398.2\left(100 \%, \beta^{-}\right)$ & $\gamma(652.4,100 \% ; 745.4,102 \%)$ \\
\hline${ }^{99} \mathrm{Tc}$ & $2.1 \times 10^{5} \mathrm{y}$ & $\beta^{-}$ & $293.7\left(100 \%, \beta^{-}\right)$ & ( \\
\hline${ }^{99 \mathrm{~m}} \mathrm{Tc}$ & $6.0 \mathrm{~h}$ & $\beta$, IT & - & $\gamma(140.5,89 \%)$ \\
\hline
\end{tabular}

Table 2 Main sources of ${ }^{99} \mathrm{Tc}$ in the environment

\begin{tabular}{lcc}
\hline Source & ${ }^{99} \mathrm{Tc}$ released $\left(\times 10^{12} \mathrm{~Bq}\right)$ & Reference \\
\hline Sellafield nuclear reprocessing plant & 1720 & {$[32]$} \\
La Hague nuclear reprocessing plant & 154 & {$[32]$} \\
Global weapons fallout (1940`s-1970`s) & 140 & {$[27]$} \\
Nuclear accident in Chernobyl & 0.75 & {$[34]$} \\
Estimated Nuclear accident in Fukushima & $>0.25$ \\
Estimated Medical application $\left({ }^{99}{ }^{90-}{ }^{99 m}\right.$ Tc generator) & $<0.02$ \\
Estimated Nuclear power plants & $<0.01$ & \\
\hline
\end{tabular}

\begin{tabular}{|c|c|c|c|c|}
\hline Source & Location & Sample & Concentration of ${ }^{99} \mathrm{Tc}$ & Reference \\
\hline \multirow[t]{2}{*}{ Chernobyl accident } & 30-km zone around the Chernobyl reacter & Soil & $1-15 \mathrm{mBq} \mathrm{g}^{-1}$ & [12] \\
\hline & 30-km zone around the Chernobyl reacter & Vegetation & $0.2-6 \mathrm{mBq} \mathrm{g}^{-1}$ & [12] \\
\hline \multirow{12}{*}{$\begin{array}{l}\text { Nuclear reprocessing } \\
\text { plants }\end{array}$} & Areas near Sellafield & Cabbage & $13 \mathrm{mBq} \mathrm{g}^{-1}$ (fresh) & [32] \\
\hline & Areas near Sellafield & Leek & $1.4 \mathrm{mBq} \mathrm{g}^{-1}$ (fresh) & [32] \\
\hline & Areas near Sellafield & Onions & $2.3 \mathrm{mBq} \mathrm{g}^{-1}$ (fresh) & [32] \\
\hline & Areas near Sellafield & Potatoes & $5.1 \mathrm{mBq} \mathrm{g}^{-1}$ (fresh) & [32] \\
\hline & Areas near Sellafield & Lobster & $250 \mathrm{mBq} \mathrm{g}^{-1}$ (fresh) & [32] \\
\hline & Areas near Sellafield & Soil & $820 \mathrm{mBq} \mathrm{g}^{-1}$ (fresh) & [32] \\
\hline & Open Irish Sea (1996-1997) & Seawater & $60 \mathrm{mBq} \mathrm{L}^{-1}$ & [43] \\
\hline & Near Balbriggan in Irish Sea (1988-1993) & Seaweed & $340 \pm 80 \mathrm{mBq} \mathrm{g}^{-1}$ & [43] \\
\hline & Near Capenhuest in Irish Sea & Sediment & $18-450 \mathrm{mBq} \mathrm{g}^{-1}$ & [32] \\
\hline & English Channel & Seawater & $5-21 \mathrm{mBq} \mathrm{L}^{-1}$ & [44] \\
\hline & North Sea (in early $1980 ` s)$ & Seawater & $15-75 \mathrm{mBq} \mathrm{L}^{-1}$ & [45] \\
\hline & Arctic area & Seawater & $0.07 \mathrm{mBq} \mathrm{L}^{-1}$ & [47] \\
\hline Weapons fallout & Japan Sea & Seawater & $1-10 \mu \mathrm{Bq} \mathrm{L} \mathrm{L}^{-1}$ & [38] \\
\hline \multirow[t]{2}{*}{ (Background) } & Japan & Soil & $4-88 \mathrm{mBq} \mathrm{kg}{ }^{-1}$ & [36] \\
\hline & Northwest and south Spain & Seaweed & $0.1-0.4 \mathrm{mBq} \mathrm{g}^{-1}$ (dry mass) & [40] \\
\hline
\end{tabular}


Table 4 A summary of reported analytical methods for the determination of ${ }^{99} \mathrm{Tc}$ in different environmental samples

\begin{tabular}{|c|c|c|c|c|c|c|c|}
\hline Sample & Sample size & Yield monitor & Separation and purification & Recovery & Determination method & Detection limit of ${ }^{99} \mathrm{Tc}$ & Reference \\
\hline Seawater & $200-400 \mathrm{~L}$ & ${ }^{99 \mathrm{~m}} \mathrm{Tc}$ & Anion exchange with AG1-X4; Solvent extraction with TiOA/xylene & $70 \%$ & Gas flow GM counter & $4.68 \times 10^{-15} \mathrm{~g} / \mathrm{L}$ & [6] \\
\hline Radioactive waste & $1-10 \mathrm{~g}$ & ${ }^{99 \mathrm{~m}} \mathrm{Tc}$ & Co-precipitation by $\mathrm{Fe}(\mathrm{OH})_{2}$; Solvent extraction with $\mathrm{CHCl}_{3}$ & $>90 \%$ & Proportional counter & $1.01 \times 10^{-11} \mathrm{~g} / \mathrm{g}$ & [59] \\
\hline Seaweed, lobster and sediment & $10 \mathrm{~g}$ & ${ }^{99 \mathrm{~m}} \mathrm{Tc}$ & Anion exchange with $1 \times 8$; Solvent extraction with TnOA /xylene & $70-95 \%$ & LSC & $1.65 \times 10^{-12} \mathrm{~g} / \mathrm{g}$ & [8] \\
\hline Aqueous sample & $1 \mathrm{~L}$ & ${ }^{97} \mathrm{Tc}$ & Solid extraction with TEVA & $>90 \%$ & ID-ICP-MS & $1.87 \times 10^{-11} \mathrm{~g} / \mathrm{L}$ & [25] \\
\hline Soil & $3-6 \mathrm{~g}$ & $\mathrm{Re}$ & On-line flow injection separation with TEVA & $62-73 \%$ & FI-HI-ICP-MS & $7.80 \times 10^{-11} \mathrm{~g} / \mathrm{L}$ & [91] \\
\hline Seaweed, sediment & $10 \mathrm{~g}$ & ${ }^{95 \mathrm{~m}} \mathrm{Tc}$ & Recrystallisation; Solid extraction with TEVA & $50-90 \%$ & ICP-MS & $1.56 \times 10^{-12} \mathrm{~g} / \mathrm{g}$ & [11] \\
\hline Water sample & $500 \mathrm{~L}$ & ${ }^{95 \mathrm{~m}} \mathrm{Tc}$ & Co-precipitation by $\mathrm{Fe}(\mathrm{OH})_{2}$; Solid extraction with TEVA & $50-80 \%$ & ICP-MS & $4.68 \times 10^{-14} \mathrm{~g} / \mathrm{L}$ & [92] \\
\hline Contaminated water sample & - & ${ }^{99 \mathrm{~m}} \mathrm{Tc}$ & Solid extraction with TEVA & $85-98 \%$ & ETV-ICP-MS & $(4.99-9.88) \times 10^{-10} \mathrm{~g} / \mathrm{L}$ & [113] \\
\hline Soil and sediment & $1-20 \mathrm{~g}$ & ${ }^{95 \mathrm{~m}} \mathrm{Tc}$ & Different solvent extraction; Anion exchange with Dowex 1-X8 & $84-92 \%$ & HR-ICP-MS & $2.50 \times 10^{-13} \mathrm{~g}$ & {$[102]$} \\
\hline Dry-up deposition sample & $3 \mathrm{~g}$ & ${ }^{95 \mathrm{~m}} \mathrm{Tc}$ & Volatilization; Solvent extraction with cyclohexanone & $77 \%$ & ICP-MS & - & [76] \\
\hline Soil and sediment & $10 \mathrm{~g}$ & $\operatorname{Re}$ & Anion exchange with Dowex 1-X8; Soild extraction with TEVA & - & ICP-MS & - & [62] \\
\hline Seawater & $14 \mathrm{~mL}$ & $\operatorname{Re}$ & USN-DM combined with Anion exchange IRA-400 resin & $>85 \%$ & ICP-MS & $4.68 \times 10^{-11} \mathrm{~g} / \mathrm{L}$ & [42] \\
\hline Seawater & $0.25-5 \mathrm{~L}$ & ${ }^{95 \mathrm{~m}} \mathrm{Tc}$ & Solid extraction with TEVA & - & AMS & $\sim 3.9 \times 10^{-15} \mathrm{~g}$ & [14] \\
\hline Soil sample & $0.25 \mathrm{~g}$ & $\operatorname{Re}$ & Flow injection and solid extraction with TEVA & $>93 \%$ & FI-ICP-MS & $2.0 \times 10^{-11} \mathrm{~g} / \mathrm{g}$ & [133] \\
\hline Vegetation & $25 \mathrm{~g}$ & ${ }^{95} \mathrm{Tc}$ & Anion exchange with Dowex 1-X8; Solution extraction with cyclohexanone & $80 \%$ & NAA & $9.36 \times 10^{-12} \mathrm{~g} / \mathrm{g}$ & [84] \\
\hline Water sample & $5-30 \mathrm{~L}$ & ${ }^{95 \mathrm{~m}} \mathrm{Tc}$ & Solution extraction with TiOA/xylene; Anoin exchange with Dowex 1-X8 & $65 \pm 15 \%$ & ICP-MS & $3.93 \times 10^{-9} \mathrm{~g} / \mathrm{L}$ & [98] \\
\hline Drinking water & $1-2 \mathrm{~L}$ & $\operatorname{Re}$ & Solution extraction with TiOA/xylene; Soild extraction with TEVA & $102 \pm 6.5 \%$ & ICP-MS & $1.01 \times 10^{-12} \mathrm{~g} / \mathrm{L}$ & [9] \\
\hline Tank waste sample & $1 \mathrm{~mL}$ & ${ }^{95 \mathrm{~m}} \mathrm{Tc}$ & On-line sequential injection separation with TEVA & - & SI-LSC & $2.03 \times 10^{-9} \mathrm{~g}$ & [132] \\
\hline Soil, Biota and sediment & $15-100 \mathrm{~g}$ & ${ }^{99 \mathrm{~m}} \mathrm{Tc}$ & Co-precipitation by $\mathrm{Fe}(\mathrm{OH})_{2}$; Solution extraction with TBP & $50-80 \%$ & Gas flow GM counter & $2.18 \times 10^{-12} \mathrm{~g}$ & [5] \\
\hline Soil sample & $50 \mathrm{~g}$ & ${ }^{95 \mathrm{~m}} \mathrm{Tc}$ & Volatilization; Solid extraction with TEVA & $62-73 \%$ & ICP-MS & $1.72 \times 10^{-15} \mathrm{~g} / \mathrm{g}$ & [94] \\
\hline Geological materials & $2.5-15 \mathrm{~g}$ & ${ }^{97} \mathrm{Tc}$ & Solution extraction with $\mathrm{CHCl}_{3}$; Anoin exchange with AGMP1X8 & $10-80 \%$ & TIMS & $1.09 \times 10^{-14} \mathrm{~g}$ & [17] \\
\hline
\end{tabular}




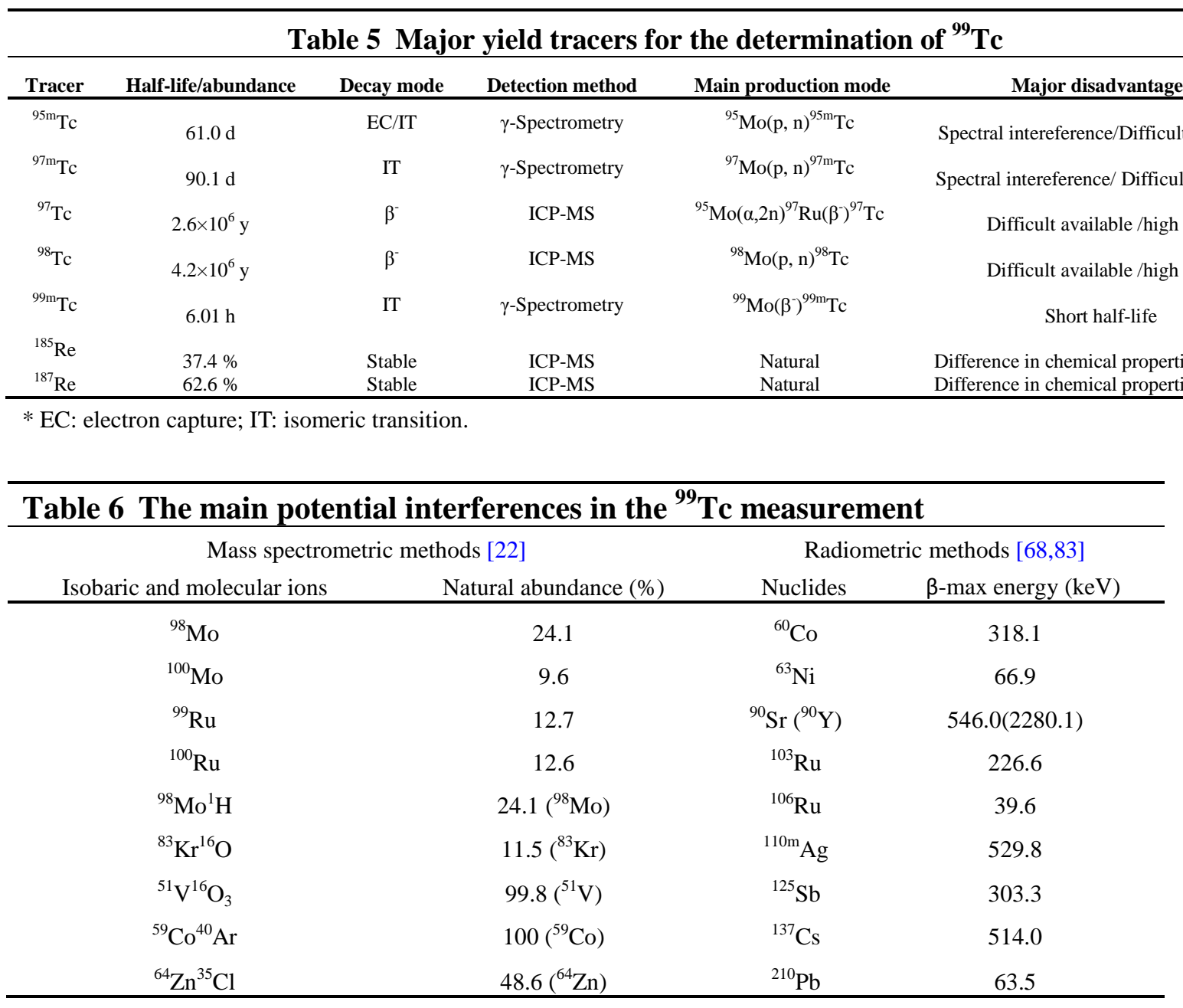

\begin{tabular}{ccccc}
\hline & Table 7 Comparison of different techniques for ${ }^{\mathbf{9 9}}$ Tc detection & \\
\hline Method & Detection limit & Detection time & Analysis cost & Reference \\
\hline LSC & $10^{-10} \sim 10^{-11} \mathrm{~g}$ & Hours & Fair/High & {$[7,8,96]$} \\
GM counting & $10^{-11} \sim 10^{-12} \mathrm{~g}$ & Days & Fair/High & {$[5,61]$} \\
NAA & $10^{-9} \sim 10^{-12} \mathrm{~g}$ & Hour/minutes & High & {$[84,114]$} \\
ICP-MS & $\sim 10^{-12} \mathrm{~g}$ & Hour/minutes & Low & {$[18,19,21]$} \\
TIMS & $\sim 10^{-15} \mathrm{~g}$ & Hour/minutes & High & {$[118,119]$} \\
RIMS & $\sim 10^{-15} \mathrm{~g}$ & Hour/minutes & Very High & {$[112,117]$} \\
AMS & $\sim 10^{-15} \mathrm{~g}$ & Hour/minutes & Very High & {$[14,15]$} \\
ETV-ICP-MS & $10^{-13} \sim 10^{-14} \mathrm{~g}$ & Hour/minutes & Relatively high & {$[19,113]$} \\
HR-ICP-MS & $\sim 10^{-13} \mathrm{~g}$ & Hour/minutes & High & {$[102]$} \\
\hline
\end{tabular}




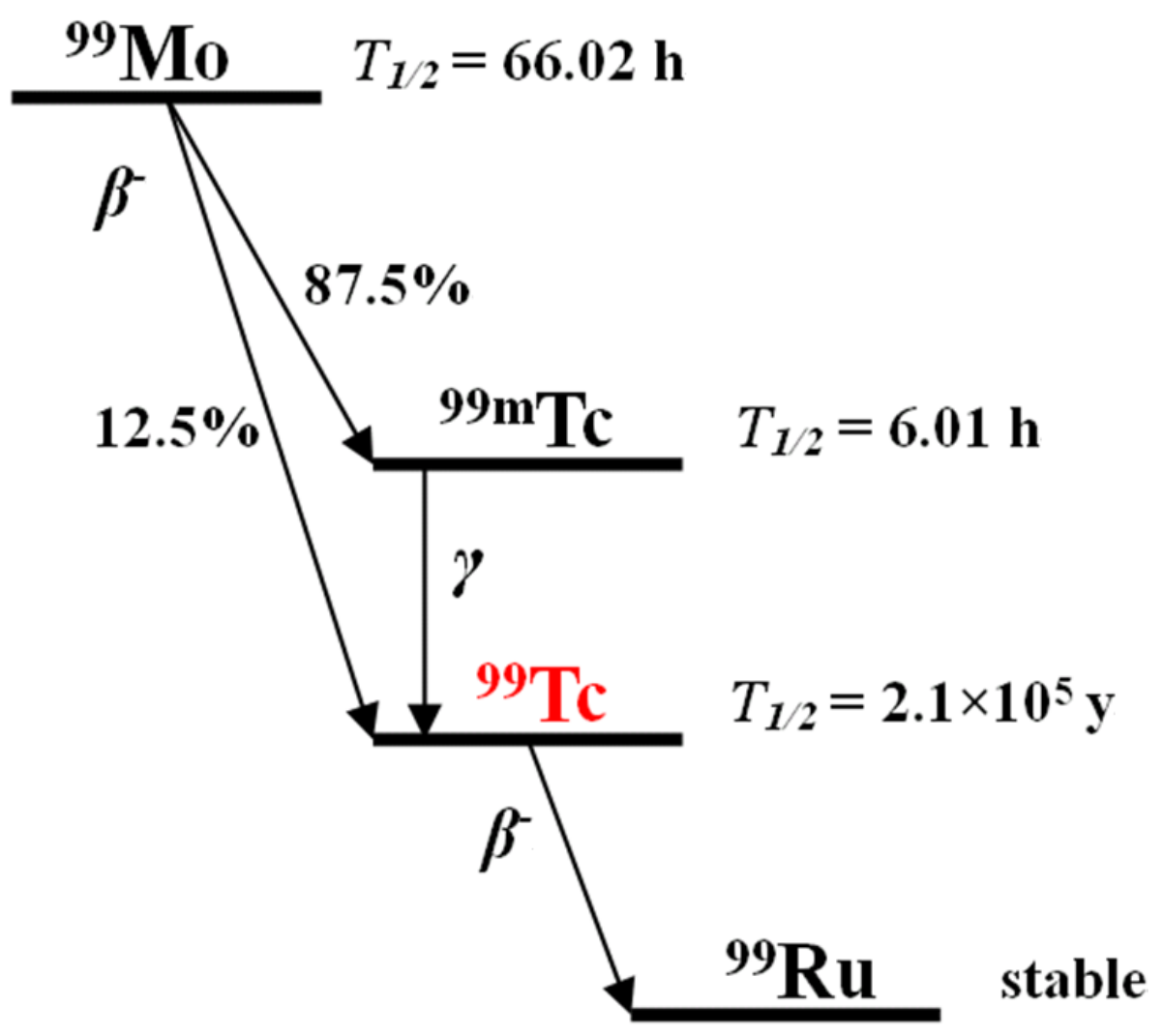

Fig.1. Decay scheme of ${ }^{99}$ Mo

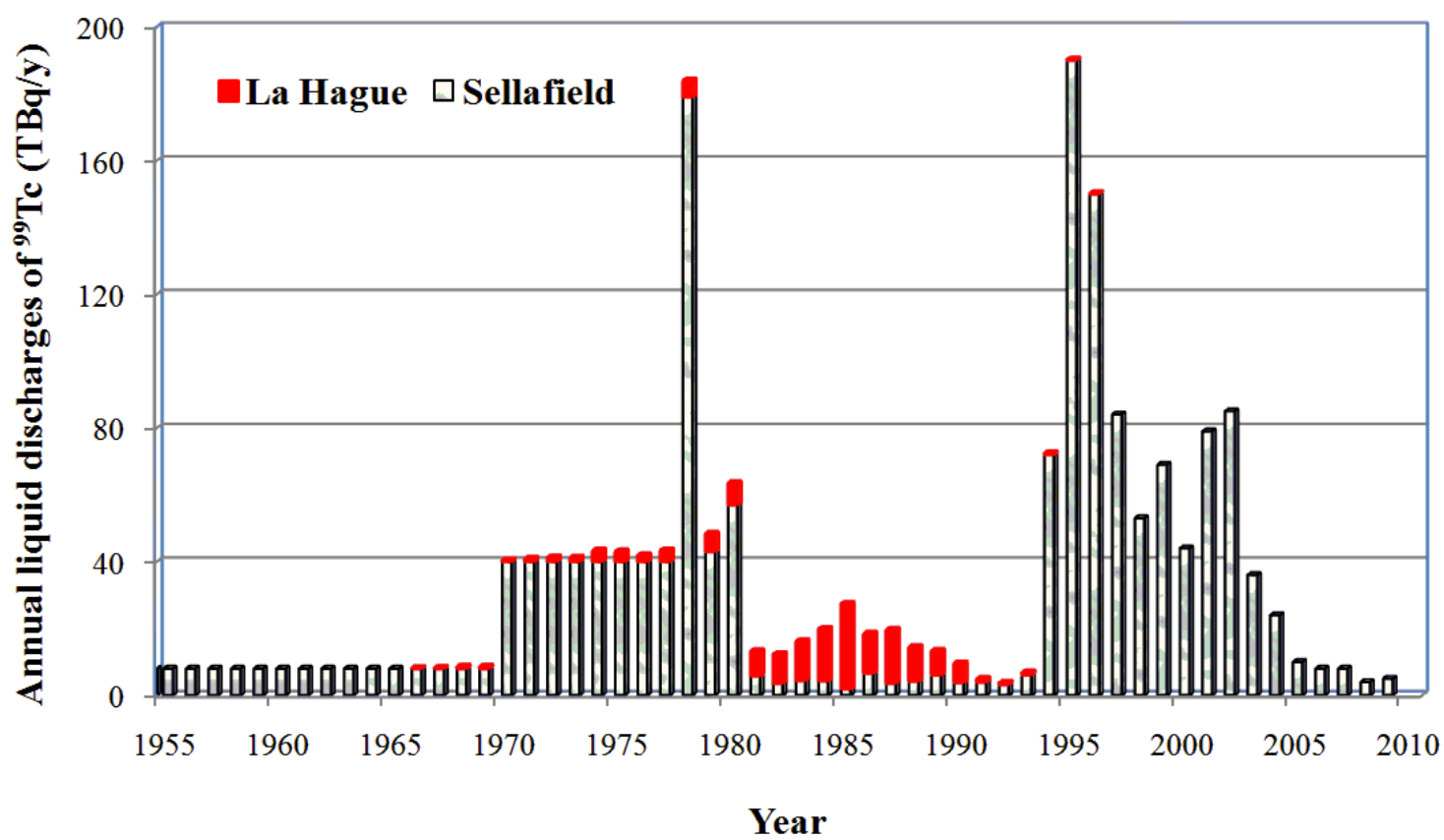

Fig.2. Liquid discharges of ${ }^{99}$ Tc from two European reprocessing plants at Sellafield (UK) and Cap de La Hague (France) to the marine system [32]. 


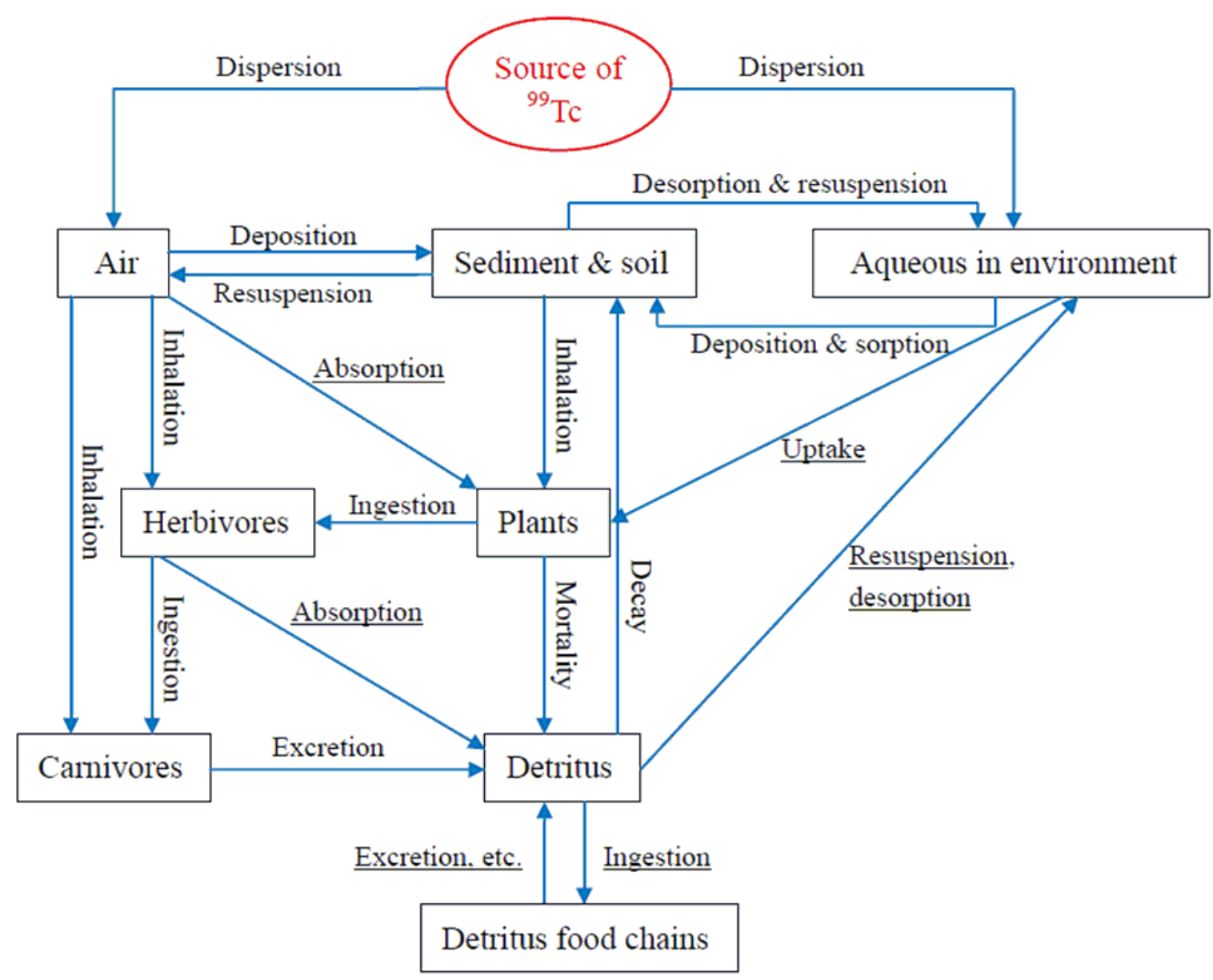

Fig.3. Possible transport processes of ${ }^{99}$ Tc in ecosystems (Modified from Wigley, 2000 [68]) 


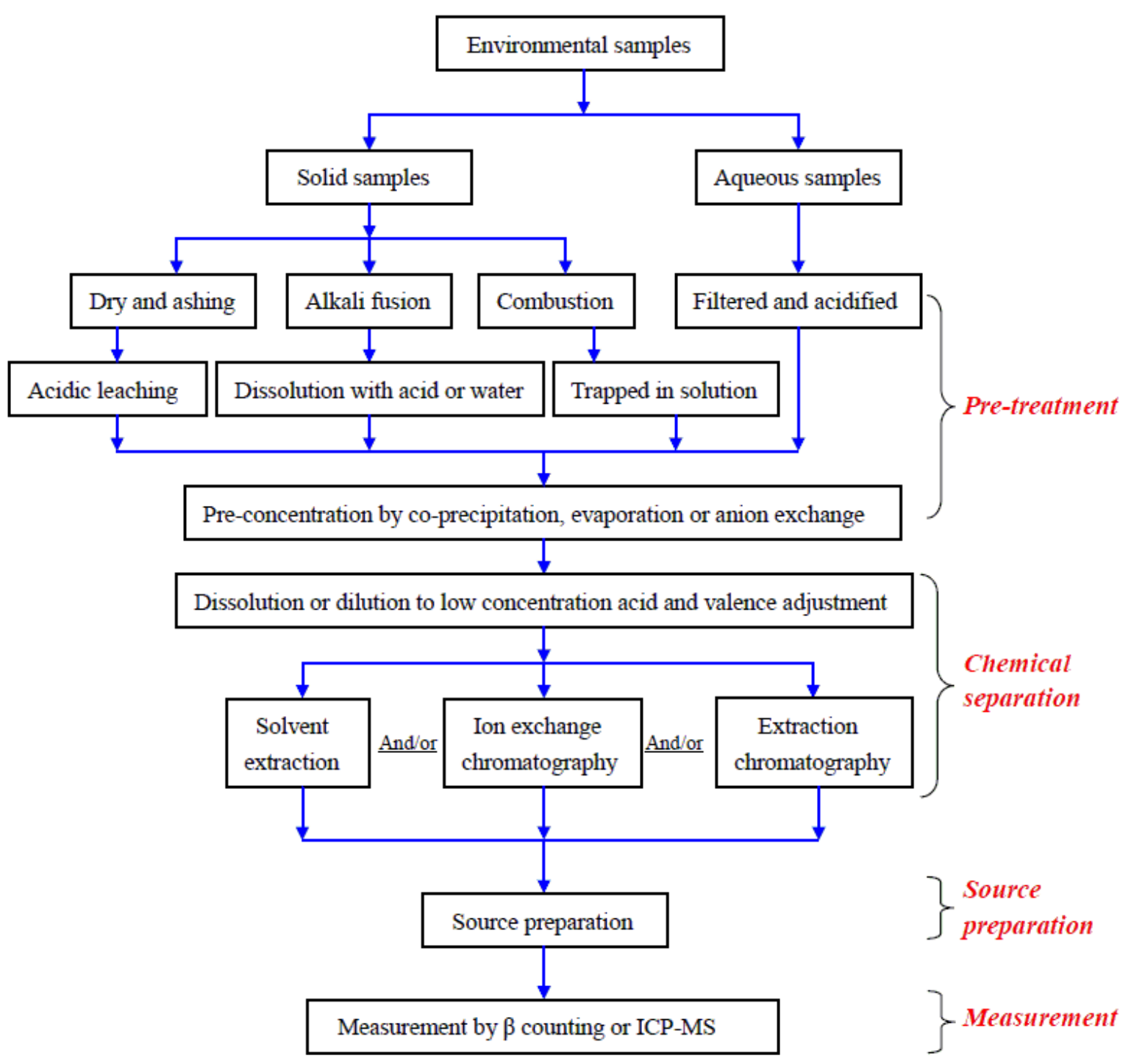

Fig.4. Flow chart of an analytical procedure for determination of ${ }^{99} \mathrm{Tc}$ in environmental samples. 


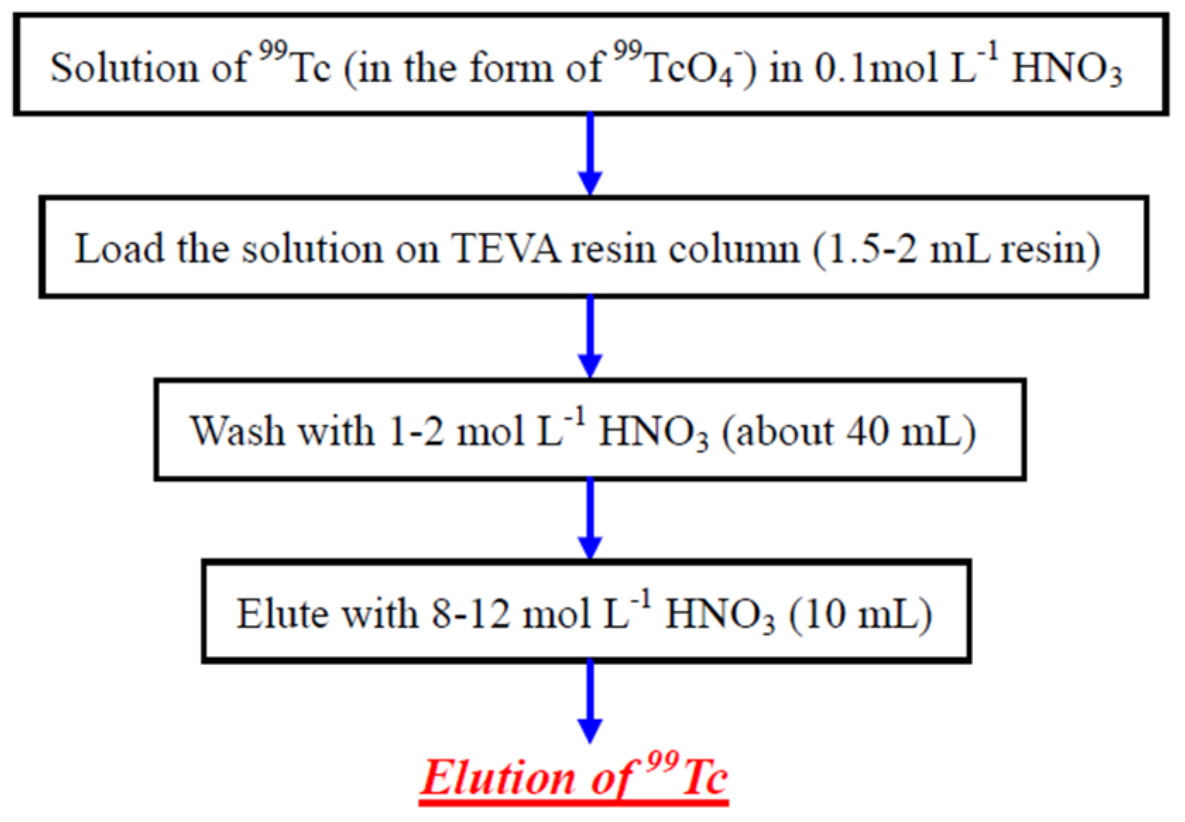

Fig.5. General procedure for separation of ${ }^{99} \mathrm{Tc}$ by extraction chromatography using TEVA resin. 


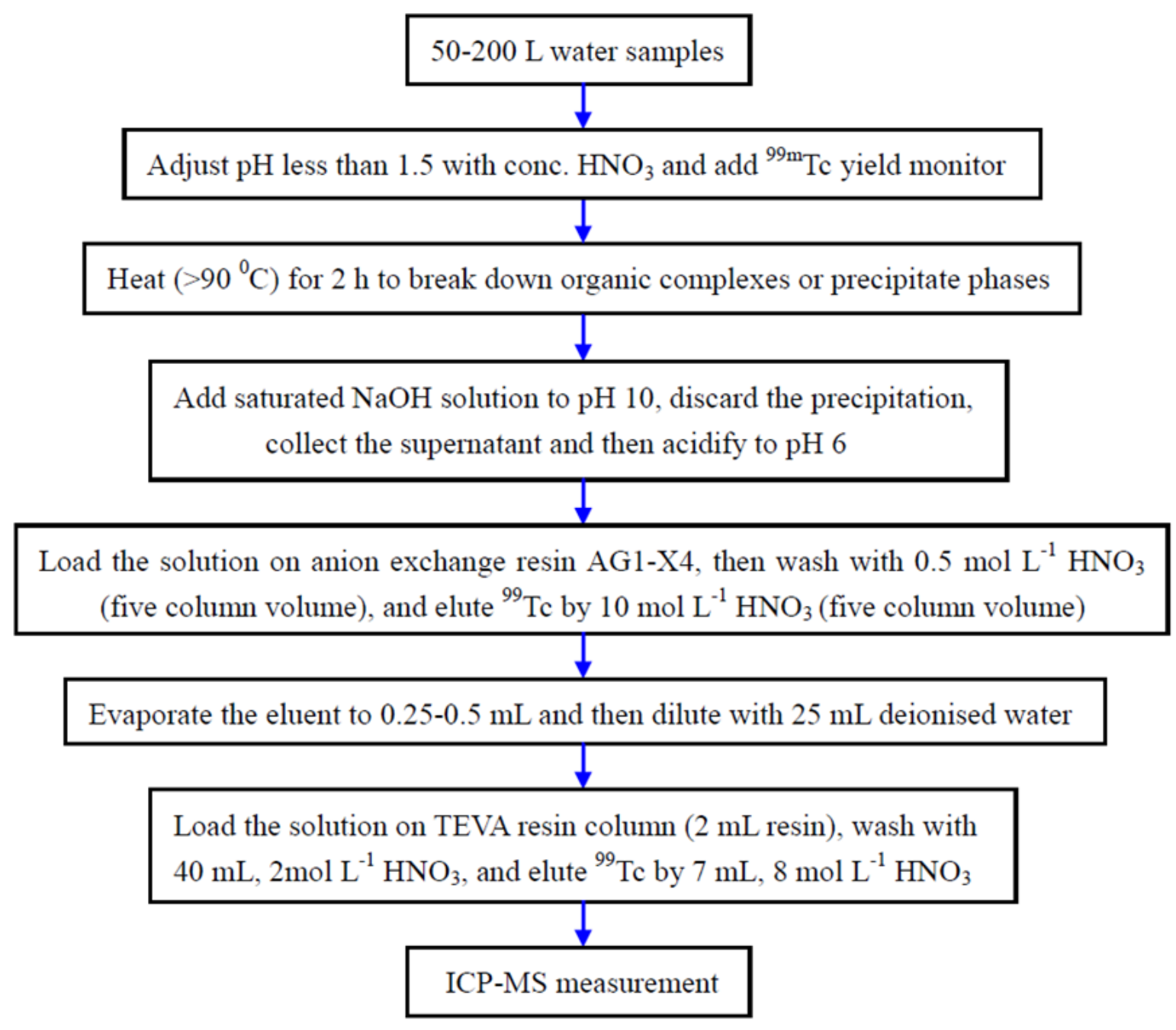

Fig.6. An analytical procedure for the determination of ${ }^{99} \mathrm{Tc}$ in large volume water sample[20]. 


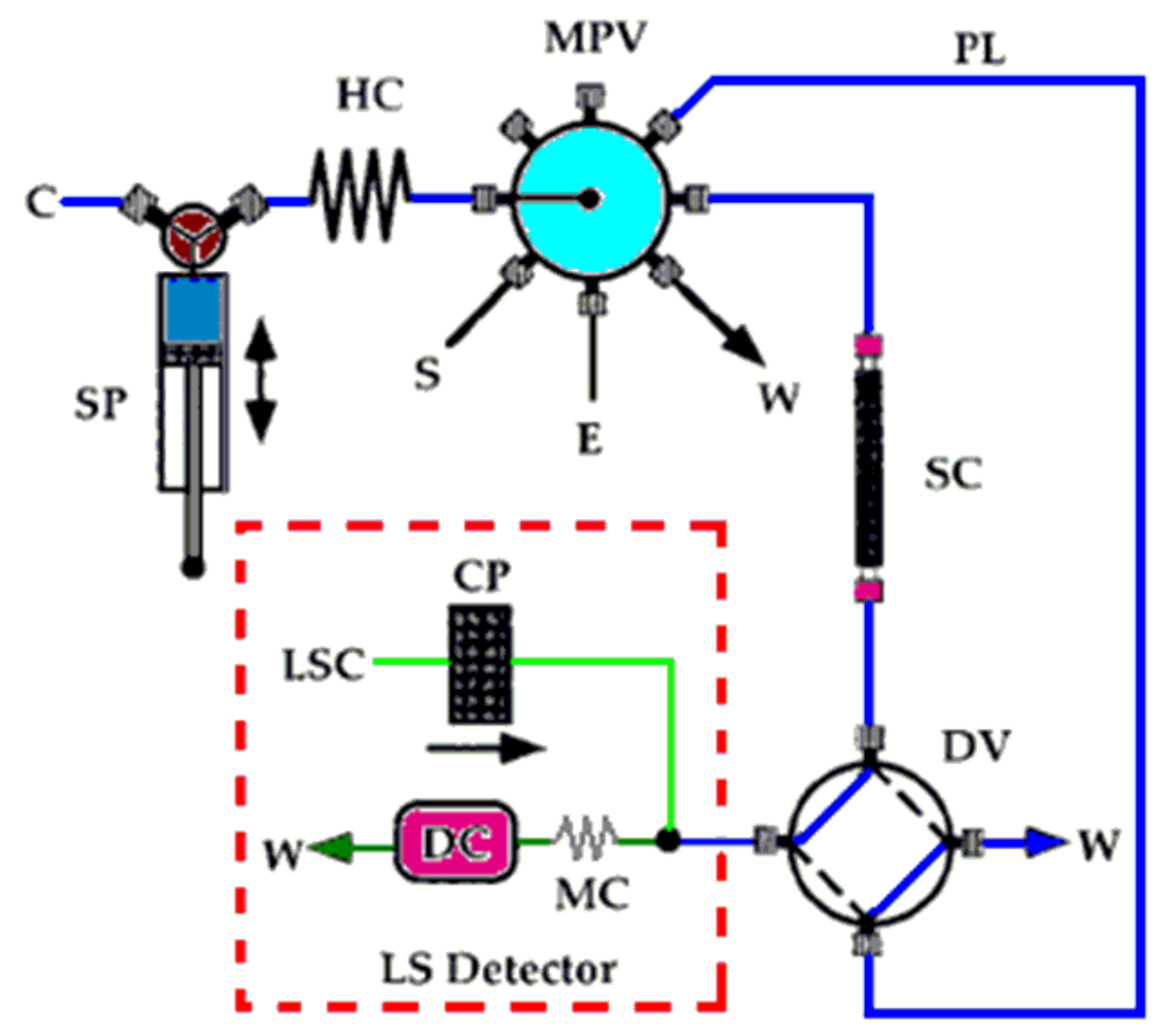

Fig.7. A schematic diagram of the sequential injection ${ }^{99}$ Tc analyzer (Adapted from

Ref. [132] with permission from American Chemical Society). C: carrier (water); SP:

Syring pump; HC: holding coil; S: sample line; E: eluent line; W: waste; MPV:

multiposition valve; SC: TEVA resin column; PL: purge line; DV: two-way diverter valve; LSC: liquid scintillation cocktail; CP: cocktail pump; DC: detector flow cell; MC: mixing coil. 
Keliang Shi is a PhD student in Risø National Laboratory for Sustainable Energy, Technical University of Denmark. His $\mathrm{PhD}$ project is "chemical speciation of long-lived radionuclide technetium-99 and its environment behavior”. He has worked on migration of radionuclides for some years (mainly on the sorption/desorption of radionuclides onto different kinds of sorbents like metal oxides, clay minerals and others). He obtained his Bachelor and Master degrees in Lanzhou University, China. His interested research areas are nuclear chemistry and radioanalytical chemistry.

Xiaolin Hou is a senior radioanalytical chemist in Technical University of Denmark. He obtained his $\mathrm{PhD}$ degree in nuclear and radioanalytical chemistry from Chinese Academy of Science in 1997. Dr. Hou joined in Risø National Laboratory, Denmark (from 2007 Risø becomes part of Technical University of Denmark) in 1998, and has being a senior scientist there since 2003. His primary research interests are radiochemical and speciation analysis of radionuclides, environmental radioactivity, radiotracer application, nuclear and radioanalytical techniques, ICP-MS and AMS. Dr. Hou has author/coauthored more than 130 research articles in peer reviewed scientific journals, one monograph and 7 book chapters.

Per Roos was born in Malmoe, Sweden in 1962 and got his $\mathrm{PhD}$ in radiation physics from Lund University in 1997. Since 1999 he has been working in the radioecology group at Risoe-DTU, since 2005 as a senior scientist. His interest includes radiometric and mass spectrometric methods and to apply these techniques to study the behaviour of radioisotopes and stable analogues in the environment. During the last four years he has been working with the remaining plutonium contamination from the Thule accident, NW Greenland, in 1968.

Wangsuo Wu is a senior radiation chemist of Lanzhou University in China. He obtained his Master and $\mathrm{PhD}$ degrees in Lanzhou University, China and then as a visitor worked at the Radiochemistry Group, Institute of Nuclear Fhysics in France from the years of 2003-2004. Now he is a professor in Lanzhou University and mainly works in the area of radiochemistry and nuclear chemistry. His primary research interests are the migration of radionuclides in the environment. 